\title{
Design and Modeling of the Cal Poly DC House Power Distribution System
}

\author{
A Thesis \\ Presented to \\ the Faculty of California Polytechnic State University, \\ San Luis Obispo
}

In Partial Fulfillment

of the Requirements for the Degree of

Master of Science in Electrical Engineering

By

Joseph Crowfoot

June 2011 
(C) 2011

Joseph Crowfoot ALL RIGHTS RESERVED 


\section{Committee Membership}

Title: Design and Modeling of the Cal Poly DC House Power Distribution System

Author: Joseph Crowfoot

Date Submitted: June 2011

Committee Chair: Dr. Taufik

Committee Member: Dr. Ali Shaban

Committee Member: Dr. Ahmad Nafisi 


\section{Abstract}

Title: Design and Modeling of the Cal Poly DC House Power Distribution System

Author: Joseph Crowfoot

The Cal Poly DC House Project is a large scale multi-student project that involves the detailed design and eventual construction of a DC powered house that will be usable in many rural parts of the world. The large scope of such a project makes it necessary to perform studies before it is designed and constructed so that any errors or problems can be recognized early on and addressed. This thesis entails a study on DC power Distribution used for the DC house. The needs for a rural DC home were identified and loads were selected. All of the system devices then modeled in the simulink software. This includes the creation and characterization of complex devices such as DC-DC converters. Once the simulation model was completed, several steady state variables including wire size, bus voltage, and circuiting configurations were tested to create an accurate power profile of the DC system. The resulting data successfully and accurately modeled the performance of the system under many different conditions. The working model was also used to perform a design case study of several potential and realistic load configurations that could be used in rural areas. 


\section{Acknowledgements}

I want to thank my parents and family for their continued support throughout my entire life, The Cal Poly Electrical Engineering faculty especially my advisor Dr. Taufik for their patience and resourcefulness, and my friends for their help and entertainment throughout my college education. 


\section{Table of Contents}

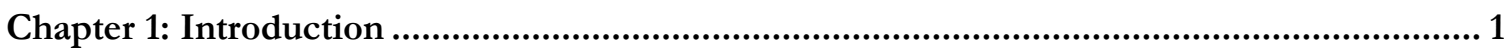

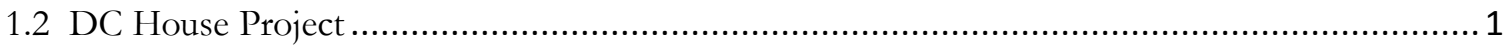

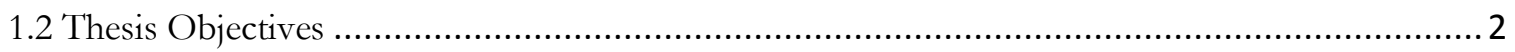

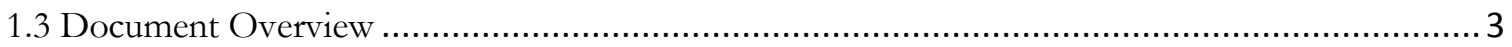

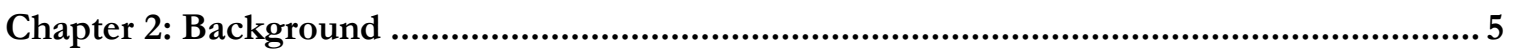

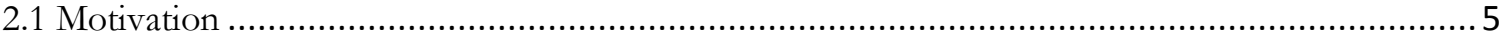

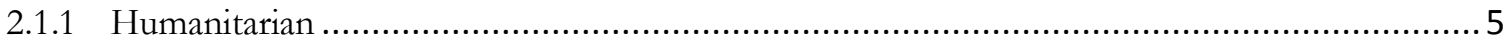

2.1.2 Sustainability, National Security, and global Warming..................................................... 6

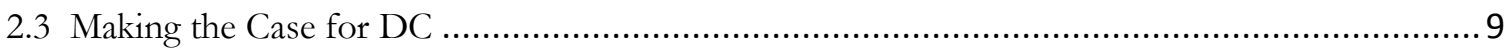

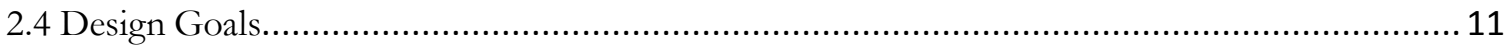

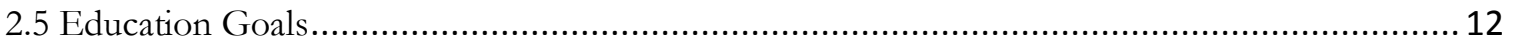

Chapter 3: Load Selection and Distribution Design .............................................................13

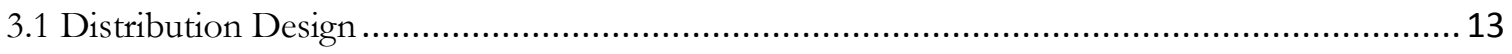

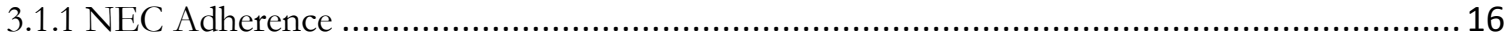

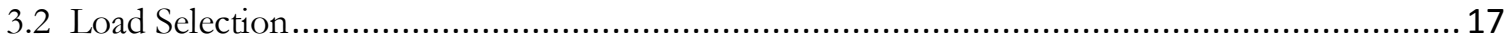

3.2.1 How the DC house Generation System Works .............................................................. 18

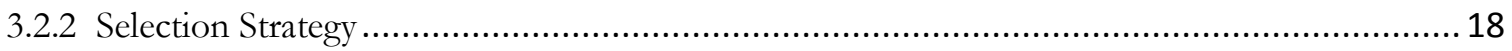

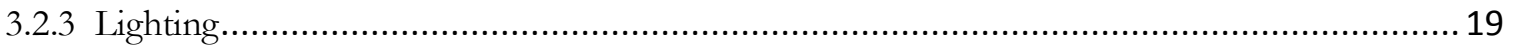

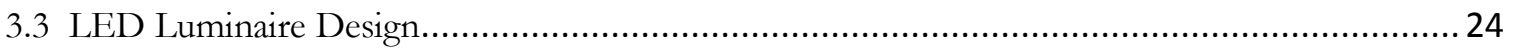

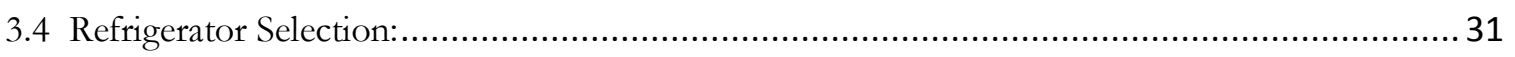

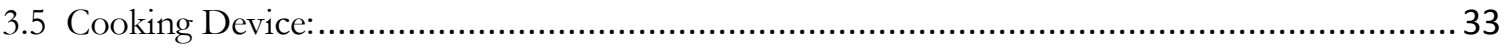

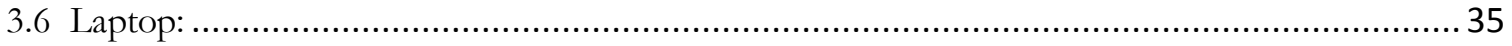

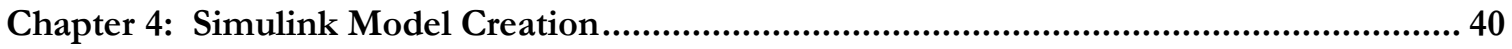

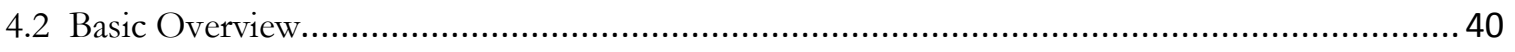

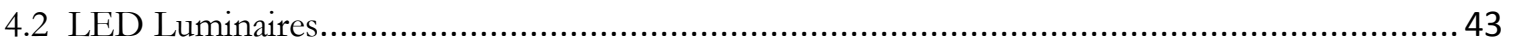

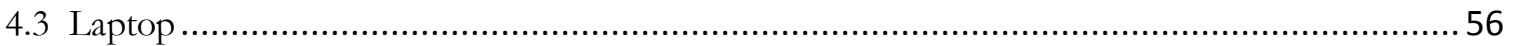

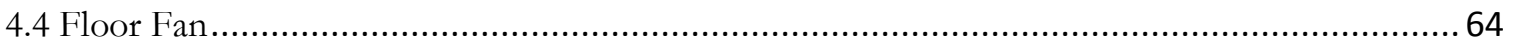

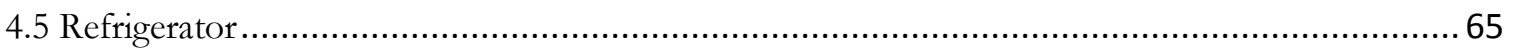

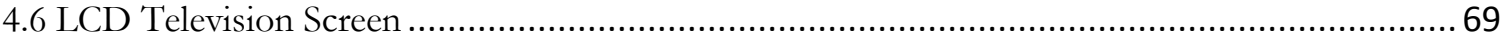

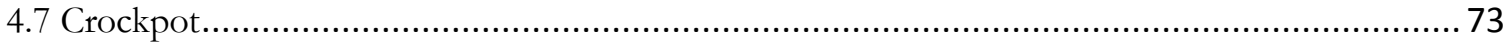

4.8 The Complete System and Efficiency Monitoring Rig ....................................................... 73 


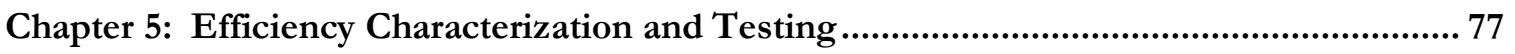

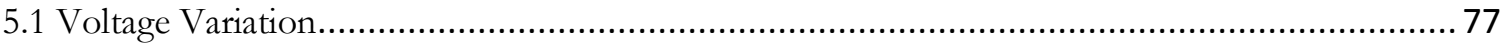

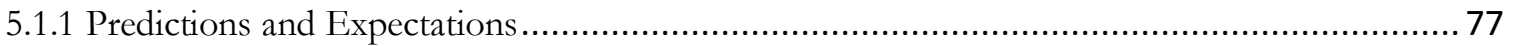

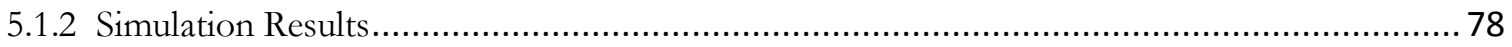

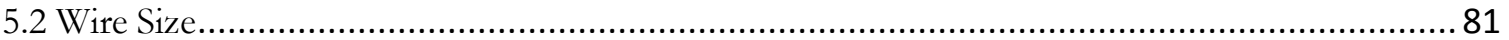

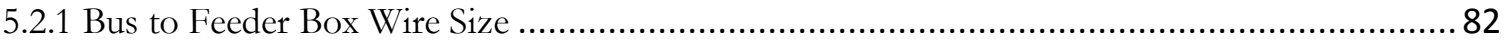

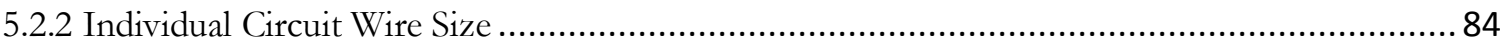

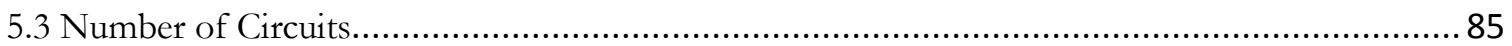

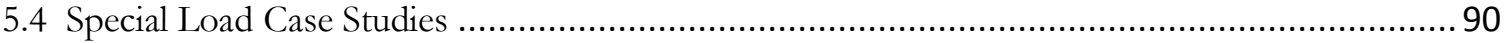

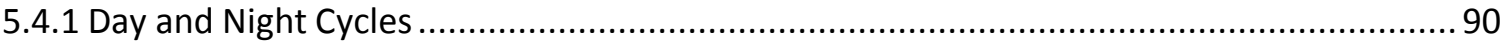

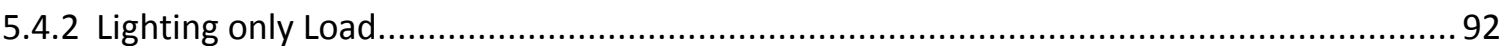

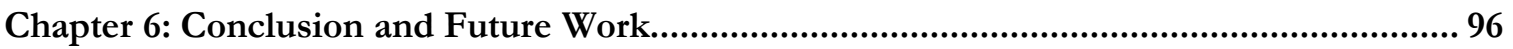




\section{List Of Tables}

Table 3-1: The NEC Current Ratings for Varying Wire Sizes at Varying Temperatures [7] .............................. 17

Table 3-2: Summary of Critical Specifications for Incandescent, Compact Fluorescent, and LED Lighting

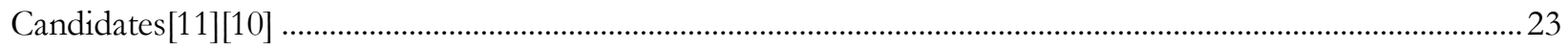

Table 3-3: Typical forward voltage of the LED's used in the DC house luminaires[11] ....................................30

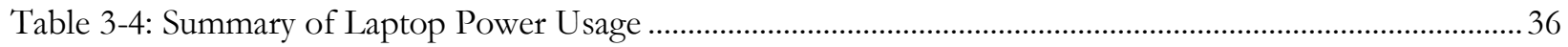

Table 3-5: Summary of Power used by Essential Loads........................................................................................ 37

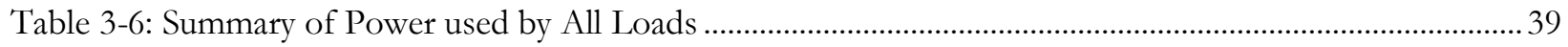

Table 4-1: Summary of Common Converter Topology Characteristics ................................................................ 46

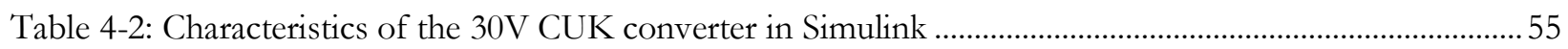

Table 4-3: Summary of Characteristics for the 21V Cuk Converter modeled in Simulink..................................56

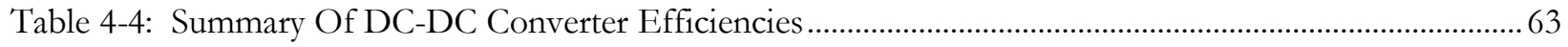

Table 5-1: Summary of Wire cost per foot and Ampacity rating for all wire sizes tested. [25]........................... 81

Table 5-2: Summary of the Day and Night Load Cycles........................................................................................ 91 


\section{List Of Figures:}

Figure 2-1: Electricity Production in TWh over the past 30 Years [3] 7

Figure 2-2: Comparison of Efficiency over Time for Various PV Technologies[2] 8

Figure 2-3: Comparison of Cost in USD per Watt for Silicon based Photovoltaics [2] 9

Figure 3-1: Overall Simplified Block Diagram of the DC House Project 13

Figure 3-2: Block Diagram Showing How the loads for the DC House will be powered 14

Figure 3-3: Direct Textual Quote from the NEC manual regarding Wire Size in DC systems[7] 16

Figure 3-4: Luminous Power Spectral density of typical Incandescent Light Bulbs Taken from the Zeiss

Online Campus For Microscopy [8] 19

Figure 3-5: Spectral Density of the common compact fluorescent light bulb. Taken from "Caged

Molecules: Principles and Practical Considerations” University of Maryland [9] 21

Figure 3-6: Photo of the Phillips PL-C 4-Pin CFL[10] 21

Figure 3-7: Color Spectrum for Lumileds Luxeon Rebel ES Cool-White LED [11] 23

Figure 3-8: I-V Characteristics of random assortment of LEDs from two different brands [Maxim] 25

Figure 3-9: Simulink model of Parallel LEDs with current limiting resistors 27

Figure 3-10: The circuit diagram for the outdoor LED Luminaire 29

Figure 3-11: Circuit Diagram for Indoor LED Luminaire 30

Figure 3-12: Overview of Swing Compressor used in Engel brand Refrigerator [13] 32

Figure 3-13: Image depicting the Crock Pot to be used in the DC house 35

Figure 3-14: Image of Floor Fan to be used in the DC house 38

Figure 4-1: Screen capture of a masked Subsystem's input array. 1 indicates the Switch to that corresponding load is closed 41

Figure 4-2: Screencapture of Basic Simulink Block Diagram 42

Figure 4-3: Simulink Models for Indoor and Outdoor LED Arrays 44

Figure 4-4: Input Current for the Buck Converter in CCM Used Later in the TV Load. Vertical Axis is in Amps, and Horizontal axis is in Seconds 47

Figure 4-5: Simulink schematic for CUK converter, output is across C2 48

Figure 4-6: Simulink Schematic for Control System for the CUK converter (PWM Squarewave

Generator) $\quad 50$

Figure 4-7: (Top) Sawtooth Waveform compared with Flat Error Signal, (Bottom) Resulting PWM

Square Wave Produced from the Comparison of the top Waveforms. 51

Figure 4-8: Complete CUK Converter Circuit Including Controls and Load 52

Figure 4-9: Simulink schematic model for the 21V CUK converter to drive the indoor LED Luminaire 53

Figure 4-10: 30 Volt CUK Output Voltage as a function of time in seconds With a 12V Input Voltage at Full Load (1A) 53

Figure 4-11: Zoomed in View of steady state output voltage for a setting of 30 Volts at full load 54

Figure 4-12: Subsystem to model the Power Consumption for the Laptop in Simulink 58

Figure 4-13: User Prompt for Determining the Steady State Power Usage of the Laptop 58

Figure 4-14: Simulink Schematic for modified 19.5V CUK Converter to be used for the Laptop 59

Figure 4-15: Screencapture of the output voltage of the 19.5V CUK converter at Full Load 60

Figure 4-16: Intput Current(Amps) for the 30V CUK Converter with 12V input Voltage Without RMS Configuration

Figure 4-17: Square, Weighted moving average and square root Blocks in Simulink configured to calculated RMS Value 
Figure 4-18: Input Current (Amps) For the 30V CUK Converter with $18 \mathrm{~V}$ Input voltage after being passed through The RMS Block

Figure 4-19: Circuitry to provide Efficiency Values for CUK Conveter in Simulink

Figure 4-20: Simulink model of DC Motor:

Figure 4-21: Permanent Magnet DC Motor Current in Amps at varying time in seconds operating at 12

Volts

Figure 4-22: Flowchart for the Logic operation of the Refrigerator Unit

Figure 4-23: Simulink model of the Refrigerator Power Consumption, Subject to either cooling or inactive States

Figure 4-24: Simple Buck Converter Modeled in Simulink

Figure 4-25: Output Voltage as a Function of time for the 12V Buck Converter with 12V input 71

Figure 4-26: Output Voltage as a function of time for the 12V Buck converter with 48V input 72

Figure 4-27: Block Diagram Level View of the 12v Buck Driving the TV Load 72

Figure 4-28: Simulink Model for the Crockpot 73

Figure 4-29: Virtual Wattmeter Subsystem View (Top), and Detailed View (Bottom) 74

Figure 4-30: Block Diagram View of the Efficiency Monitor Block (top), Detailed View of Efficiency

Monitor Block (bottom) 75

Figure 4-31: Screen capture of the Complete Simulink Model of the DC House 76

Figure 5-1: Efficiency Plot for Standard Model of DC house at Varying Voltage Levels 79

Figure 5-2: Efficiency Profiles For Varied Bus to Feeder Box Wire Size 82

Figure 5-3: Incremental Efficiency Gain Per unit Cost for Going with larger Wire Sizes 83

Figure 5-4: Plot Of Efficiency Profiles of the DC House at Varied Individual Circuit Sizes 84

Figure 5-5 Incremental Increase in Efficiency Per Unit Cost for Upgrading from Each wire Size 85

Figure 5-6 Efficiency Profile for DC System With Varied Number of Load Circuits 87

Figure 5-7: 3D Depiction of Figure 5-6, Efficiency Profile For Varied Number of Circuits and Bus

Voltage

Figure 5-8 Incremental Increase in Efficiency Per Dollar Spent for Increasing Circuit Numbers: 89

Figure 5-9: Efficiency Profile for DC House Day and Night Cycles 91

Figure 5-10: Modified Simulink Model for the Special Case of Lighting Only Load 92

Figure 5-11: Plot of Efficiency for the Lighting only Load at Varying Voltages 93

Figure 5-12: Efficiency Profile for the Medical Center Load Case Study 95 


\section{Chapter 1: Introduction}

\subsection{House Project}

The DC House project is a vast project that will eventually require the help and contributions from many senior projects and master's theses. The primary creator of the DC House project is Dr. Taufik who outlined the idea as a humanitarian effort to provide electrical power to people who live off of the electrical grid. It is meant to supplement the living conditions of a family that does not have access to typical grid tied AC power sources. The DC house is a venture into designing, simulating and eventually constructing a set of loads that can be used with multiple DC power sources.

The complete DC house project has been roughly broken into three phases. The first phase will focus on the individual DC powered home including the design for several possible DC power sources. These generator source designs include: a Hydro-power generator, a photovoltaic power generator, a human powered generator, and a wind powered generator. Phase 1 will also include the design of the DC-DC converter that can interface the many DC generation sources to a single DC bus that will power the home. The determination of the exact bus voltage level, as well as a selection of possible loads and a complete simulation of the DC house will also be performed.

The goal is to gradually increase the scale of the project with each phase, thus phase 2 will emphasize on protecting the power system, as well as explore the implementation of micro-grid to intertie many DC homes to form a DC "neighborhood". The concept of a DC neighborhood is appealing because it can provide power from several potential sources 
of power to many people. It also adds in an extra element of reliability by letting generation sources from one area support houses who's generation capability is otherwise out of service.

Phase 3 of the project will further the design of a centralized DC house network which would connect multiple neighborhoods together. There are also plans to construct the DC house and implement a field test of its operation in this third phase.

\subsection{Thesis Objectives}

The extent of research conducted for this thesis is of design and simulation. This will include extensive research of available DC loads for use in the DC house. Examples include a motor, lighting, oven, a cooler, laptop or computer, cellphone charger, etc. This will include complete breakdown of devices and a comprehensive comparison of possible selections and finally an accurate model to simulate the chosen devices' behavior. The DC house is only in the planning and design stages, therefore it is ideal to have an accurate idea of how the house's distribution system will operate before it is constructed.

These loads will require a complex DC distribution system that can efficiently and safely provide power to the devices. Therefore it is important to satisfy these varied voltage and safety demands, but minimize the number of inefficient devices that are needed to achieve this goal of safety and distribution. In order to accurately account and study the efficiency of the distribution system, a simulation of the DC system will be necessary. The results of these simulations will be analyzed so as to arrive at a comprehensive 
recommendation for the distribution system for the DC house. This simulation will be done in Simulink.

The deliverables for this thesis consist of:

1. List of recommended loads/devices for the DC house.

2. A complete modeling and characterization of the DC House and its loads

3. An efficient and safe DC distribution design,

4. A Simulink simulation of the distribution system and the loads.

5. A comprehensive recommendation for the distribution system and load selection for the DC house.

6. Design Case Study Of other realistic load configurations

\subsection{Document Overview}

Chapter two will outline the background and motivations for the genesis of the DC house project. This will include a comprehensive look at the global political climate, the continued development and rapid proliferation of DC power sources, as well as the humanitarian discrepancies between developed and undeveloped countries. This chapter will also serve to briefly discuss the future plans for the DC house project. It will also consist of a background survey of literature and related works that can be used to provide a foundation for the DC load types and DC distribution system.

Chapter three will consist of a breakdown of design constraints on the complete DC house. This will include a discussion of the basic requirements on the distribution system, the DC loads, and their limitations in the context of the complete DC house and its future 
construction. It will serve to explain any modifications necessary for their implementation into a single bus voltage level, as well as a discussion of how they operate electrically.

Chapter four will outline the development of the Simulink model. Discussing the development of modeling an electrical system will be a primary focus. This includes the implementation of simple circuit elements, to the design and control of the many DC-DC converters necessary to drive the loads that need them. It will begin with the basic design approach and design goals of the simulink model. It will continue with the discussion on why a subsystem was implemented and how it makes the simulation better. Any and all problems with the simulation during development will be discussed, and all possible solutions to each problem will be explored so that the chosen solution can be justified.

Chapter five will outline the conclusions made from all of the data and plots obtained from the simulation as well as an in depth discussion of the results. It will describe the trade-offs between the many design decisions made throughout the process and will end with a final recommendation for the details of how the power distribution system should be implemented.

Chapter six will serve as the conclusion section, and will reflect on the results and postulate potential future work. 


\section{Chapter 2: Background}

\subsection{Motivation}

The DC house project is a large endeavor that will span several years and include the work of dozens of students. Before we dive into the design details of such a large project, it is important to justify all of this work and planning with some kind of motivation.

Therefore, this section will outline some of these motivations so that we can understand why this project is important.

\subsubsection{Humanitarian}

As of 2009, there were approximately 1.4 billion people who do not have access to electricity and 2.7 billion people who rely on traditional use of biomass for cooking [1]. This truly alarming statistic raises several questions about the impacts of globalization in many areas of the world. Despite the globalization of many technologies including advancements in industry, medicine, agriculture and services, why is electrification still severely lacking?

Traditionally, transmission lines are necessary to transmit large amounts of power generated from large scale power plants to regions of high population density who can use it for commercial and residential applications. A large portion of those without electricity live in remote areas, with a more dispersed population density. It becomes a problem of economics - the high initial cost of the infrastructure (substations, transmission lines, transformers, etc.) is tough to justify for a small village of a dispersed people. In essence, it is prohibitively expensive to bring the traditional electrical grid to remote areas of the world. This creates an opportunity for engineers to apply new technologies to fulfill these empty humanitarian gaps that still exist despite globalization and huge strides in the development of technology in the western world. 


\subsubsection{Sustainability, National Security, and global Warming}

The current primary energy sources for the world come from fossil fuels: petroleum, coal, and natural gas. There are three problems that arise with the use of these resources for energy, and they are in the areas of sustainability, national security, and global warming.

Fossil fuels are a finite resource, this inherently makes them a non-sustainable energy source because they will eventually be completely consumed. There are concerns about the reserve levels of these fossil fuels, and there are many different takes on the remaining quantity . Estimating accurately the levels of fossil fuels is an extremely difficult task, because technology is constantly allowing new sources to be tapped. However it is estimated that 50,60 , and 200 years left of oil, natural gas, and coal respectively are left at the current rate of consumption [1]. This is somewhat alarming, especially considering that the industrialization of high population countries such as China will increase the consumption rate of these fuels. There are a finite amount of fossil fuels remaining on planet earth, so finding alternative and renewable energy sources as well as effective and efficient systems to use them is key to achieving a sustainable future.

A disproportionate amount of the remaining fossil fuel reserves are located outside of the USA. The United States has only 2 percent of the world's petroleum reserves, and (in 2005) must import 43 percent of its annually consumed petroleum from other countries [1]. This creates conflicts of interest for our nation to become reliant on other countries for purchasing fuels in the United States [3]. Figure 2-1 illustrates how much electricity is produced from hydro, nuclear, and fossil fuels. Renewables are extremely small, but have been increasing over time. 


\section{Electricity Production in the USA (TWh)}

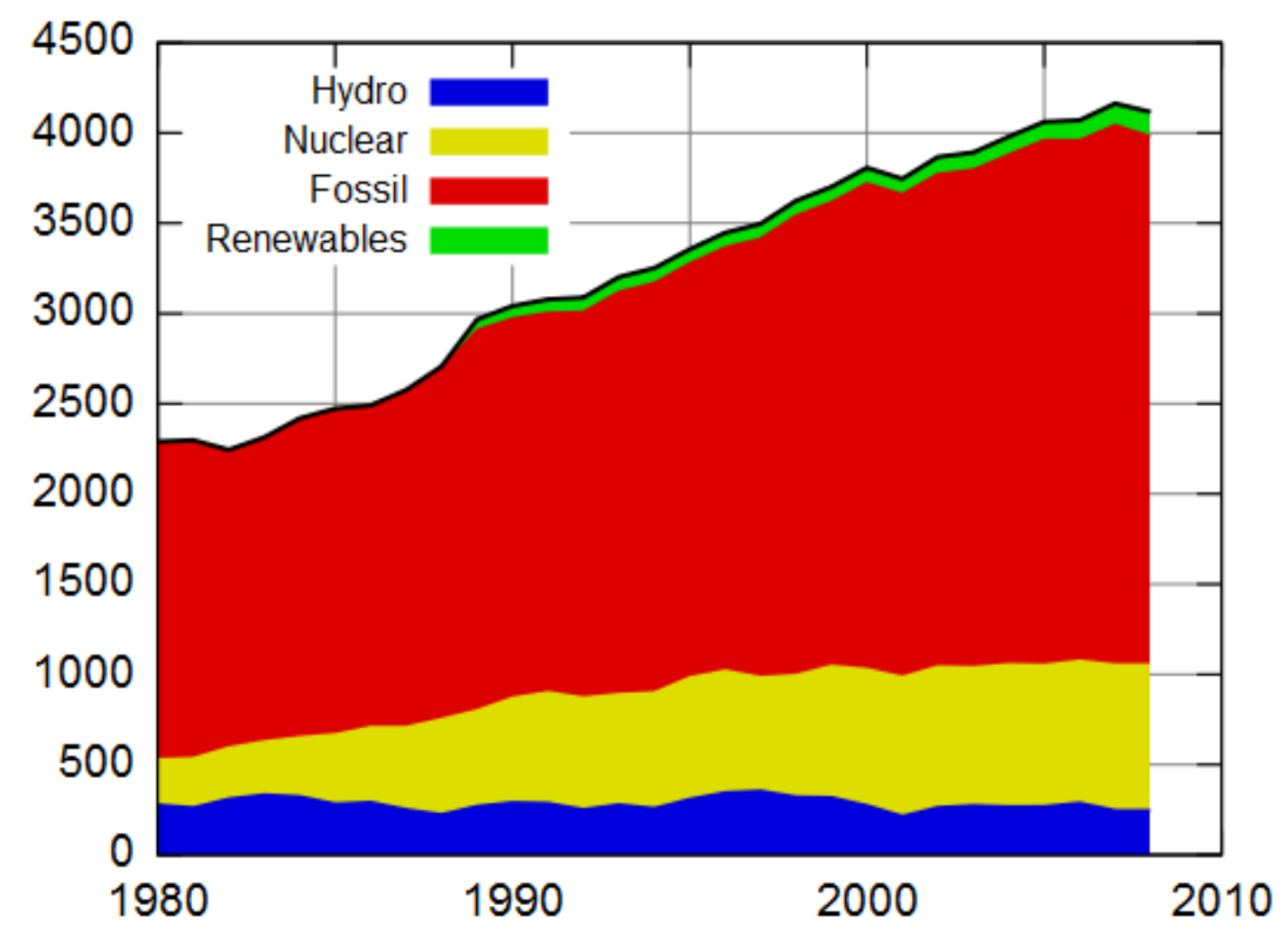

Figure 2-1: Electricity Production in TWh over the past 30 Years [3]

The responsibility falls on engineers to create systems that minimize the use of fossil fuel powered energy. One way to do this is to create electrical systems that take advantage of renewable energy sources, such as photovoltaics, to supplement electricity generated by fossil fuels. By localizing power generation, there is less reliance on other countries for our energy needs, which creates a more stable international political climate.

Global warming is a phenomena where greenhouse gases produced from burning fossil fuels such as petroleum and coal warms the earth. This creates many negative environmental effects which affect both human and non-human life on earth. Renewable energy sources don't emit green-house gases, and can help stop this problem from getting 
worse. If engineers can design systems that use renewable energies, they will proliferate their use in place of fossil fuel based energy - which will serve to stagnate the growth of global warming and its negative effects on the earth.

\subsection{Understanding the Growth and Future Proliferation of Renewable Energy}

In order to take on the problems outlined in the previous section, we must grasp the importance and promise in the development of renewable energy sources. Many renewable energy sources can be operated at a small scale to power an isolated system such as a DC

house. Photovoltaic technology is one example of a renewable technology that can operate in a remote area isolated from the grid. Additionally, this technology has shown tremendous progress over the past twenty years. For example, solar cell technologies have been continuously improving efficiency over the past 25 years as can be seen below in Figure 2-2 $[2]$.

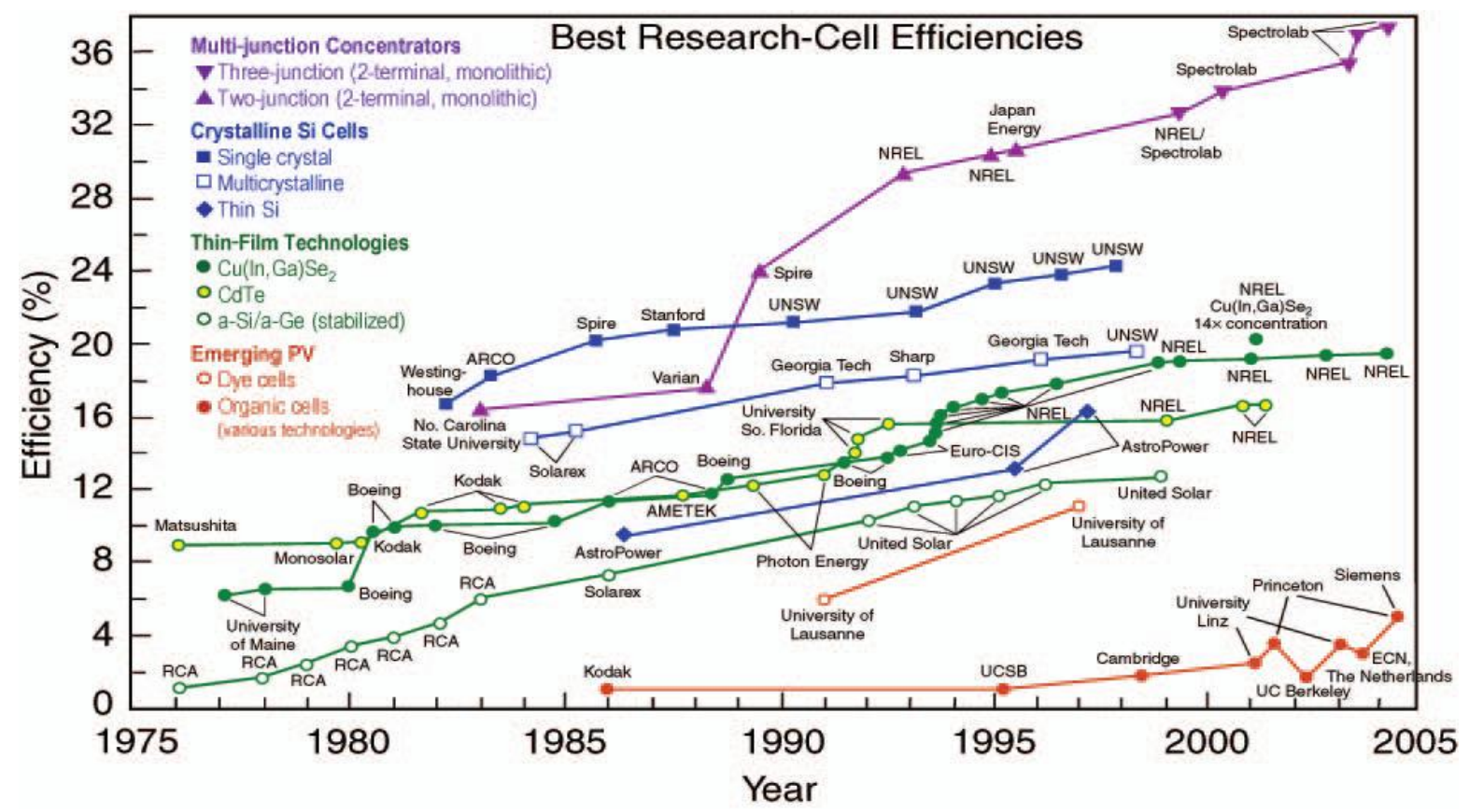

Figure 2-2: Comparison of Efficiency over Time for Various PV Technologies[2] 
This growth is especially promising when combined with the information from

Figure 2-3 below which demonstrates that efficiency is increasing and cost per watt is decreasing over time, a perfect combination that ensures an economically viable alternative to fossil fueled power.

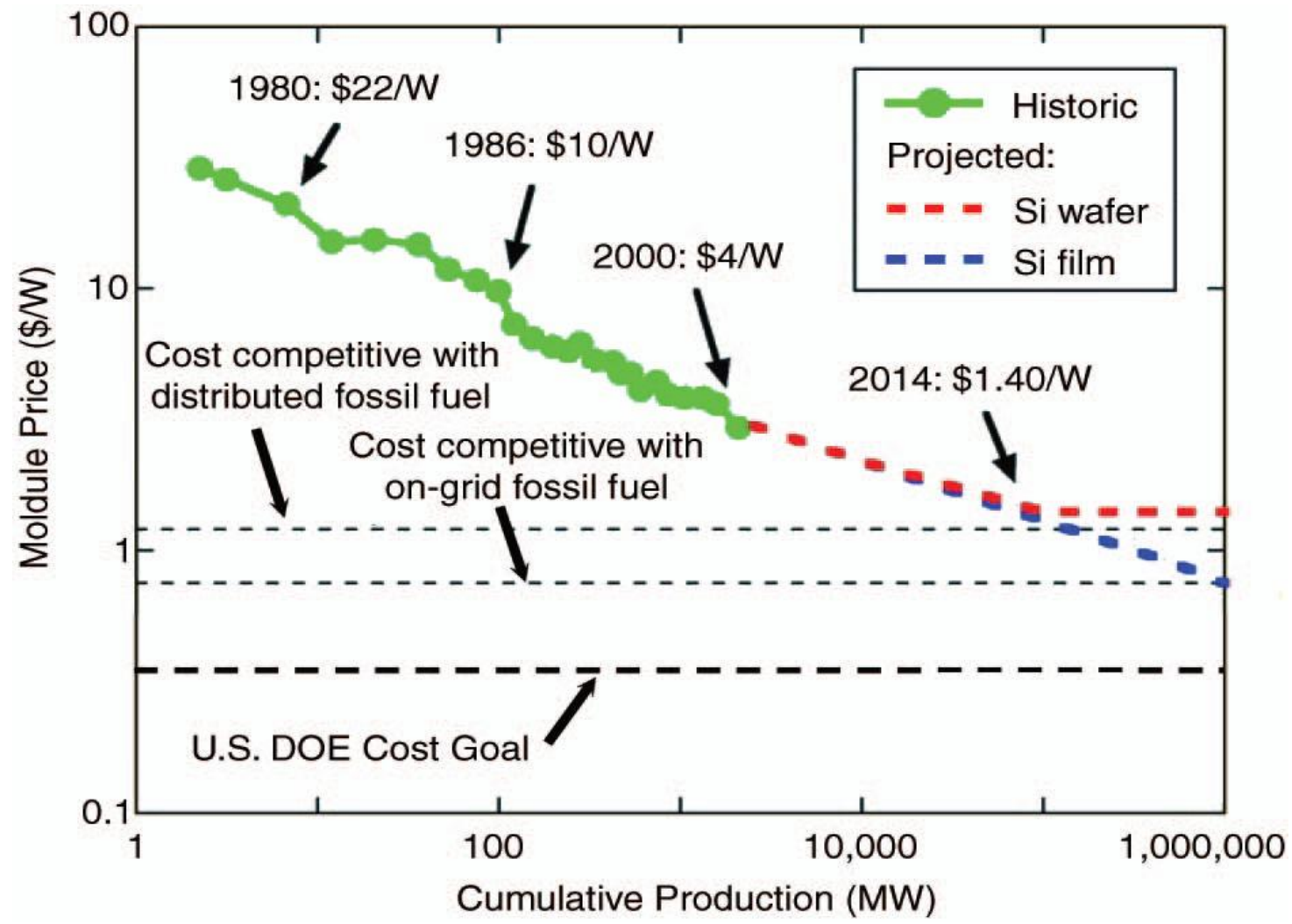

Figure 2-3: Comparison of Cost in USD per Watt for Silicon based Photovoltaics [2]

Unfortunately, like most renewable power sources, the reliability of photovoltaics is subject to weather and time of day. In an off-grid application such as the DC house, it will be necessary to incorporate a battery system to provide stability to the unreliable power generation. 


\subsection{Making the Case for DC}

A DC powered electrical system is not a new and an uncommon concept. For example the electronics in a car or RV are powered on a $12 \mathrm{~V} \mathrm{DC}$ system with one or more batteries. The car's motor drives an alternator which produces $\mathrm{AC}$ voltage. The AC power is rectified to DC and the voltage level is regulated via a voltage regulator. The regulator feeds into the car battery. The regulator controls the power flow to the battery so that the battery is never overcharged. This system is used to power the on board electronics and lighting in a car. The reason that the car uses DC is for several reasons. DC power is required for many onboard electronics such as the car stereo for example. DC also permits the use of a battery, which gives the car's power system some flexibility. This way, the car's motor doesn't have to be on and powering the car for the lights, radio, and electronics to work. This basic power system is very similar in motivation and function to a power system that incorporates renewable energy sources. It provides a voltage bus that supply DC powered loads, and via battery provide power to those loads when the energy source is inactive (cloudy weather for photovoltaic generation).

As described in the previous section, a primary weakness of renewable energy sources is that their operation is not guaranteed based on many things such as weather conditions, and we need to deliver power to a home that will use the power at any given time. Using a DC system allows the incorporation of batteries to address the issue of uncertainty in renewable power generation.

Additionally, because photovoltaics and other renewable power sources natively output DC power, they typically must be run through an inverter in order to power an AC load. As with any power device, there is an associated inefficiency with the inverter which 
can range from $95 \%$ to $97.5 \%$ depending on the manufacturer and type of inverter. The Enphase 230W D380 micro-inverter boasts a 95\% CEC weighted average [4] and the Eaton 250kW S-Max inverter has a 96.5\% CEC weighted average efficiency [5]. Although this is a relatively high efficiency, it is still significant enough to note especially on such a large scale. The more important problem with inverters isn't of efficiency but rather of lifetime. Electrolytic capacitors are a necessary component in most inverter topologies. Unfortunately, electrolytic capacitors are notorious for a short lifespan, and result in a typical lifespan of only 5 to 8 years [6]. This necessitates the implementation of maintenance plans that can be costly and require power shutdown during replacements. Both of these reasons provide strong incentives for us to avoid AC power if possible.

The only final question is of whether or not a typical home's electrical needs can be fulfilled with DC powered devices. With recent breakthroughs and continued advancement in LED lighting, there is a huge opportunity to use LEDs to fulfill any lighting needs. Additionally, the existing RV and camper market has many DC home appliances available to fulfill any other home appliance needs.

\subsection{Design Goals}

The DC house is meant to serve as a replacement to the traditional grid-tied AC powered home. Therefore it must fulfill the needs that a typical home provides. The home should provide indoor and outdoor lighting, food storage capabilities, food preparation options, and many other services. Therefore it is important to remember the intended use of the house when making critical design decisions. Then we will be able to interface with multiple power sources whose operation will be uncertain. When coupled with a battery, it is simpler to consider the power source as a DC bus, and then focus on a more complex 
model for the loads. For the purposes of this thesis, the power source will be modeled, and more effort will go into the simulation of the electronics and details of the loads and distribution system. The DC house will serve as a means for renewable energy sources to be used to power an off grid home. This will bring power to those who do not have grid access, and increase the opportunity for the use of clean renewable energy sources.

\section{$2.5 \quad$ Education Goals}

The complete DC house project has several design themes and goals to be accomplished in each phase of operation. The over-arching theme of this project is to apply engineering principles from several disciplines to address the growing problems described in section 2.1. Each student involved must understand the impacts of their project on the overall progress of the DC house project. This will require each person involved to understand the basics of the complete system regardless of what their specific project is. This way every student can identify system limitations and strengths while suggesting and incorporating changes to address these issues throughout the project lifecycle.

Additionally, the DC house project embodies a core engineering principle emphasized at Cal Poly - sustainability. This project brings a concept that is sometimes lost in the realm of rhetoric and not brought to the forefront in practicality. Hopefully the DC house project will get people excited about sustainable engineering, so that they can realize the importance of sustainable design in other student projects where it wasn't previously considered. 


\section{Chapter 3: Load Selection and Distribution Design}

\subsection{Distribution Design}

The distribution system will serve the simple purpose of delivering power from the Multi-Input DC-DC Converter to a set of loads that will in total accumulate to approximately 400 Watts. The Overall Simplified Block diagram of the complete DC House system can be seen below in Figure 3-1:

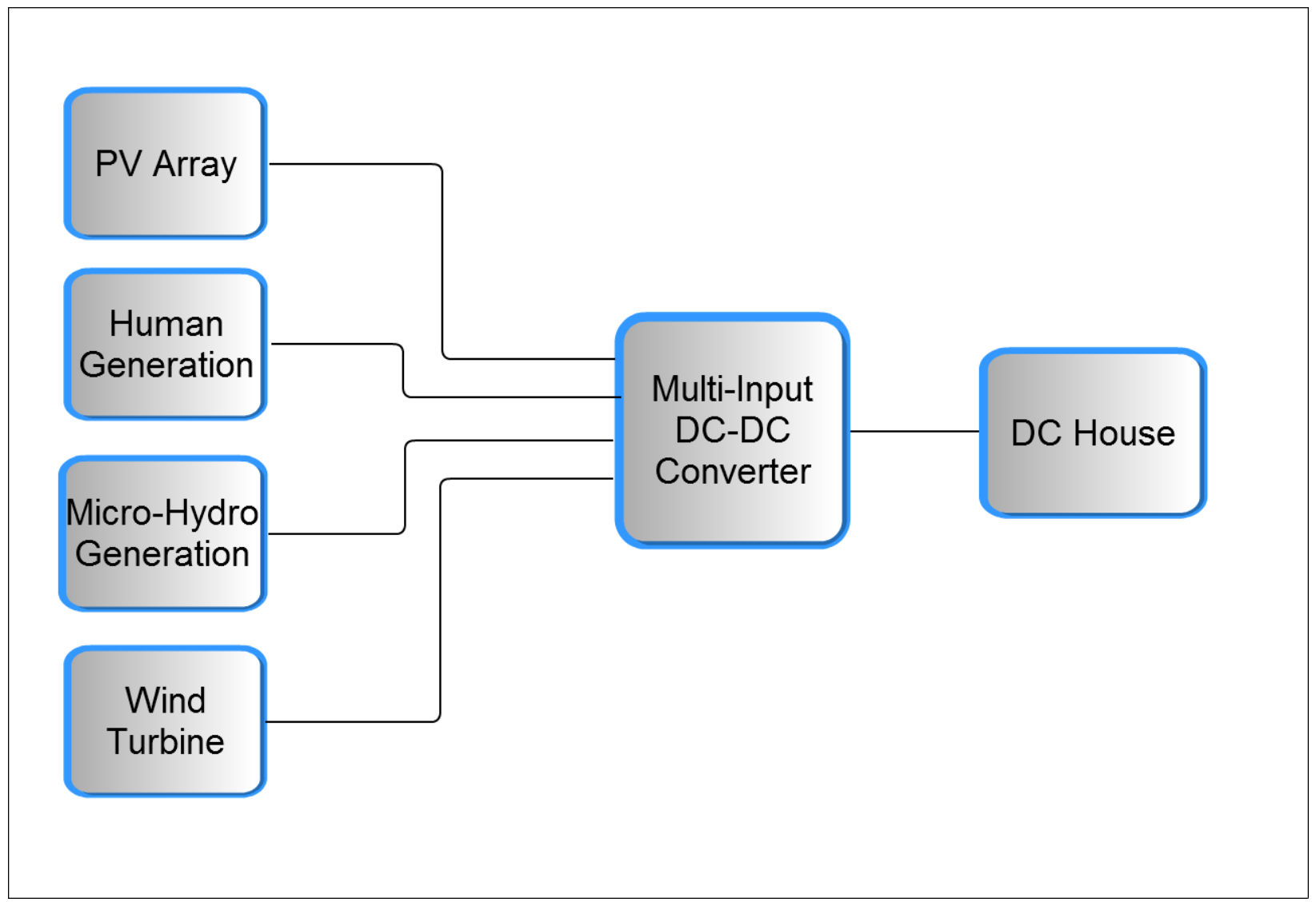

Figure 3-1: Overall Simplified Block Diagram of the DC House Project

As can be seen in the above figure, the many generation sources feed into a complex multiinput DC-DC converter. The multi-input DC-DC converter takes in multiple inputs at different voltage levels and produces one DC output voltage. For the purpose of this thesis, the output of this converter will be modeled simply as a constant DC voltage source. The 
output of the DC-DC converter will lead to a feeder box which will provide separate circuits for each load (or set of loads). Figure 3-2 shows the block diagram model of the system starting from e the multiple input DC-DC Converter.

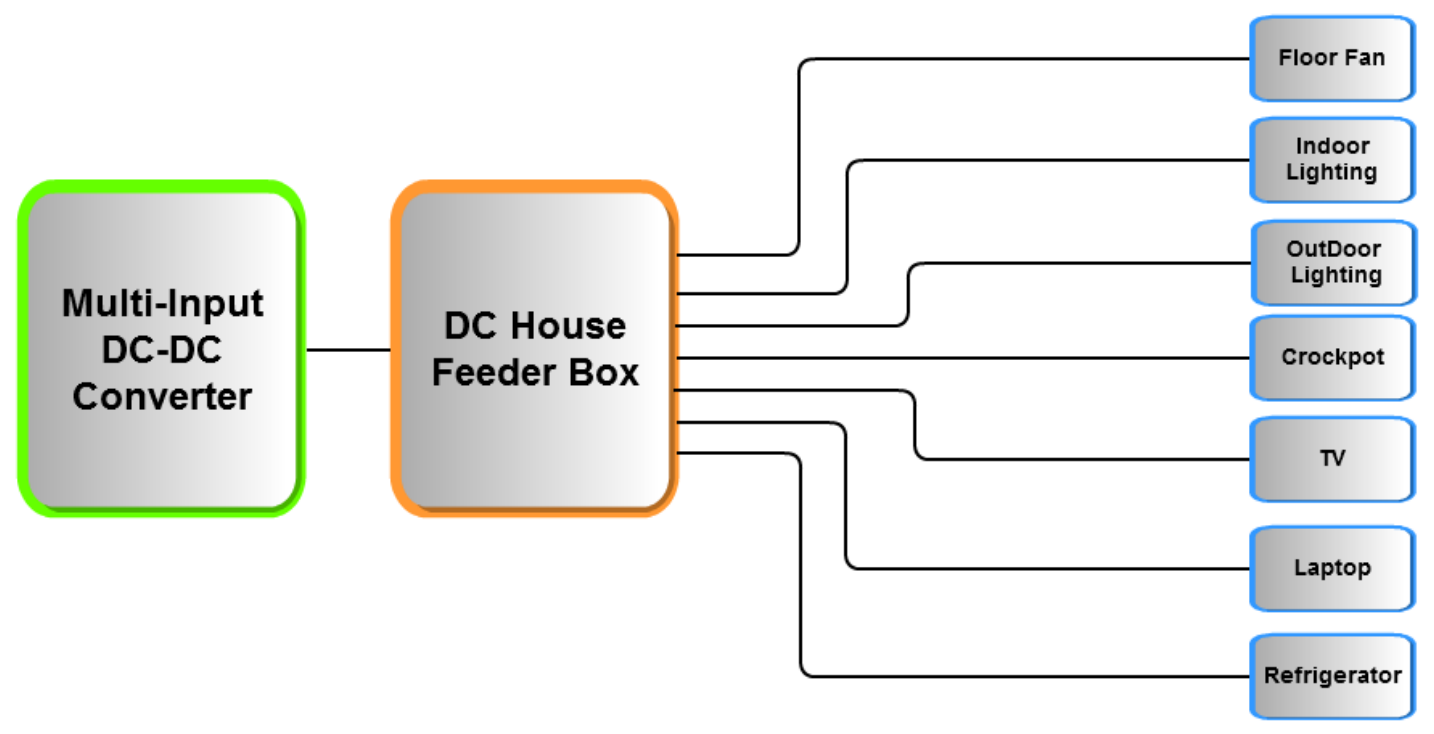

Figure 3-2: Block Diagram Showing How the loads for the DC House will be powered

The distance between the mutli-input DC-DC converter and the feeder box will be approximated based on the planned implementation of the system. Ideally, this distance will be minimized because the low voltage and high power output of the DC-DC converter will create relatively large currents, which further creates problems for efficiency of the distribution system. The power dissipated by a resistive element such as a conducting wire can be derived as a function of its resistance R and RMS current flow by using Ohm's Law and the equation for electrical power.

$$
P=\mathrm{I}^{2} R
$$


Equation 3-1 shows that an increase in current will create an exponential increase in the power dissipated in a wire. This is why large currents present an inherent inefficiency and should be noted so that both current and wire resistance can be minimized in this design wherever possible. Because DC voltage generation is usually at low voltage and high current, using a conductor with minimal resistance is necessary.

\section{Conductor Resistance}

A conductor's resistance depends primarily on three factors - the length, the thickness, and the type of material. All conductors have an associated resistivity value ( $\rho)$ which can be used in conjunction with the length (l) and cross-sectional area (A) of the wire to determine the wire's resistance. This relationship follows the equation below:

$$
\mathrm{R}=\frac{\rho \mathrm{l}}{\mathrm{A}}
$$

Electrical wiring is sized based on it's cross-sectional area. Particularly, they are sized in circular mils or American Wire Gauge (AWG) ratings. AWG is a standardized gauging system used to describe the cross-sectional area of a conductor, where the bigger number indicates a smaller cross-sectional area. For example, a conductor that is sized at 22 AWG is smaller than a 2 AWG wire. One circular mil or [cmil] is equivalent to the area of a circle with diameter of $1 \mathrm{mil}$, where a mil is one thousandth of an inch. The kcmil is equivalent to 1000 cmils. The kcmil is only used to describe the cross-sectional area of a conductor that is larger than 4/0 AWG wire. These are the standards that the NEC uses for all conductors.

Typically aluminum and copper conductors are used as conductors. Aluminum has resistivity of $2.82 \times 10^{-8}[\Omega \cdot \mathrm{m}]$ and copper has a resistivity of $1.68 \times 10^{-8}[\Omega \cdot \mathrm{m}] . \quad$ In theory, copper is always preferable over aluminum conductors because it has a lower resistivity 
which means lower power losses. Despite this, aluminum is sometimes used because copper is significantly more expensive. This makes it a preferred option to reduce costs drastically in large scale transmission lines and high voltage distribution services. Additionally, in photovoltaic generation copper is always used because the low generation voltage and high generation currents would create unacceptable inefficiencies. The NEC in fact requires the use of copper conductors on the low voltage DC power output from a photovoltaic array $[7]$.

\subsubsection{Wire Size}

As stated in the previous chapters, the DC house will adhere to NEC electrical standards in every regard. There are two important ways that the NEC will impact in the DC house distribution system. The first is that no individual home load circuit must be fused at no more than 15 Amps found in 240.4(D)[7], see figure 3-3.

(D) Small Conductors. Unless specifically permitted in $240.4(\mathrm{E})$ or $240.4(\mathrm{G})$, the overcurrent protection shall not exceed 15 amperes for 14 AWG, 20 amperes for 12 AWG, and 30 amperes for 10 AWG copper; or 15 amperes for 12 AWG and 25 amperes for 10 AWG aluminum and copper-clad aluminum after any correction factors for ambient temperature and number of conductors have been applied.|

\section{3-3: Direct Textual Quote from the NEC manual regarding Wire Size in DC systems[7]}

The second concern deals with the wire size selection. There is a set of standards that detail the wire size that is appropriate for different rated currents. These ratings follow the NEC tables shown in Table 3-1. 
Table 3-1: The NEC Current Ratings for Varying Wire Sizes at Varying Temperatures[7]

Allowable Ampacities of Insulated Conductors Rated 0 Through 2000 Volts, 60 C Through $90^{\circ} \mathrm{C}\left(140^{\circ} \mathrm{F}\right.$ Through $\left.194^{\circ} \mathrm{F}\right)$, Not More Than Three Current-Carrying Conductors in Raceway, Cable, or Earth (Directly Buried), Based on Ambient Temperature of $30^{\circ} \mathrm{C}\left(86^{\circ} \mathrm{F}\right)$

\begin{tabular}{|c|c|c|c|c|c|c|c|}
\hline \multirow{4}{*}{$\begin{array}{c}\text { Size AWG or } \\
\text { kcmil }\end{array}$} & \multicolumn{6}{|c|}{ Temperature Rating of Conductor (See Table 310.13.) } & \multirow{4}{*}{$\begin{array}{c}\text { Size AWG or } \\
\text { kcmil }\end{array}$} \\
\hline & $60^{\circ} \mathrm{C}\left(140^{\circ} \mathrm{F}\right)$ & $75^{\circ} \mathrm{C}\left(167^{\circ} \mathrm{F}\right)$ & $90^{\circ} \mathrm{C}\left(194^{\circ} \mathrm{F}\right)$ & $\begin{array}{c}60^{\circ} \mathrm{C} \\
\left(140^{\circ} \mathrm{F}\right) \\
\end{array}$ & $75^{\circ} \mathrm{C}\left(167^{\circ} \mathrm{F}\right)$ & $90^{\circ} \mathrm{C}\left(194^{\circ} \mathrm{F}\right)$ & \\
\hline & Types TW, UF & $\begin{array}{c}\text { Types RHW, } \\
\text { THHW, THW, } \\
\text { THWN, XHHW, } \\
\text { USE, ZW }\end{array}$ & \begin{tabular}{|c} 
Types TBS, SA, SIS, \\
FEP, FEPB, MI, RHH, \\
RHW-2, THHN, \\
THHW, THW-2, \\
THWN-2, USE-2, \\
XHH, XHHW, \\
XHHW-2, ZW-2 \\
\end{tabular} & $\begin{array}{c}\text { Types } \\
\text { TW, UF } \\
\end{array}$ & $\begin{array}{c}\text { Types RHW, } \\
\text { THHW, THW, } \\
\text { THWN, } \\
\text { XHHW, USE }\end{array}$ & \begin{tabular}{|c|} 
Types TBS, SA, SIS, \\
THHN, THHW, \\
THW-2, THWN-2, \\
RHH, RHW-2, USE-2, \\
XHH, XHHW, \\
XHHW-2, ZW-2 \\
\end{tabular} & \\
\hline & \multicolumn{3}{|c|}{ COPPER } & \multicolumn{3}{|c|}{ ALUMINUM OR COPPER-CLAD ALUMINUM } & \\
\hline $\begin{array}{l}18 \\
16 \\
14^{*} \\
12^{*} \\
10^{*} \\
8 \\
\end{array}$ & $\begin{array}{l}\overline{-} \\
\overline{20} \\
25 \\
30 \\
40\end{array}$ & $\begin{array}{l}- \\
20 \\
25 \\
35 \\
50 \\
\end{array}$ & $\begin{array}{l}14 \\
18 \\
25 \\
30 \\
40 \\
55\end{array}$ & $\begin{array}{l}\bar{z} \\
\overline{20} \\
25 \\
30 \\
\end{array}$ & $\begin{array}{l}\bar{z} \\
\overline{20} \\
30 \\
40 \\
\end{array}$ & $\begin{array}{l}= \\
\bar{z} \\
25 \\
35 \\
45\end{array}$ & $\begin{array}{l}\bar{z} \\
\overline{12 *} \\
10^{*} \\
8\end{array}$ \\
\hline $\begin{array}{l}6 \\
4 \\
3 \\
2 \\
1 \\
\end{array}$ & $\begin{array}{r}55 \\
70 \\
85 \\
95 \\
110 \\
\end{array}$ & $\begin{array}{r}65 \\
85 \\
100 \\
115 \\
130 \\
\end{array}$ & $\begin{array}{r}75 \\
95 \\
110 \\
130 \\
150\end{array}$ & $\begin{array}{l}40 \\
55 \\
65 \\
75 \\
85 \\
\end{array}$ & $\begin{array}{r}50 \\
65 \\
75 \\
90 \\
100 \\
\end{array}$ & $\begin{array}{r}60 \\
75 \\
85 \\
100 \\
115 \\
\end{array}$ & $\begin{array}{l}6 \\
4 \\
3 \\
2 \\
1 \\
\end{array}$ \\
\hline $\begin{array}{l}1 / 0 \\
2 / 0 \\
3 / 0 \\
4 / 0 \\
\end{array}$ & $\begin{array}{l}125 \\
145 \\
165 \\
195 \\
\end{array}$ & $\begin{array}{l}150 \\
175 \\
200 \\
230 \\
\end{array}$ & $\begin{array}{l}170 \\
195 \\
225 \\
260 \\
\end{array}$ & $\begin{array}{l}100 \\
115 \\
130 \\
150 \\
\end{array}$ & $\begin{array}{l}120 \\
135 \\
155 \\
180 \\
\end{array}$ & $\begin{array}{l}135 \\
150 \\
175 \\
205 \\
\end{array}$ & $\begin{array}{l}1 / 0 \\
2 / 0 \\
3 / 0 \\
4 / 0 \\
\end{array}$ \\
\hline $\begin{array}{l}250 \\
300 \\
350 \\
400 \\
500 \\
\end{array}$ & $\begin{array}{l}215 \\
240 \\
260 \\
280 \\
320 \\
\end{array}$ & $\begin{array}{l}255 \\
285 \\
310 \\
335 \\
380 \\
\end{array}$ & $\begin{array}{l}290 \\
320 \\
350 \\
380 \\
430 \\
\end{array}$ & $\begin{array}{l}170 \\
190 \\
210 \\
225 \\
260 \\
\end{array}$ & $\begin{array}{l}205 \\
230 \\
250 \\
270 \\
310 \\
\end{array}$ & $\begin{array}{l}230 \\
255 \\
280 \\
305 \\
350 \\
\end{array}$ & $\begin{array}{l}250 \\
300 \\
350 \\
400 \\
500 \\
\end{array}$ \\
\hline $\begin{array}{l}600 \\
700 \\
750 \\
800 \\
900 \\
\end{array}$ & $\begin{array}{l}355 \\
385 \\
400 \\
410 \\
435 \\
\end{array}$ & $\begin{array}{l}420 \\
460 \\
475 \\
490 \\
520\end{array}$ & $\begin{array}{l}475 \\
520 \\
535 \\
555 \\
585 \\
\end{array}$ & $\begin{array}{l}285 \\
310 \\
320 \\
330 \\
355 \\
\end{array}$ & $\begin{array}{l}340 \\
375 \\
385 \\
395 \\
425 \\
\end{array}$ & $\begin{array}{l}385 \\
420 \\
435 \\
450 \\
480\end{array}$ & $\begin{array}{l}600 \\
700 \\
750 \\
800 \\
900 \\
\end{array}$ \\
\hline $\begin{array}{l}1000 \\
1250 \\
1500 \\
1750 \\
2000\end{array}$ & $\begin{array}{l}455 \\
495 \\
520 \\
545 \\
560\end{array}$ & $\begin{array}{l}545 \\
590 \\
625 \\
650 \\
665\end{array}$ & $\begin{array}{l}615 \\
665 \\
705 \\
735 \\
750\end{array}$ & $\begin{array}{l}375 \\
405 \\
435 \\
455 \\
470\end{array}$ & $\begin{array}{l}445 \\
485 \\
520 \\
545 \\
560\end{array}$ & $\begin{array}{l}500 \\
545 \\
585 \\
615 \\
630\end{array}$ & $\begin{array}{l}1000 \\
1250 \\
1500 \\
1750 \\
2000\end{array}$ \\
\hline
\end{tabular}

Using these guidelines, the default wire sizes were chosen to be 10 AWG for the individual circuits, and 4 AWG for the Voltage bus to feeder box connection. The length for each individual circuit was chosen to be 25 feet, and the bus to feeder box length was chosen to be 100 feet. To appropriately calculate the resistance for each wire, the length was doubled to account for the return path.

\subsection{Load Selection}


In order to select the loads needed for the DC house it is important to consider the needs of the people living there and the humanitarian goals of the DC house project and weigh them against the constraints that an isolated generation system provides. First we should accurately define the limitations of our generation system, then develop a strategy to select the loads that can fit in those constraints. The following subsections discuss this issue.

\subsubsection{How the DC house Generation System Works}

The DC house will utilize several generation sources such as a photovoltaic array, a human powered generator, a wind turbine, and many others. These sources will each have their own output wattage that will depend on weather conditions and in some cases human interaction (such as the exercise bike generator). Because these sources could all generate at different voltage levels, they will be fed into a multi-input DC-DC converter which will be tied in with a battery. This way, whenever the power sources create excess power, it can be stored in the battery. The battery will also provide a means to provide power to the DC house when the power sources are not operating. The specifics of the battery and power sources have not been specified, but based on the assumption that this is a small power system for a single home, it will be assumed that a maximum output power of $400 \mathrm{Watts}$ will be provided by the source. The resulting implications of this setup is that the maximum rate of energy output is $400 \mathrm{~W}$, and that with the combined use of the battery, will be able to sustain this energy output for periods where the generation sources are not functioning.

\subsubsection{Selection Strategy}

First a set of basic home needs will be defined, and loads will be chosen to fulfill those basic needs. Then, if these "basic needs" loads do not fulfill the $400 \mathrm{~W}$ limitation, 
additional convenience loads will be added if possible. The basic humanitarian goals that should be met by the DC house are: lighting, some means of cooking, food storage, and laptop charging.

\subsubsection{Lighting}

A light fixture or luminaire can be characterized by two important factors - its brightness measured in lumens, and its power usage rated in watts. A lumen is defined as the brightness (power) of light that is perceived by the human eye. When a light source is active it emits light in all parts of the electromagnetic spectrum. For example, the common incandescent light bulb emits light in the power spectral density shown in figure 3-4 :

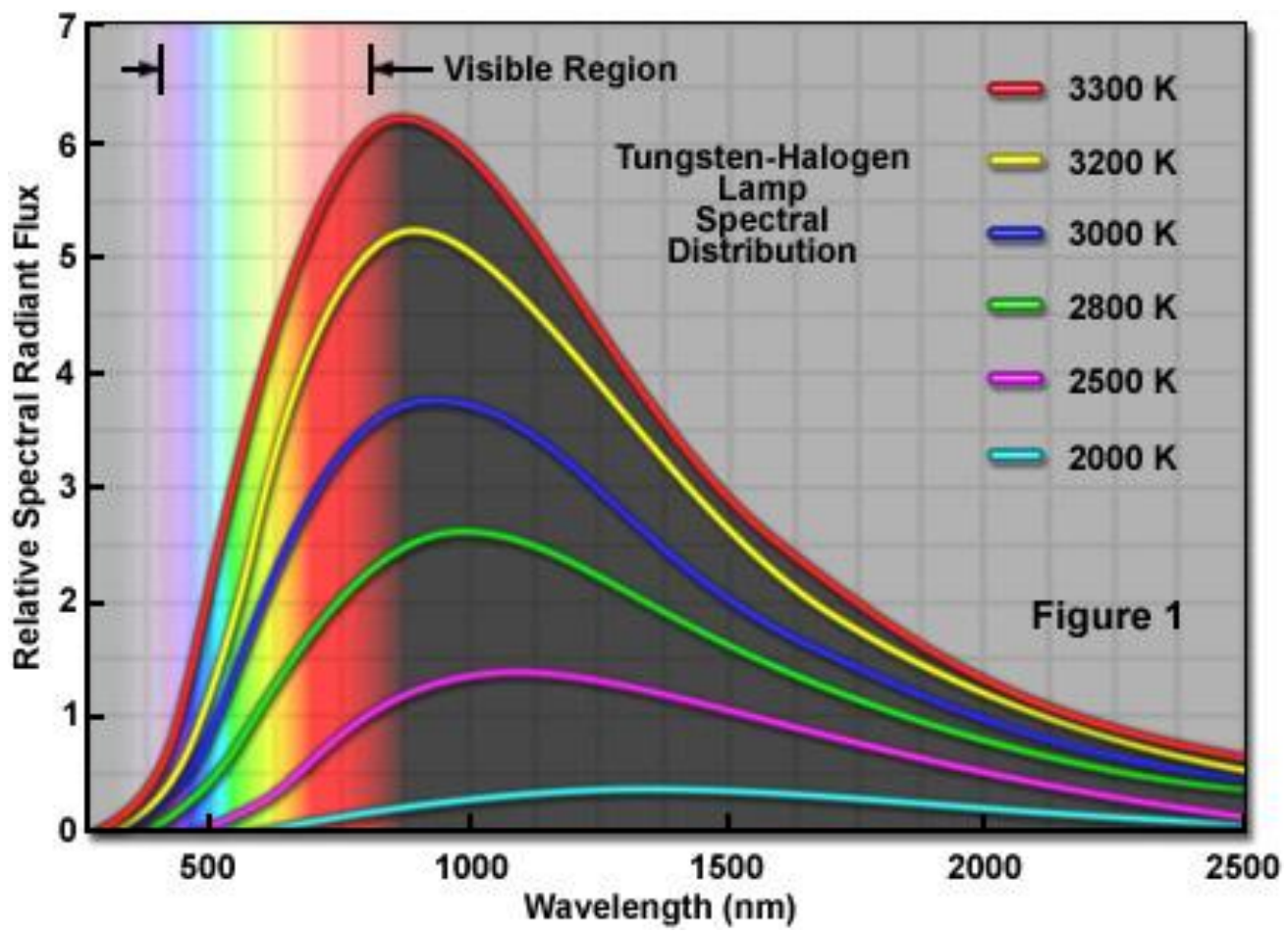

Figure 3-4: Luminous Power Spectral density of typical Incandescent Light Bulbs Taken from the Zeiss Online Campus For Microscopy [8] 
Notice that a large portion of the luminous power emitted is not in the visible spectrum. This makes the incandescent light bulb inherently inefficient, because there is wasted power generating light that humans cannot see. Therefore the more efficient light source, will be one which minimizes the luminous power outside of the visible spectrum. A common metric used to quickly determine the luminous efficiency of a light source is the ratio of lumens to total electrical power used by the device. This metric is called luminous efficacy. The higher efficacy indicates a more efficient light.

There are three kinds of lighting generally used in the home lighting setting Incandescent, Compact fluorescent, and LED.

Incandescent lighting is the most antiquated, and runs an electric current through a piece of tungsten to generate light. Incandescent lights generally have a low luminous efficacy because much of the energy used is lost as heat and as non-visible light (infrared). The Phillips 75W Med 130V A19 FR PRO 1CT Incandescent lightbulb was examined as a candidate for the lighting role. This 75 Watt bulb featured a luminous efficacy of 15.33 lumens per watt and a lifespan of 750 hours on average [10].

Incandescent lighting is still used sometimes in photography. This is because the color spectrum creates a "warmer" image when captured on film or video. In the end, Incandescent lighting is not the ideal choice for the DC house where the only use of the light is for reading or for visibility to perform common household tasks and high efficiency is ideal.

The compact fluorescent Light bulb (CFL) was developed more recently, and boasts a higher luminous efficacy than an incandescent because it generates more light inside the 
visible spectrum as can be seen in Figure 3-5.

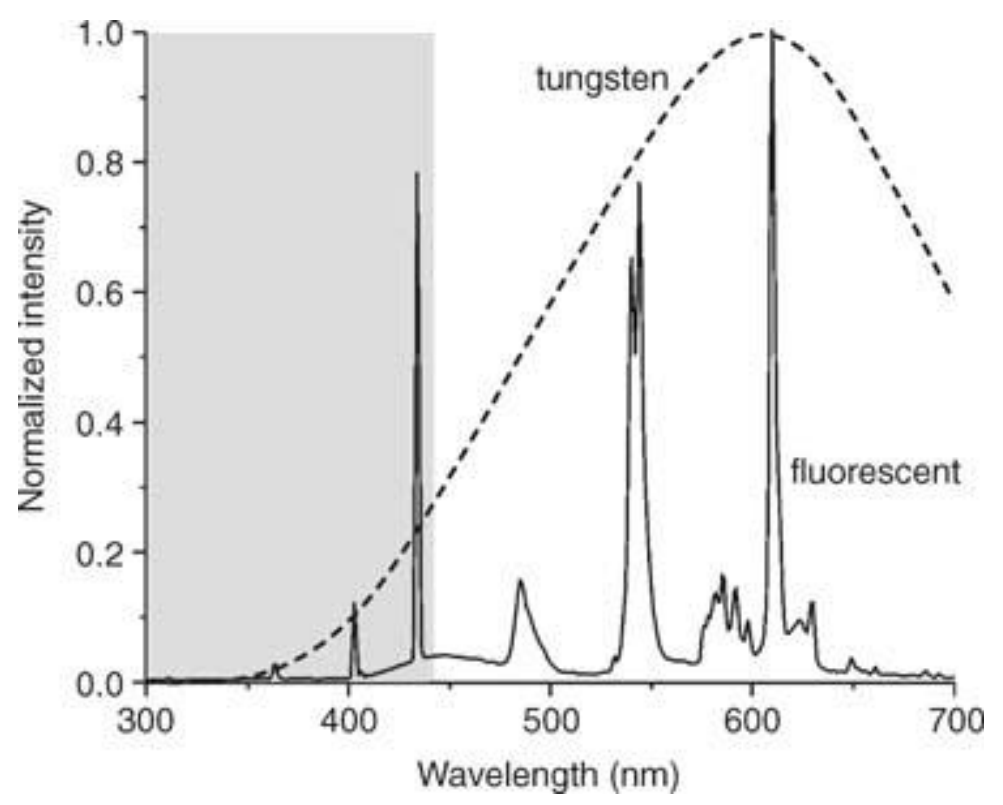

Figure 3-5: Spectral Density of the common compact fluorescent light bulb. Taken from “Caged Molecules:

Principles and Practical Considerations" University of Maryland [9]

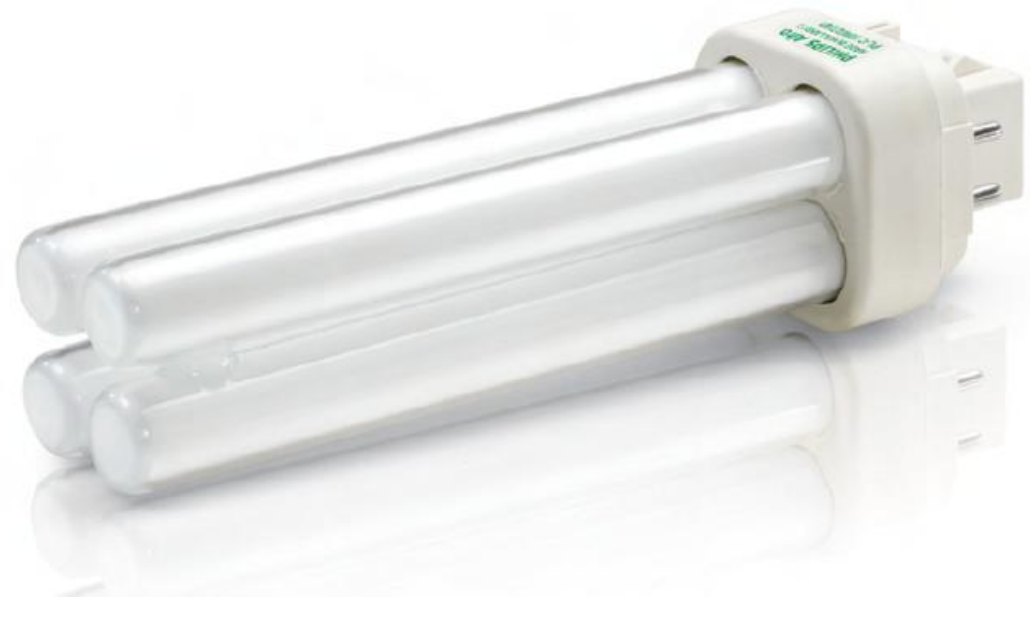

Figure 3-6: Photo of the Phillips PL-C 4-Pin CFL[10] 
The PL-C 4-Pin CFL was examined as a candidate for the DC house lighting. It features a luminous efficacy of 69.23 lumens per watt [10]. The CFL also featured a much longer lifespan than the incandescent light bulb, for the PL-C 4-pin CFL 12,000 hours for 3 hour start and 16,000 hours for 12 hour start. One problem with the CFL is that all models are designed for $\mathrm{AC}$ power and would require an inverter for the DC House. This makes it an efficient but impractical candidate for the DC house project.

LED lighting technology has continued to evolve over the last 15 years. It features high luminous efficacy with it's main downside is that it requires the use of DC power. Normally DC power is cumbersome because the typical home uses AC power which would require rectification and other power electronics in order to drive an LED luminaire. The Luxeon Rebel ES Cool-White LED was examined as a candidate for the LED to be used. This power LED has a spectral power distribution as shown below in Figure 3-7. 


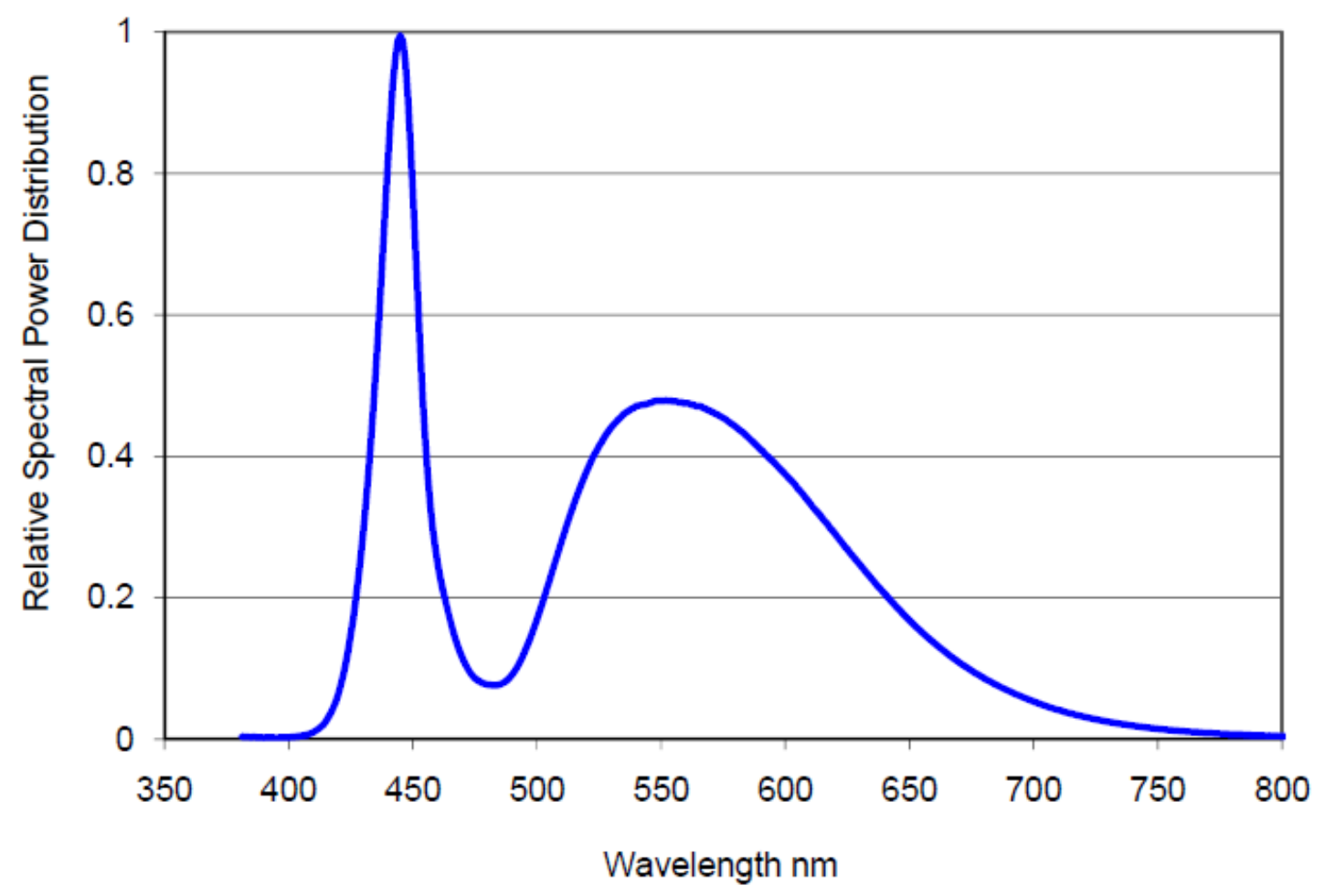

Figure 3-7: Color Spectrum for Lumileds Luxeon Rebel ES Cool-White LED [11]

Notice that there is very little power outside of the visible spectrum $(400 \mathrm{~nm} \sim$

750nm). This makes the device have a high luminous efficacy of 111.9 Lumens per Watt

[11]. LEDs also feature an even longer lifespan than CFL's. The performances of these devices are summarized in Table 3-2 below:

Table 3-2: Summary of Critical Specifications for Incandescent, Compact Fluorescent, and LED Lighting Candidates[11][10]

\begin{tabular}{|c|c|c|}
\hline Device & $\begin{array}{c}\text { Lumninous } \\
\text { Efficacy } \\
{[\mathrm{Im} / \mathrm{W}]}\end{array}$ & $\begin{array}{c}\text { Rated } \\
\text { Lifetime } \\
\text { [Hours] }\end{array}$ \\
\hline $\begin{array}{c}\text { Phillips Medium } \\
75 W \\
\text { Incandescent }\end{array}$ & 15.33 & 750 \\
\hline Phillips PL-C CFL & 69.23 & 16,000 \\
\hline Luxeon Rebel ESLED & 111.9 & 35,000 \\
\hline
\end{tabular}


Although the compact fluorescent boasts a higher efficacy than the incandescent both devices function natively in an $\mathrm{AC}$ system, and would require inversion and other additional power electronics for operation. These facts about the operation of an LED make it the obvious choice for the required high efficiency and native DC power of the DC house project.

\subsection{LED Luminaire Design}

The Luxeon rebel LED was selected as the principal component to fulfill the lighting needs of the DC house. Unfortunately, this LED could not provide enough lumen output by itself, as each LED can only create 320 lumens of light. Additionally, the DC home will require both indoor and outdoor lighting. This allowed for the opportunity to design two different LED luminaires - one indoor and one outdoor, that would output adequate light.

Therefore, a luminaire had to be designed that could provide the same lumen output of a standard home light fixture. The CFL examined in the previous section was used as a baseline for the lumen output requirements of the LED luminaire. This particular CFL outputs 1800 lumens of light [10]. Therefore six LEDs would be used at 320 lumens each to create a lumen output of 1920. A 50 Watt high pressure sodium street light bulb outputs 4400 lumens rated[12] . This street light was used as a baseline to justify a 10 LED luminaire that would output 3200 lumens. Once the number of LEDs necessary to provide adequate light for both indoor and outdoor luminaires was determined, it was necessary to determine the ideal LED driver schematic. 
An LED's lumen output is proportional to the current driven through it. The luxeon rebel ES has a forward voltage drop of 3 Volts, and will output 320 lumens at $1000 \mathrm{~mA}$ of current. Any variations in current, especially surges, will reduce the lifespan of the LED. Additionally, all LEDs - even those of same model and made in the same batch have unique I-V Characteristics. This can best be observed in Figure 3-8:

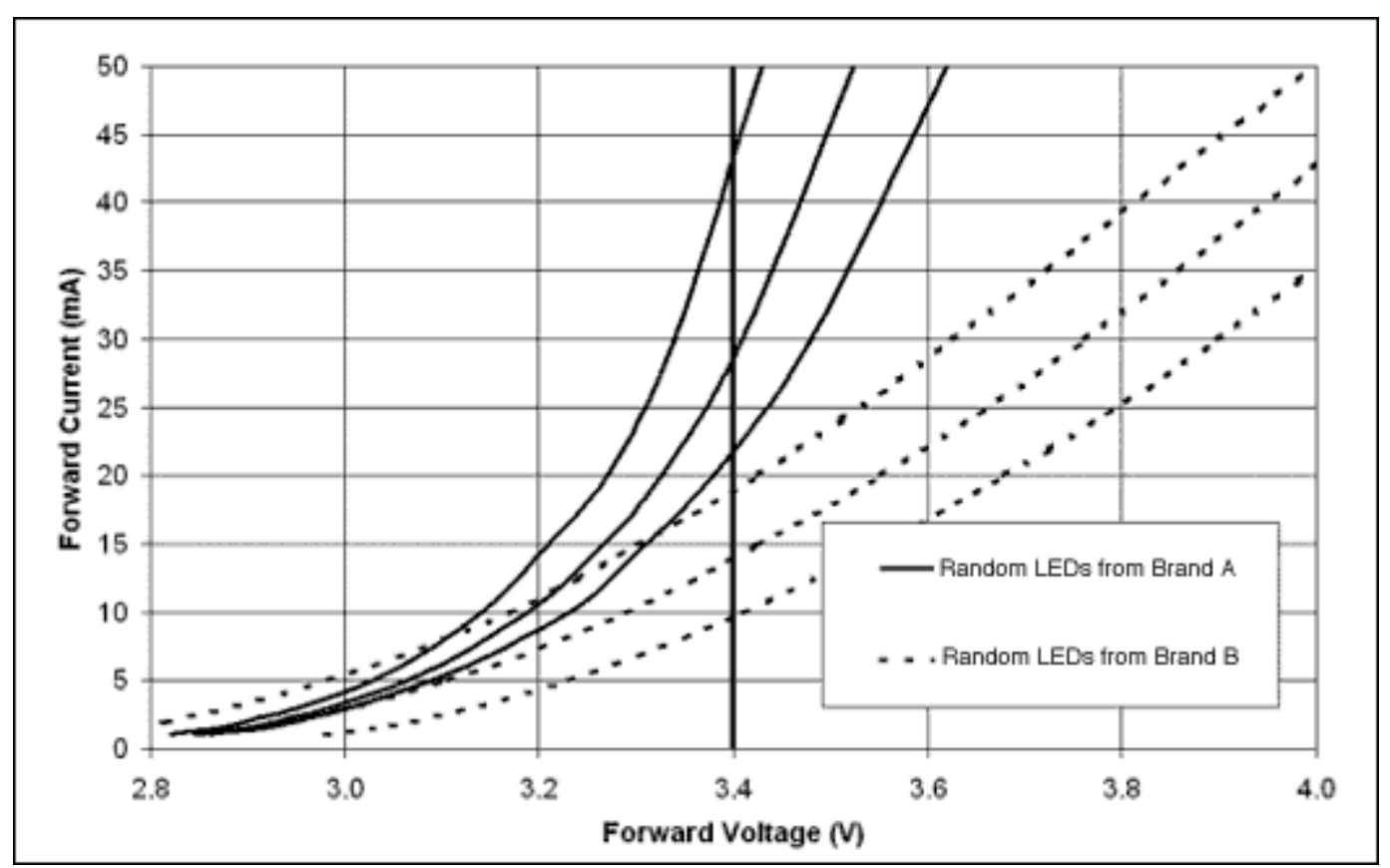

Figure 3-8: I-V Characteristics of random assortment of LEDs from two different brands [Maxim]

As indicated in the above graph, the I-V characteristics of LEDs will never be exactly the same. This makes the option of wiring LEDs in Parallel less appealing. A parallel configuration such as that shown in Figure 3-9 would result in inconsistent currents in each branch. This is because the forward voltage drop for each LED would not be the same, and using KVL, LEDs that have a higher voltage drop would use less current. Additionally, the more LEDs that are strung in series, the higher the overall efficiency. This can be demonstrated by a sample calculation for the circuit in Figure 3-9 making a few assumptions. 
The source voltage is 12 volts, the forward voltage drop of each LED is 3.2 volts, and each resistor value is $2.4 \mathrm{Ohms}$. These assumptions would result in a branch current of:

$$
\mathrm{I}=\frac{[12 \mathrm{~V}-(3 * 3.2 \mathrm{~V})]}{2.40 \mathrm{Oms}}=1 \mathrm{~A}=1000 \mathrm{~mA}
$$

Next, the power dissipated by each LED and the resistor were determined.

$$
\begin{gathered}
\mathrm{P}_{\text {Resistor }}=I^{2} \times \mathrm{R}=1^{2} \times 2.4=2.4 \mathrm{~W} \\
\mathrm{P}_{\mathrm{LED}}=\mathrm{I} \times \mathrm{V}=1 \times 3.2=3.2 \mathrm{~W}
\end{gathered}
$$

Then the Efficiency of the string could be calculated by determining the amount of power dissipated by the LEDS compared to the amount of power dissipated by the entire string. Where " $n$ " is the number of LEDs in the string, the following equation for efficiency was determined:

$$
\text { Efficiency }_{\text {string }}=\frac{\left(\mathrm{n} \times \mathrm{P}_{\mathrm{LED}}\right)}{\mathrm{P}_{\text {Resistor }}+\left(\mathrm{n} \times \mathrm{P}_{\mathrm{LED}}\right)}
$$

Therefore this equation indicated that the more LEDs there are in a string, the more efficient the string is. This is because there will always be a power loss associated with the current limiting resistor, and this cannot be removed because it is necessary to limit the current through the string and thus would protect the LEDs from damage. It is possible however to increase the number of LEDs per string, which would make the power wasted by the resistor less significant, because it will always stay the same regardless of the number of LEDs in the circuit. The tradeoff however associated with increasing the number of 
LEDs is that a higher overhead voltage is needed to drive a higher number of LEDs in series.

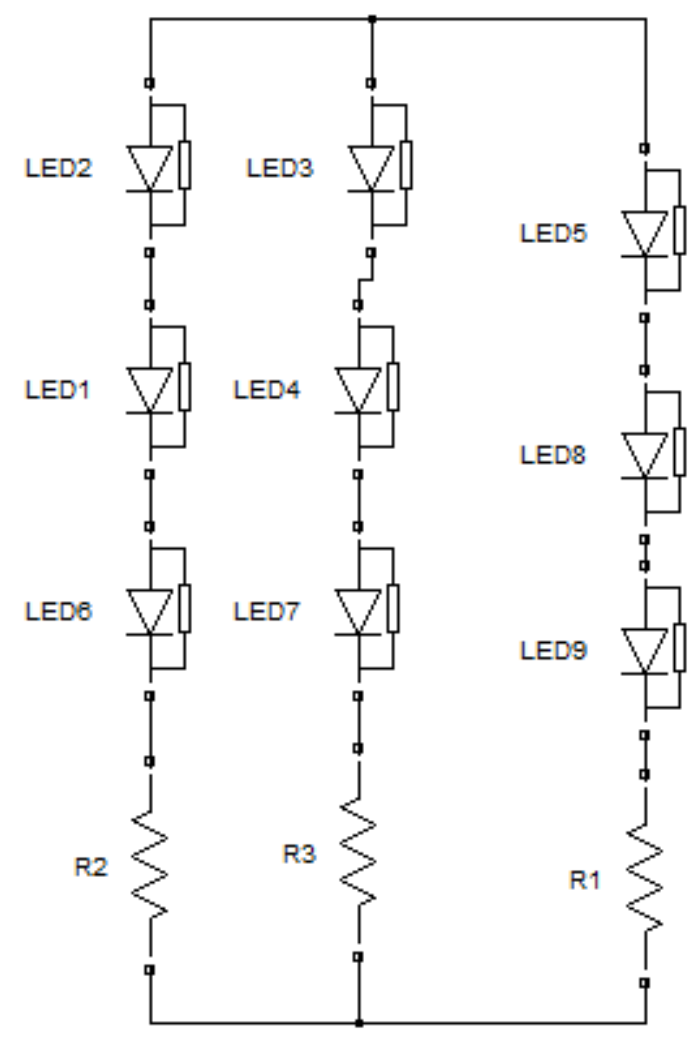

Figure 3-9: Simulink model of Parallel LEDs with current limiting resistors

It is obvious that the number of LEDs in a string should be maximized, in order to maximize efficiency. However a DC-DC converter would be necessary to drive the LEDs so as to ensure that the voltage level is as constant as possible, so that no current surges or dimming would affect the luminaire's output. The DC-DC converter would also solve the problem of high overhead voltage associated with many LEDs in series. Specifically, a boost-buck converter could be used to boost the voltage to any level necessary to drive many LEDs in series. A boost buck or CUK converter would be ideal because it has a 
"good" output current characteristic. That is - it has a constant current output capability that is inherent to the boost buck topology, and not inherent to the buck-boost nor boost topologies. This is necessary because LEDs require constant current for proper operation.

The resulting LED luminaire for indoor and outdoor lighting would consist of the required number of LEDs in a single string in series with a current limiting resistor that would limit the string current to $1000 \mathrm{~mA}$. Each LED string would be driven by a separate boost-buck converter, as they would each need different voltage levels to drive the high number of LEDs in series. The resulting schematics are depicted in Figures 3-10 for the outdoor LED luminaire and 3-11 for the indoor LED luminaire. The indoor luminaire would consist of the same series setup, but would be driven by a lower voltage of $21 \mathrm{~V}$. 


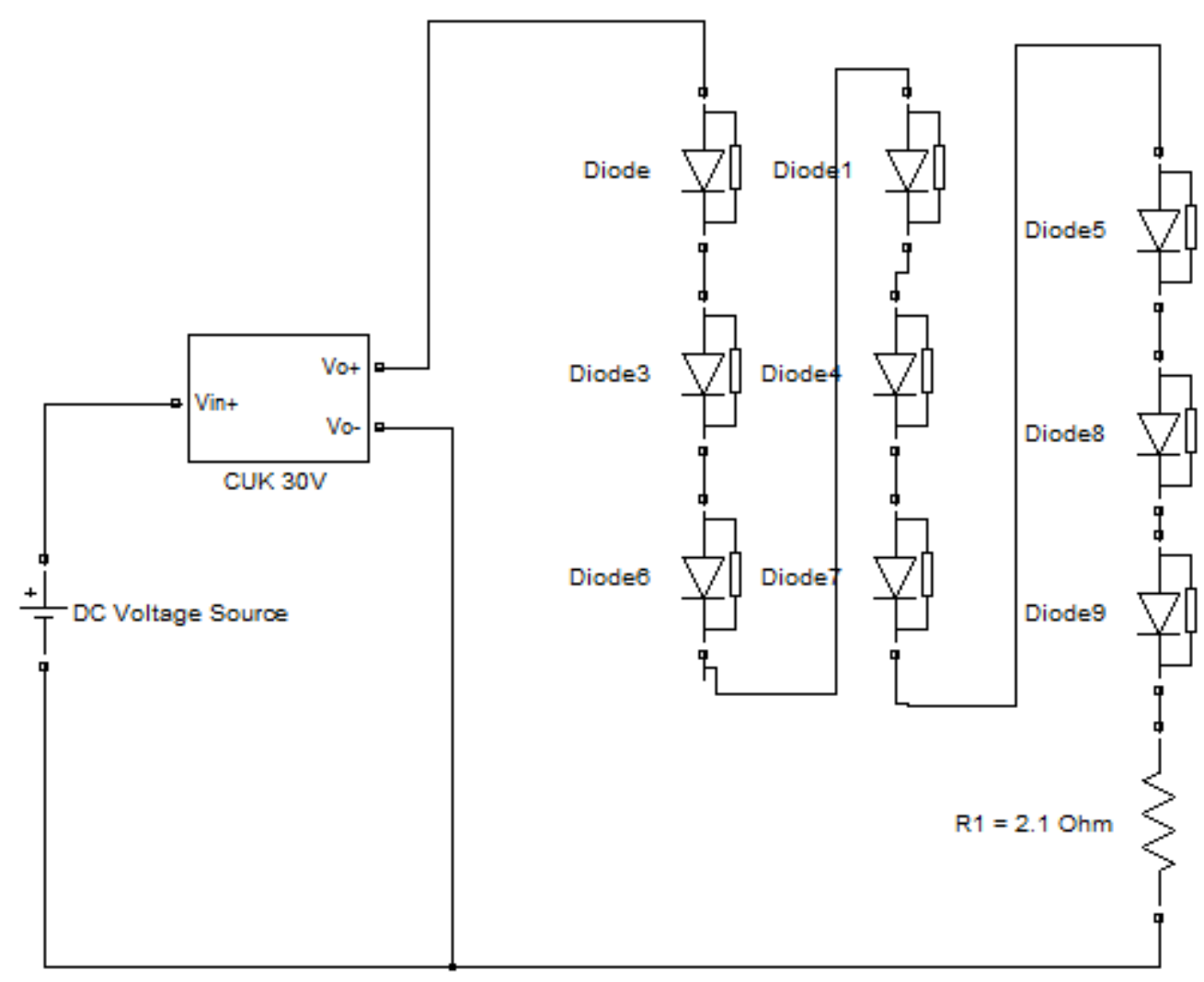

Figure 3-10: The circuit diagram for the outdoor LED Luminaire 


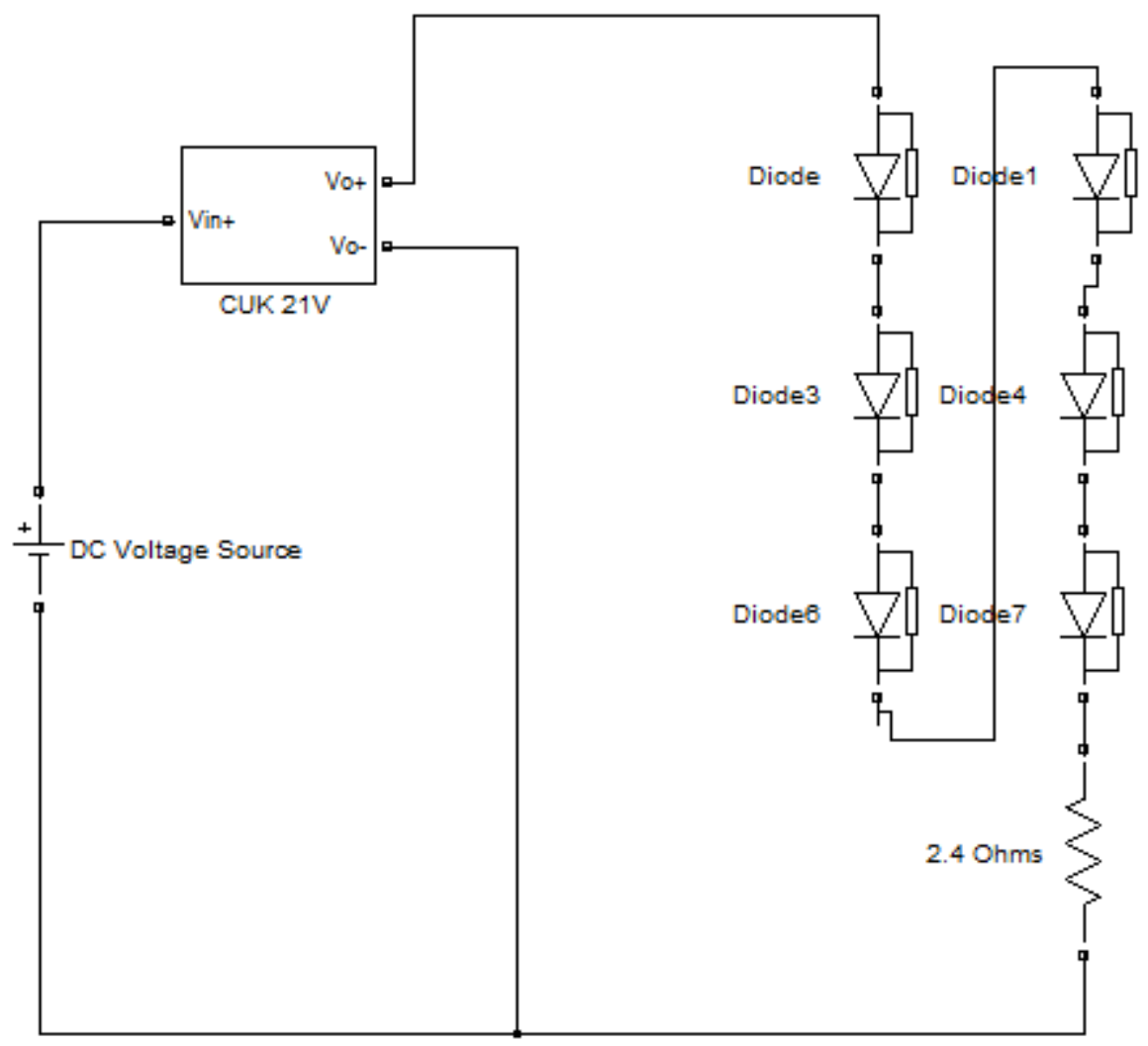

Figure 3-11: Circuit Diagram for Indoor LED Luminaire

Both of these circuits use current limiting resistors that will ensure that the LEDs are driven with a current of $1000 \mathrm{~mA}$. Each LED was modeled based on the datasheet provided by the manufacturer. The I-V characteristics for the LED will fluctuate from $2.85 \mathrm{~V}$ to $3.1 \mathrm{~V}$ depending on the current- using Table 3-3 [11].

Table 3-3: Typical forward voltage of the LED's used in the DC house luminaires[11]

\begin{tabular}{|c|c|c|c|}
\hline Color & $\begin{array}{l}\text { Typical Forward Voltage } \mathrm{V}_{\mathrm{f}}(\mathrm{V}) \\
\text { @ } 350 \mathrm{~mA} \text { Forward Current }\end{array}$ & $\begin{array}{l}\text { Typical Forward Voltage } V_{f}(V) \\
@ 700 \text { mA Forward Current }\end{array}$ & $\begin{array}{l}\text { Typical Forward Voltage } V_{f}(\mathrm{~V}) \\
\text { @ } 1000 \mathrm{~mA} \text { Forward Current }\end{array}$ \\
\hline Neutral-White & 2.85 & 3.00 & 3.10 \\
\hline Cool-White & 2.85 & 3.00 & 3.10 \\
\hline
\end{tabular}


Table 3-3 was used to make the assumption that the forward voltage drop of each LED was 3.1 V. Then KVL was applied to solve for the appropriate resistance that would produce $1000 \mathrm{~mA}$ of current in the circuit.

$$
\begin{gathered}
I_{\text {outdoor }}=\frac{[30 \mathrm{~V}-(9 \times 3.1 \mathrm{~V})]}{\mathrm{R}_{\text {outdoor }}}=1 \mathrm{~A}=1000 \mathrm{~mA} \\
\mathrm{I}_{\text {indoor }}=\frac{[21 \mathrm{~V}-(6 \times 3.1 \mathrm{~V})]}{\mathrm{R}_{\text {indoor }}}=1 \mathrm{~A}=1000 \mathrm{~mA}
\end{gathered}
$$

Rearrange to get resistance for each circuit:

$$
\begin{aligned}
& \mathrm{R}_{\text {outdoor }}=\frac{[30 \mathrm{~V}-(9 \times 3.1 \mathrm{~V})]}{1}=2.10 \mathrm{hms} \\
& \mathrm{R}_{\text {indoor }}=\frac{[21 \mathrm{~V}-(6 \times 3.1 \mathrm{~V})]}{1}=2.4 \mathrm{Ohms}
\end{aligned}
$$

\subsection{Refrigerator Selection}

The DC home should provide a means for food storage that will not overstress the design constraints on the system such as the low output power of the generation system. In order to select a refrigerator that will fit in these constraints, the operation of a refrigerator will be briefly explained.

The refrigerator process uses the fundamental rule of heat transfer - heat goes from "hot" to "cold" - and creates a situation where the food in a refrigerated space is warmer than its surroundings. Therefore heat transfers from the food to the refrigerated space. The process manipulates the heat transfer process by ensuring that the refrigerated space always stays colder than the food stored, so that eventually the food is cooled (or frozen). The heat 
pump consists of two principle components - a compressor and a fan. The compressor is used to increase the pressure of the refrigerant, and the fan is used to blow air over the coils to increase heat transfer. These are the two components that use the most power. A conventional compressor typically has a large startup current because the motor that drives the compressor has an associated inrush current. This is not ideal for the DC house because the high inrush current - though momentary - would be much higher than what the generation source could provide. Luckily, an alternative compressor exists which is characterized by a low startup current. This compressor is called the swing-compressor because it uses a swing motor to drive It's operation. The swing compressor is depicted in Figure 3-12.
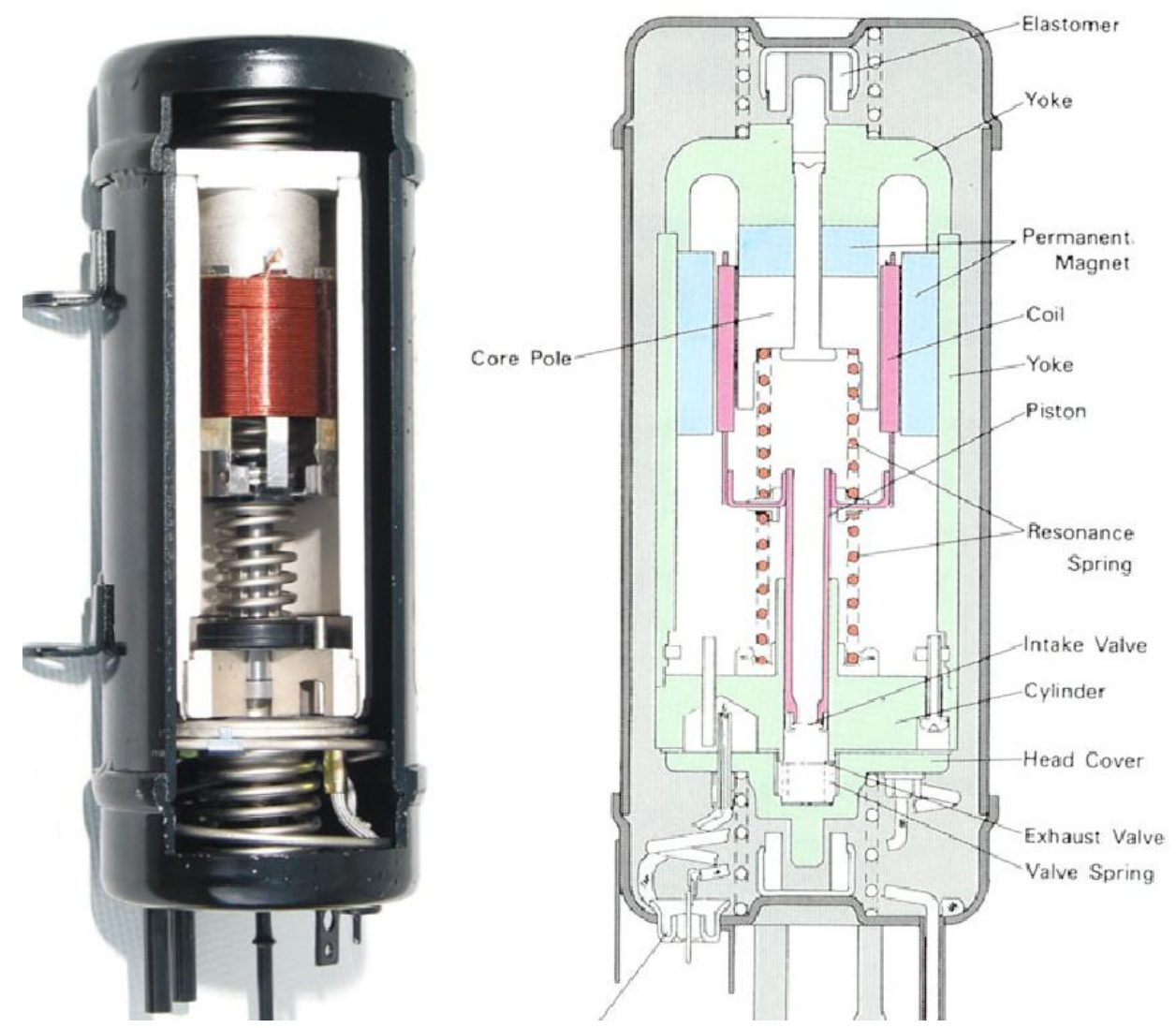

Figure 3-12: Overview of Swing Compressor used in Engel brand Refrigerator [13] 
The swing compressor has low startup current, because when it starts up it can simply move down just a fraction then return. Then it slowly increases the distance the piston travels each stroke until it reaches a full stroke. The Sawafuji swing motor does not need to perform a full stroke on startup, unlike the conventional rotary type compressor that must perform a complete cycle and need much more current on startup [13].

The refrigerator chosen was a Engel MRFD-015 Refrigerator/freezer. This device uses the swing compressor and will therefore negate any large inrush currents. The freezer has a storage capacity of 14 quarts and is controlled via a rotational thermostat. The available temperature settings range from 0 to 45 degrees Fahrenheit, and the corresponding power draw varies from 11 to 47 Watts [13]. This power rating was extremely reasonable, and would fit nicely into the power profile of the DC house.

\subsection{Cooking Device}

The DC house should provide a means to prepare food that does not involve the use of burning biomass. As stated in chapter 1, a principle goal of the dc house is to minimize the proliferation of burning biomass to cook food, therefore a load must be selected that would have a low wattage, but be powerful enough to fully cook common foods.

A typical American home uses an oven, microwave, or stove top to prepare meals. These selections are not ideal for several reasons. The microwave oven has a few problems - the first of which is that it does not actually cook food. Microwave ovens' only serve to heat up food that has been previously cooked so that it is more palatable or appetizing. Additionally, the microwave oven has an extremely high power rating - typically over 1000 Watts. For example, a brief survey of three popular general electric microwave ovens each have a wattage rating of $1000 \mathrm{~W}, 1200 \mathrm{~W}$, and $1100 \mathrm{~W}[14,15,16]$. This is a huge problem 
because the power output of the DC house's generation system is much lower at about 400 Watts. Even though the microwave operates for a short period of time (a few minutes at a time), the power output rate is not feasible with the DC house's power system.

A conventional electric powered oven and electric powered stove top also present problems in their wattage ratings. The typical conventional oven requires $240 \mathrm{~V}$, and will typically draw 3 Amps of current, yielding an unusable wattage rating of 720 Watts. For example the General Electric JKP70SP single convention oven requires 816 Watts of power at rated operation [17]. Stove top cooking presents similar problems, despite some variations in types of heating methods. The PP972SMSS GE electric stove top will use 427 Watts of power per heating surface [18]. The alternative induction stove tops are renowned for their extremely fast water boiling time. The GE PHP960SMSS electric induction stovetop uses 3200 Watts per surface element to achieve this incredibly fast boiling time[19]. It is obvious from these specifications that a stovetop surface is not practical for the DC house.

The best alternative to cook foods at a low wattage proved to be a device that is characterized by its long cook times and relatively small wattage requirements. The crockpot cooking device fulfilled this role perfectly. A crockpot or slow cooker, as shown in figure 313 , is a device that operates at low wattage for extended periods of time (usually 8 hours) to cook food. This power profile fits well with the dc house constraints. The model examined as a candidate was the 12 Volt RoadPro Slow cooker Crock Pot. The device is rated at 78 Watts [20], well within acceptable levels for the DC house project. 


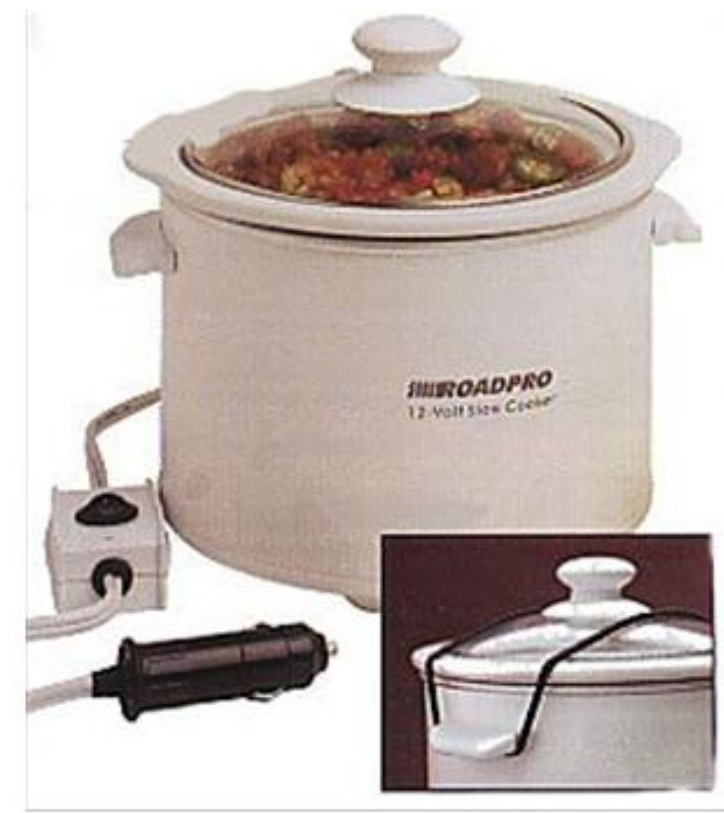

Figure 3-13: Image depicting the Crock Pot to be used in the DC house

\subsection{Laptop}

The DC home should provide the capability to charge a standard home laptop. Laptop's have become a growing necessity for many people, as they provide the means for communication and limtless potential for knowledge via internet. Additionally, they serve as a means to practice fundamental computer skills that are becoming increasingly necessary for success in the modern technological world.

A Laptop operates on DC power and typically require a power supply that contains an AC-DC and DC-DC converter to convert the typical 120VAC to the required 12V DC used by the laptop. Knowing this, it was decided to use a buck converter that could provide a stable $12 \mathrm{~V}$ DC to the laptop so that it will operate ideally with any fluctuation in source 
voltage. The DC-DC converter design for the laptop and for the LED luminaires will be discussed and designed in more detail in the later sections.

A typical portable laptop uses the combination of a power supply and a battery to satisfy its power needs. The battery allows for portability, and the power supply provides reliability. For the purposes of this thesis, only the power supply operation is necessary for incorporation into the DC house. The laptop and battery charger were characterized in the lab to determine the power draw from a laptop under the following conditions. The laptop battery is depleted and plugged into the power supply. The laptop battery is fully charged and plugged into the power supply. All conditions were performed with light computer usage. This means that the wireless network adapter was disabled, and only simple programs such as the Microsoft office suite were used. The results are tabulated in table 3-4:

Table 3-4: Summary of Laptop Power Usage

\begin{tabular}{|c|c|}
\hline Status & Power Draw (Watts) \\
\hline Charged & 31.8 \\
\hline Uncharged & 53.3 \\
\hline
\end{tabular}

As expected, the laptop draws more current when the battery is depleted. These two power conditions will be used to model the power draw of the laptop in simulink as detailed in the next chapter. An additional setting will be included that will model the power draw at the rated 60Watts for a worst case scenario analysis.

\subsection{Non-Essential Loads:}

Table 3-5 summarizes the total wattage used by the "essential" loads described in the previous sections. 
Table 3-5: Summary of Power used by Essential Loads

\begin{tabular}{l|r|} 
Load & Max Wattage (W) \\
\hline Crockpot & 78 \\
\hline Indoor Luminaire & 21 \\
\hline Outdoor Luminaire & 30 \\
\hline Refrigerator & 47 \\
\hline Laptop & 60 \\
\hline & \\
\hline Total: & 236 \\
\hline
\end{tabular}

Given the budget of 400 Watts and the total power used by the essential loads, there is still room for a few non-essential loads in the DC house.

The first non-essential load selected was a floor mounted fan for use in periods of hot temperature. The fan serves as a basic level of comfort for occupants during warmer months. The fan selected to fulfill this role was the DC powered Freedom Fan model 302 from Soldon Sun, as seen in Figure 3-14. This is a 20" fan that sits on the floor and operates from 15 to 48 Watts depending on speed setting. This device will easily fit within the wattage limitations of the DC house and is therefore an obvious selection for inclusion. The model can be operated at 12 or 24 volts DC which is also in line with the DC house's power specifications [21]. 


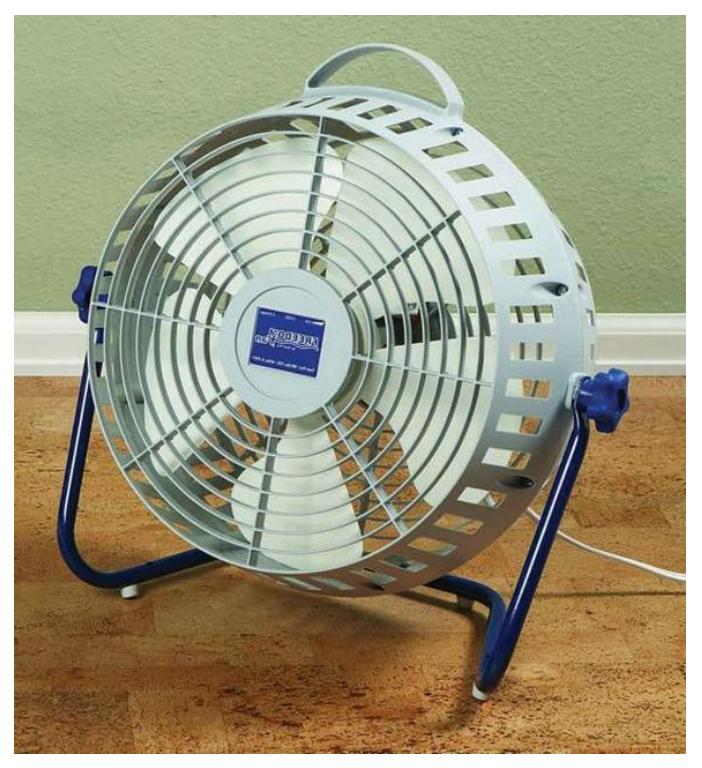

Figure 3-14: Image of Floor Fan to be used in the DC house

The next non-essential load chosen was a small Television set. This device will serve as a means for some entertainment for the occupants of the dc house. The model chosen was the Naxa NX563 LCD HDTV. This device is rated for a maximum power consumption of 60 Watts, but typically operates at 36 Watts [22]. It has an AC input as well as 12VDC input which is what will be used in the DC house. The surprisingly low wattage rating of the device makes it the perfect device to add that will round out the total load selections for the DC house. The LCD TV exact operation and simulation model will be discussed in the next chapter. The result of adding these additional non-essential loads yields the following total maximum wattage as summarized in Table 3.6. 
Table 3-6: Summary of Power used by All Loads

\begin{tabular}{l|c|}
\multicolumn{1}{c|}{ Load } & Max Wattage (W) \\
\hline Crockpot & 78 \\
\hline Indoor Luminaire & 21 \\
\hline Outdoot Luminaire & 30 \\
\hline Refrigerator & 47 \\
\hline Laptop & 60 \\
\hline TV & 36 \\
\hline fan & 45 \\
\hline \multicolumn{2}{|c|}{ Total: } \\
\hline \multicolumn{2}{r|}{} \\
\hline
\end{tabular}




\section{Chapter 4: Simulink Model Creation}

The simulink toolbox of the MATLAB software is an extremely powerful tool that can be used to model anything from complex thermodynamic reactions to electric circuit simulation. It operates on the fundamental principles behind any known process. In the case of electrical circuits, it relies on the mathematical equations that model each component such as resistor, transformer, inductor and capacitor to create a simple user interface that can model complex circuits. Simulink can also model logic operations using more abstract diagramming, which makes it easier to model controls for electrical devices. Normally these electrical controls are modeled abstractly and then translated into electronic circuits that carry out these logic functions. Simulink removes this tediousness, as well as provides versatility to model devices other than electric circuits. This powerful combination makes it the perfect program to use for a simulation of the DC House's power distribution system.

\subsection{Basic Overview}

To begin the simulink model of the DC house, it was best to start from the basics and build up. The most logical starting point is therefore the basic overview of the DC house - Power source, feeder box, and Loads.

The DC house is powered from a single, ideal voltage source, through a long resistive wire. This resistive wire was chosen to be 4 AWG wire based on NEC current rating limitations. The wire goes into a feeder box where it is split to each load. The feeder box feeds each of the 7 loads through separate resistive wires. These wires are of the size 10 
AWG again due to NEC current regulations. This basic overview provides the foundation for the operation of the DC house simulation.

In order to institute a degree of controllability, the feeder box was altered to be a masked sub-system. Creating a subsystem in simulink is the process of abstracting a complex circuit or diagram into a simple box with inputs and outputs. Masking a subsystem allows for the user to quickly change key variables - such as whether or not a switch is open or closed - without having to open up the subsystem. In the case of the feeder box, what this does is create the ability for the user to change which load is activated via a prompt that comes up upon a double click on the subsystem. This example is shown in Figure 4-1.

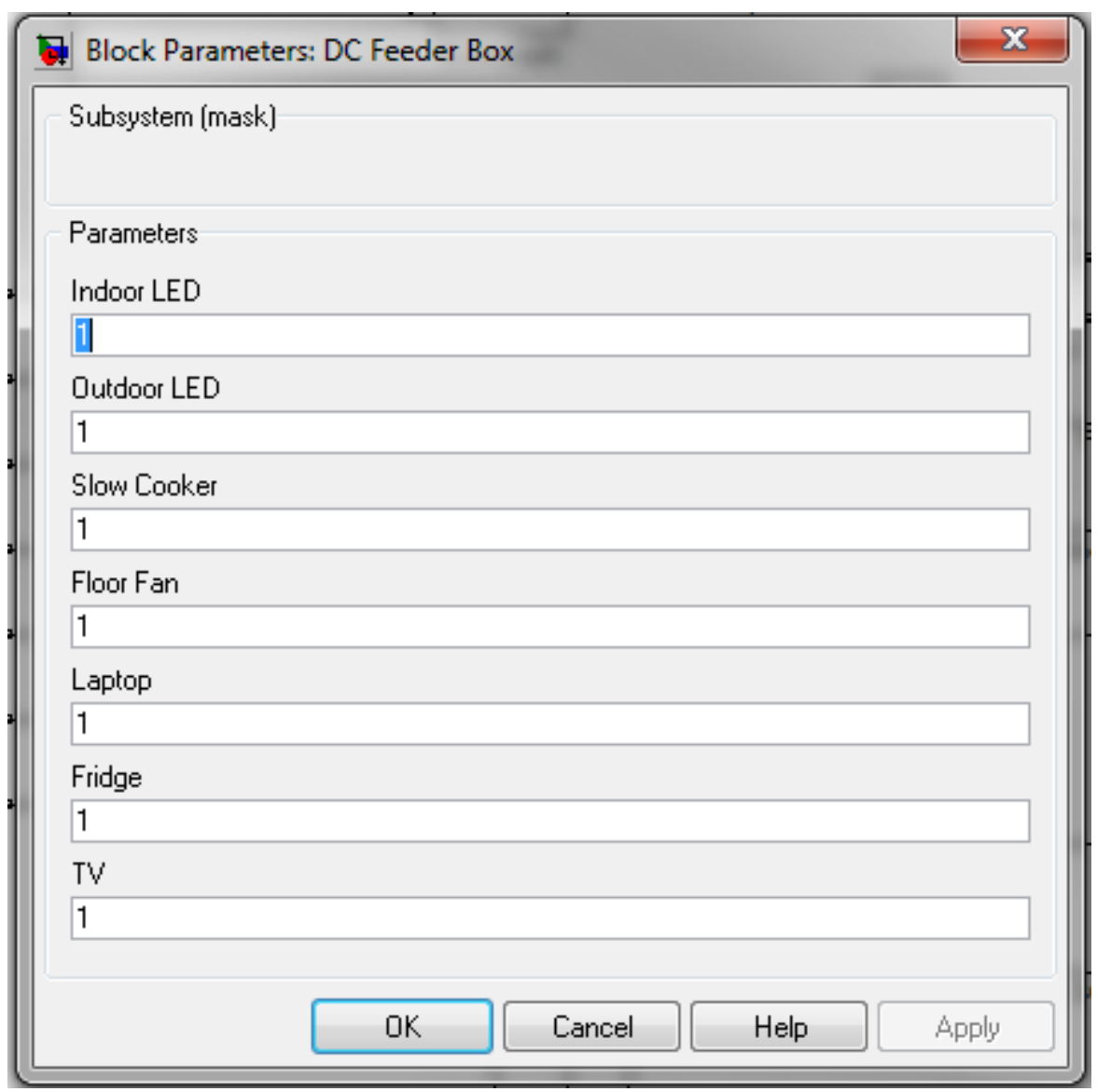

Figure 4-1: Screen capture of a masked Subsystem's input array. 1 indicates the Switch to that corresponding load is closed 
Focusing back on the basic layout, the resistivity of each wire is dependent on the length of the wire. Therefore all of the resistors from the feeder box to the loads and from the source to the feeder box, were put into a subsystem that prompts the user for a length of wire in feet, and will automatically calculate the resistance of each wire. A subsystem was also created for each individual load and DC-DC converter. This way the block diagram clutter is kept to an absolute minimum. The resulting basic simulink block diagram is captured in figure 4-2:

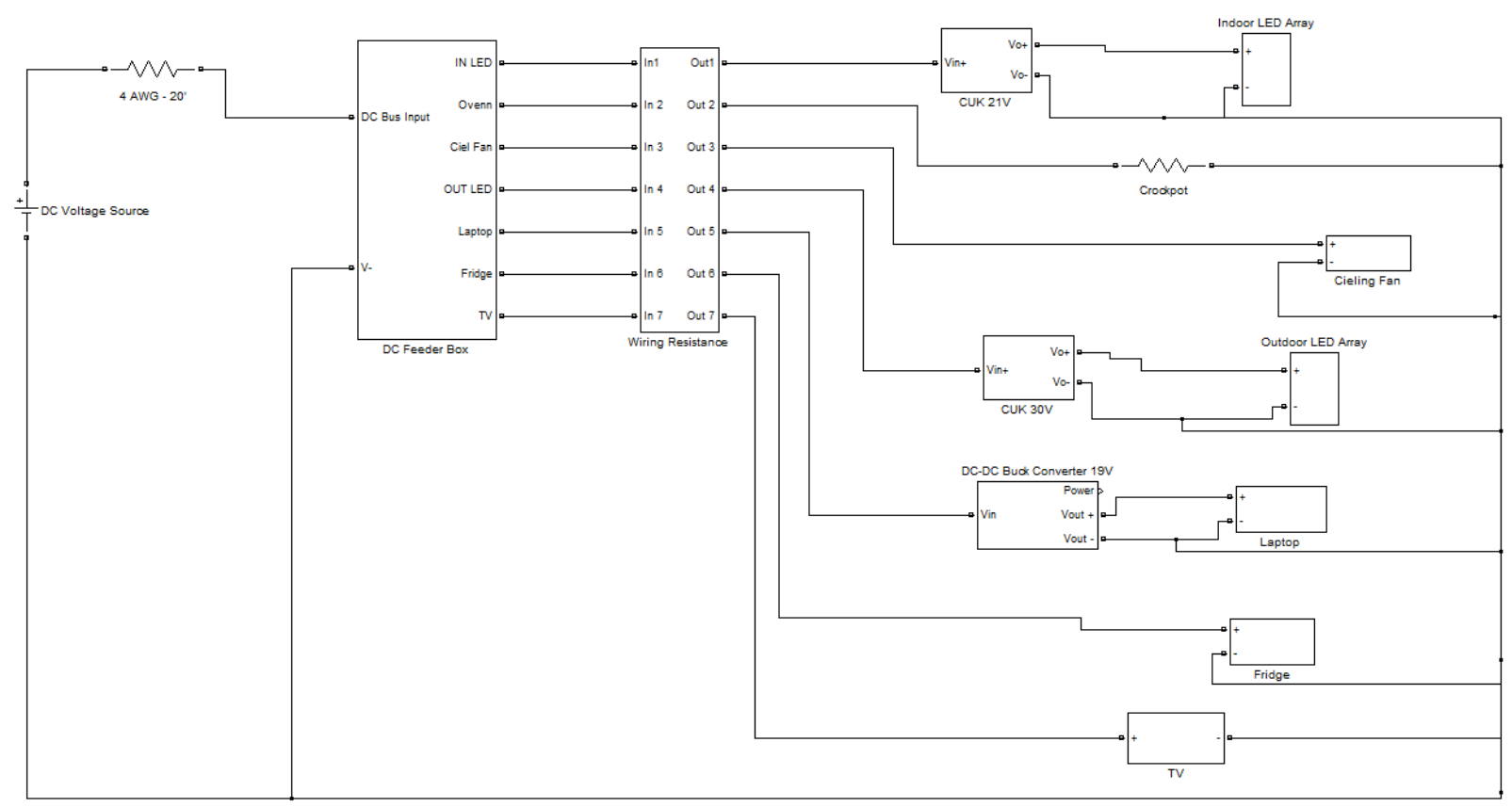

Figure 4-2: Screencapture of Basic Simulink Block Diagram

From here the objective will be to flesh out each of subsystems using electrical engineering knowledge, as well as to integrate the capability for the simulink block diagram to quickly output the efficiency of the system for a given source voltage. 


\subsubsection{Modeling the Wire}

The wire was modeled as a simple resistance clumped together for each circuit. The lengths for each specified wire were doubled to account for the return path. The individual circuit wire resistances were grouped into a subsystem so that the wire size could be changed on the fly, and simulink could automatically calculate the resistance for each wire. This subsystem was masked and configured to prompt the user to enter a wire size resistivity in Ohms per foot. It then calculates the resistance, this subsystem is shown in Figure 4-2, as the large block titled "Wiring Resistance".

\subsection{LED Luminaires}

The LED luminaires consist of strings of LEDs in series with a current limiting resistor. Electrically, an LED behaves almost exactly the same as a diode. That is - they have a constant voltage drop when forward biased, and have very little resistance when conducting. Simulink allows for the customization of diode properties such as forward voltage drop. The diodes were calibrated to match the rated forward voltage drop of the LED datasheet under typical rated conditions of 3.1 Volts [11]. Therefore the indoor and outdoor luminaires appear as the following in figure 4-3. 


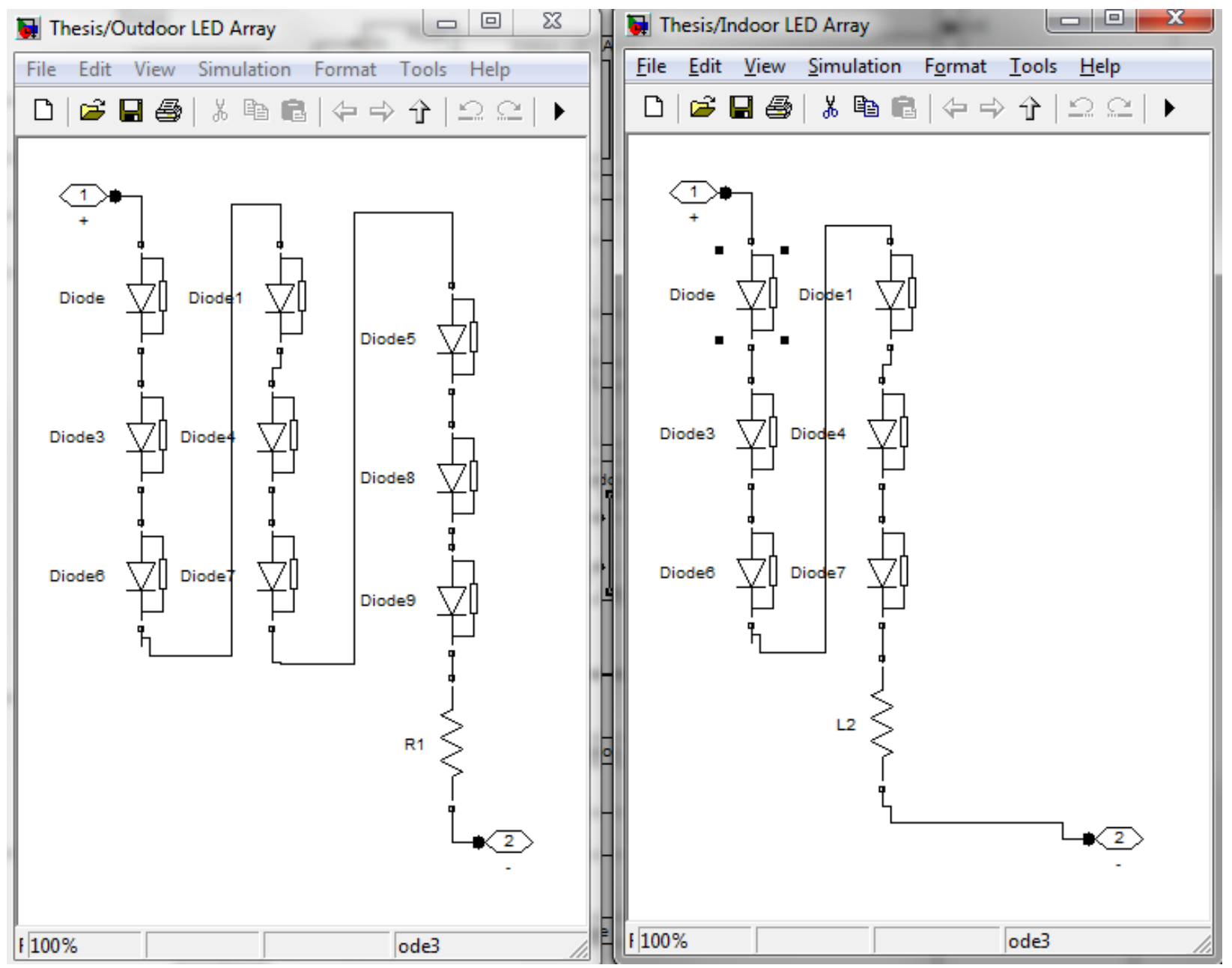

Figure 4-3: Simulink Models for Indoor and Outdoor LED Arrays

\subsubsection{DC-DC Converters to Drive the LED Luminaires}

Because each LED luminaire will require its own DC voltage level for desired operation, it was necessary to design and simulate DC-DC converters that could provide that functionality. There are several kinds of DC-DC converter topologies available to choose from. In order to select which topology was to be used in this application, it was necessary to understand how the input voltage would behave. 
The source voltage will vary from 12 to 48 Volts in order to determine the optimal voltage level. Therefore the DC-DC drivers for these luminaires will need to provide output voltages that are both above and below the input voltage. This means that the DC-DC converter will have to behave like a boost and a buck converter - have the capability to increase or decrease a dc input voltage depending on the situation. Additionally, it is important that the LEDs be driven at constant current because any current variations will result in poor or non-ideal luminous output. Now that the requirements for the LED driving DC-DC converters were established, the appropriate converter topology and specifications could be selected.

DC-DC converters fall in the field known as power electronics. The four basic DCDC converter topologies are the Buck, Boost, Buck-Boost, and Cuk converters. DC-DC Converters use the combination of two switching elements(either two switches or 1 switch and 1 diode) and an inductor to increase or decrease an input voltage to a specified output voltage. The switching elements are typically operated at a high frequency on the order of 100's of kilohertz. What dictates the output voltage however, is not the switching frequency, but rather the duty cycle of the control signal for each switching element. A brief summary of their operation is contained below in table 4-1: 
Table 4-1: Summary of Common Converter Topology Characteristics

\begin{tabular}{|c|c|c|c|}
\hline DC-DC Topology & Output Voltage & $\begin{array}{c}\text { Input Current } \\
\text { Characteristic }\end{array}$ & $\begin{array}{c}\text { Output Current } \\
\text { Characteristic }\end{array}$ \\
\hline Buck & $V_{\text {out }}=V_{\text {in }} D$ & Bad & Good \\
\hline Boost & $V_{\text {out }}=\frac{V_{\text {in }}}{1-D}$ & Good & Bad \\
\hline Buck-Boost & $V_{\text {out }}=-V_{\text {in }}\left(\frac{D}{1-D}\right)$ & Bad & Bad \\
\hline CUK & $V_{\text {out }}=-V_{\text {in }}\left(\frac{D}{1-D}\right)$ & Good & Good \\
\hline
\end{tabular}

The symbol 'D' stands for duty cycle which can vary from 0 to 1 . Using this fact, the capabilities of each topology can be easily deciphered. To briefly elaborate on what "good" or "bad" indicates for the input and output characteristic current. Good indicates that the current is continuous, and bad indicates that current is discontinuous. Figure 4-4 below depicts the input current of a Buck converter which is "Bad". 


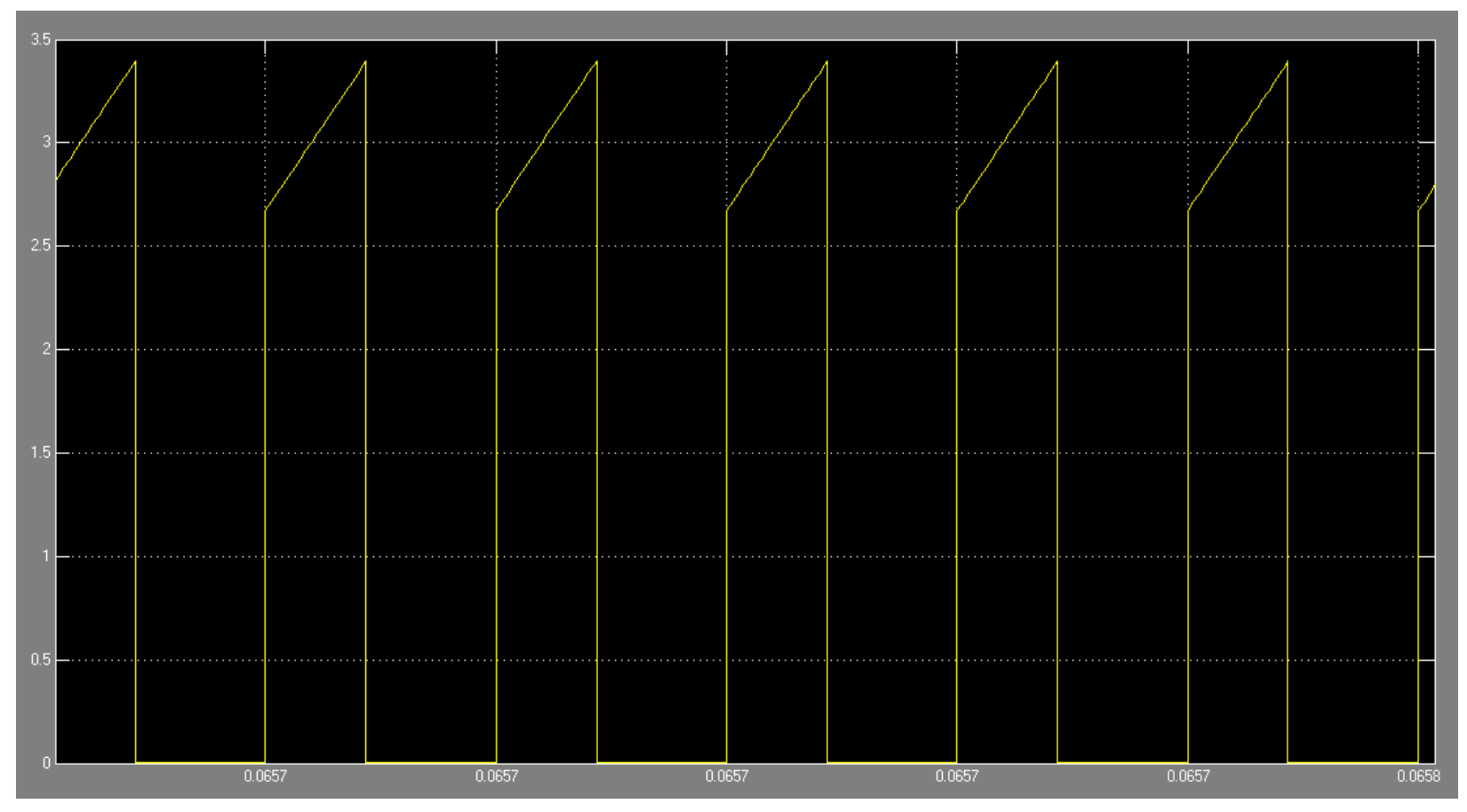

4-4: Input Current for the Buck Converter in CCM Used Later in the TV Load. Vertical Axis is in Amps, and Horizontal axis is in Seconds

As can be seen, the input current is not always conducting. This is the result of how the topology of the circuit is arranged. In general, if the inductor of the circuit feeds to the output, then the output current will be "good". Using the previous information, the final choice came down to a buck-boost or CUK converter. The CUK converter was selected because it can provide a good continous current output. The topology for the CUK Converter is shown in figure 4-5: 


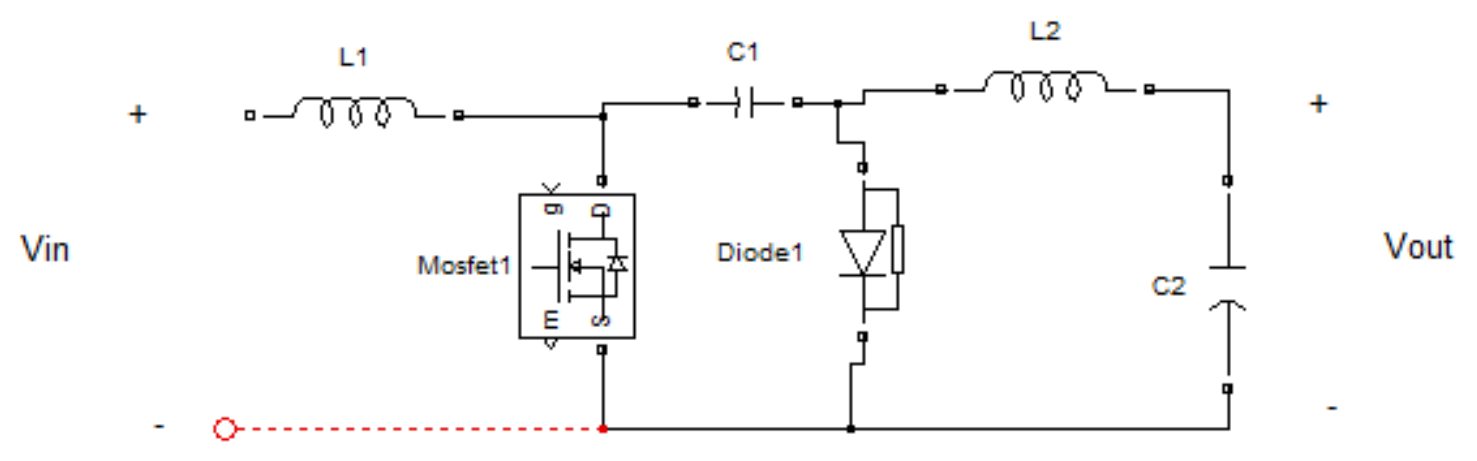

Figure 4-5: Simulink schematic for CUK converter, output is across C2

The CUK converter's two switching elements are the mosfet and the diode, which operate at the same frequiency but are timed asynchronously. In order to model the CUK converter correctly in simulink, the components had to be sized correctly.

The design for the $30 \mathrm{~V}$ CUK converter was completed first. The $30 \mathrm{~V}$ converter must supply 1A of current with little ripple. There will be no dimming controls, so the load size (and therefore current drawn) won't vary drastically. Some simple circuit analysis combined with the fundamental operational characteriscs for an inductor can be used to derive the effect of the inductor size on the current ripple during constant conduction mode.

$$
\mathrm{L}_{2}=\mathrm{V}_{\mathrm{i}}\left[\frac{\mathrm{D}}{\left(\Delta_{\mathrm{IL}} \times \mathrm{f}\right)}\right]
$$

That is, for a given duty cycle, frequency, and input voltage one can determine how much current ripple exists for a given inductor size. For both designs, the inductor size was chosen to be $200 \mathrm{uH}$. Using a switching frequiency of $25 \mathrm{kHz}$ and a duty cycle of $75 \%$ (as a worst case scenario), the inductor size will yield a current ripple of $0.1 \mathrm{~A}$. This small ripple is a worst case scenario, and will be easily stable enough for normal operation of the LED luminaires. Both CUK converters will use the same components for the basic topology, 
however the difference that will separate the two operationally, will be in the controls for the mosfet.

In order to control the output voltage of a DC-DC converter, there must be a feedback system that can change the duty cycle dynamically to maintain a steady voltage on the output at the desired level. One method to achieve this feedback is to monitor the output voltage, and compare it with a desired voltage level. This comparison will produce an error signal that will change in magnitude and in sign depending on the error between output and desired output voltages. This error signal is then compared with a sawtooth waveform which is generated at the desired switching frequency. This comparison will create a pulse width modulated (PWM) square wave that will be sent into the switching device of the CUK converter. This is a common control scheme and will need to be slightly modified in order to properly control a CUK converter. This modification was a means to limit the error signal to values that will not produce a PWM squarewave with very large duty cycles. This is critical because of how the duty cycle affects output voltage - as seen below:

$$
\mathrm{V}_{\mathrm{o}}=-\mathrm{V}_{\mathrm{i}}\left[\frac{\mathrm{D}}{(1-\mathrm{D})}\right]
$$

Notice that as Duty Cycle approaches 100\%, the output voltage approaches infinity. This is a situation that would be extremely bad for the safety of our circuit, as the output voltage would be extremely high. Additionally, limiting the error signal from being too small or too large will help reduce any volatility associated with the adjustment of the output voltage. That is, the control system wont over-react to sudden changes in input or output voltages. Limiting the Duty cycle to be unable to reach a value of one is also bad, because as the equation for output voltage above indicates, the output voltage would try to climb to infinity. Figure 4-6 is a screen capture of this control system modeled in simulink. 


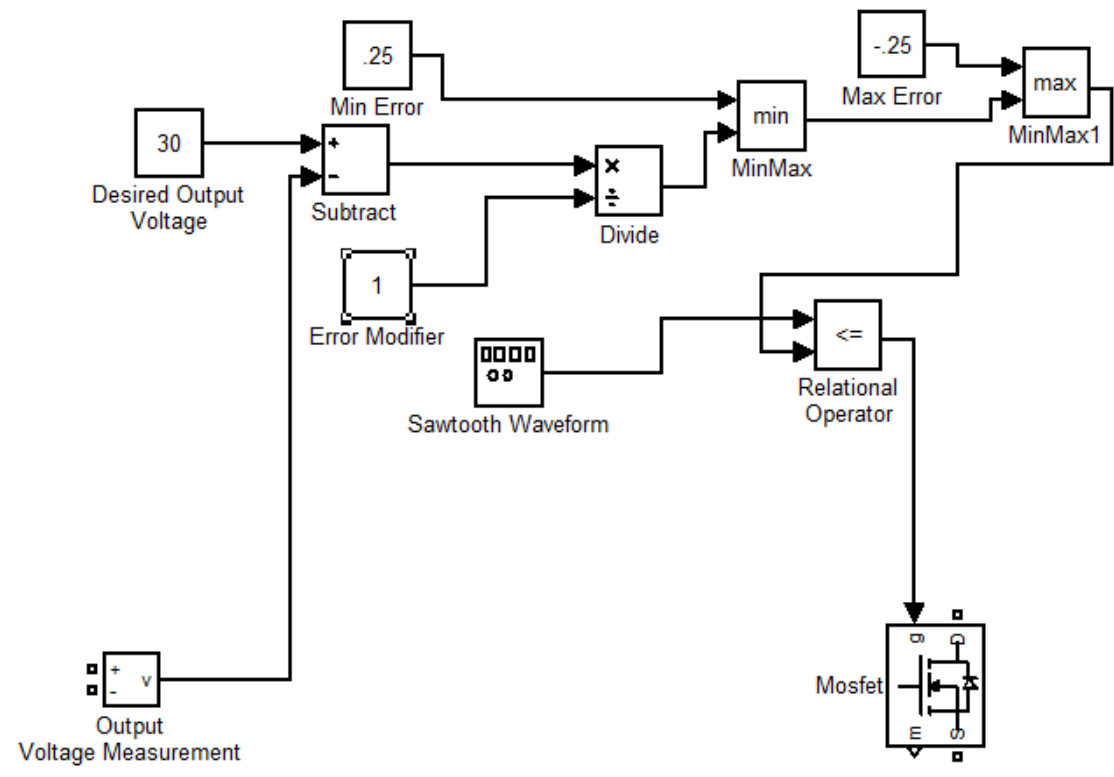

Figure 4-6: Simulink Schematic for Control System for the CUK converter (PWM Squarewave Generator)

This control circuit will create the following waveforms when used in conjunction with the CUK converter. A picture of the error signal, sawtooth waveform, and resulting PWM waveform to drive the switch can be observed in Figure 4-7. Notice that the duty cycle of the square wave is a direct result of the error signal value, That is, the PWM waveform syncs up perfectly with the intersections of the Error signal and the sawtooth waveforms. 


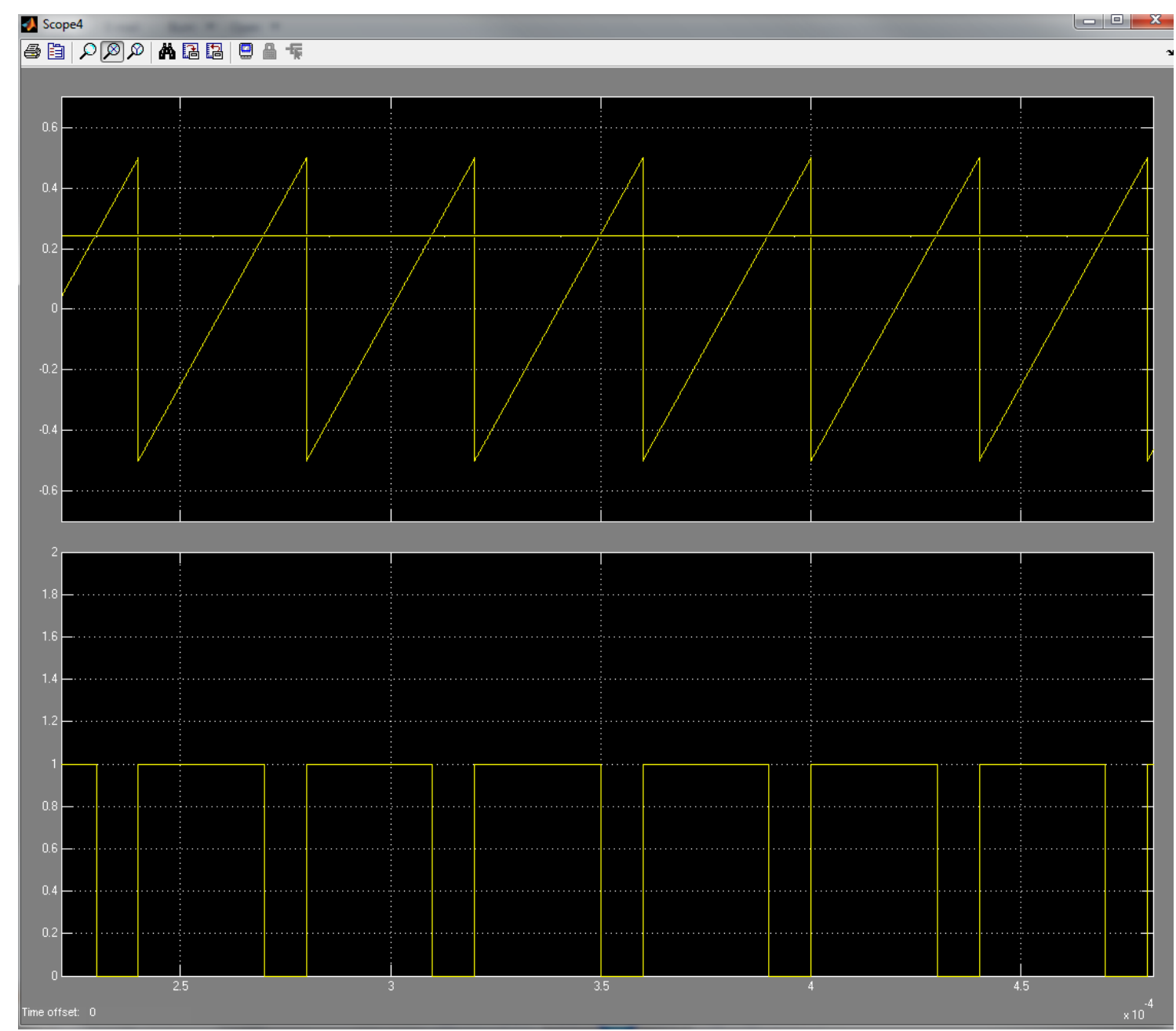

Figure 4-7: (Top) Sawtooth Waveform compared with Flat Error Signal, (Bottom) Resulting PWM Square Wave Produced from the Comparison of the top Waveforms.

This streamlined control circuit allows for easy modifications to achieve simple changes. For example, in order to produce a different output voltage, simply change the reference value to the desired output voltage, and the controls will automatically steer the DC-DC converter to that value. Additionally, other tweaks can be made to how quickly the control system reacts for example by tweaking the error modifier value you can have a slower and smoother reaction. Also, the error signal can be limited to certain values to help limit over-reactions and undesired voltage conditions. 
The complete circuit combination of CUK converter and Feedback controls were assembled in simulink as shown in Figure 4-8:

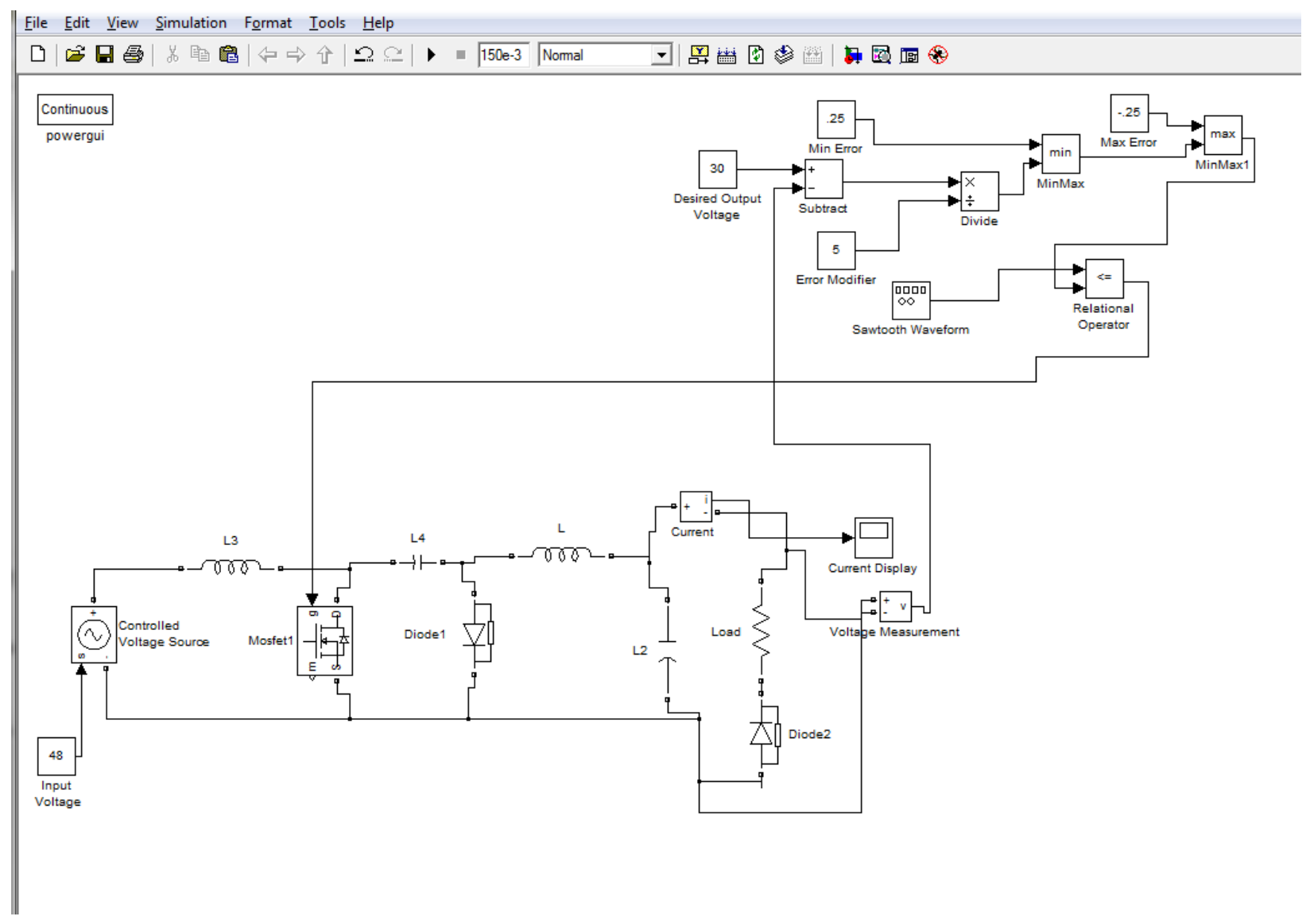

Figure 4-8: Complete CUK Converter Circuit Including Controls and Load

This Configuration is intended for the $30 \mathrm{~V}$ output. The only difference between this CUK converter and the $21 \mathrm{~V}$ CUK converter will be that the "Desired Output Voltage" constant will be set to 21. This modified schematic is shown in Figure 4-9. Some quick characterizations were made of the 30 Volt CUK converter, including its response to a 12 Volt input voltage, shown in Figure 4-10. 


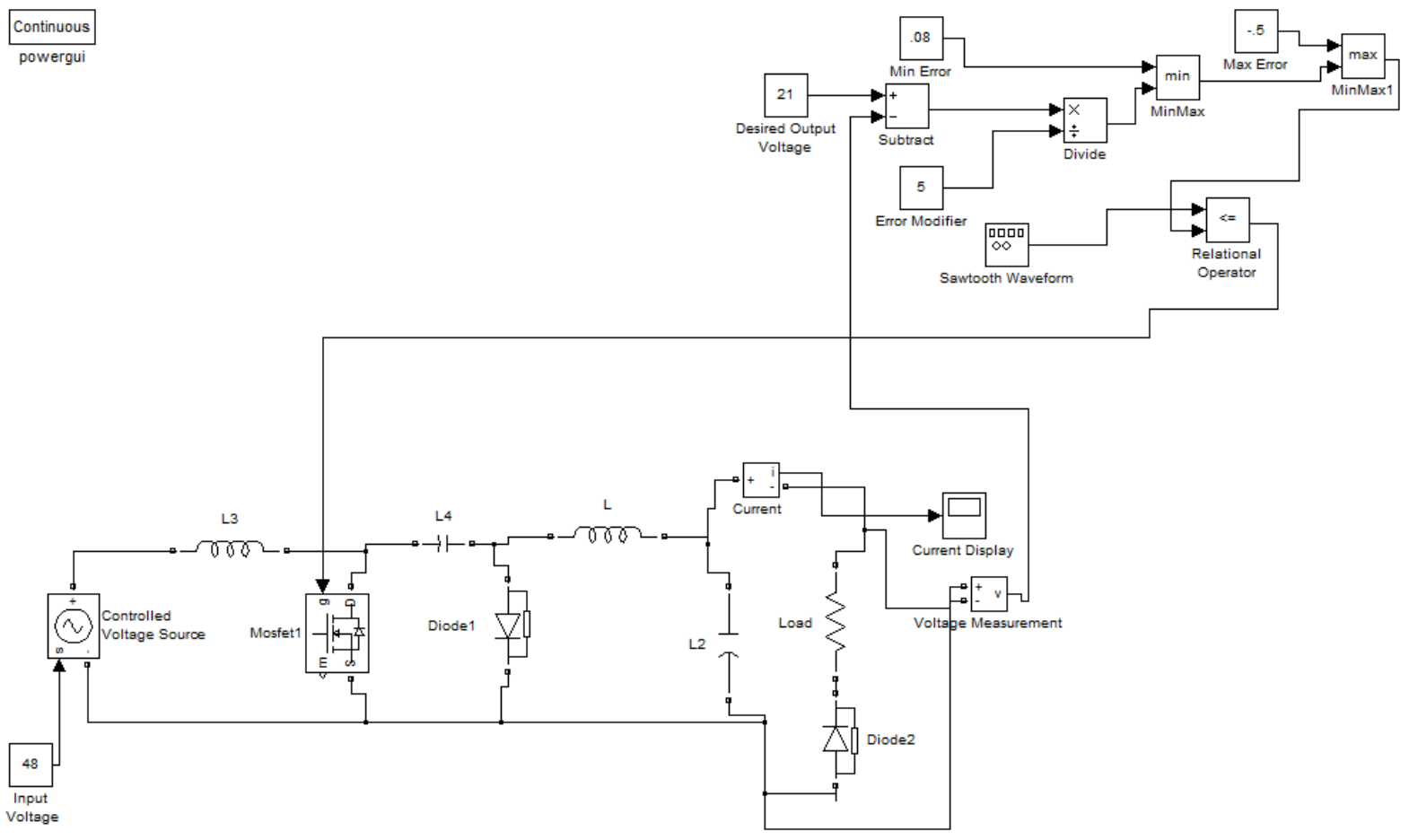

Figure 4-0-9: Simulink schematic model for the 21V CUK converter to drive the indoor LED Luminaire

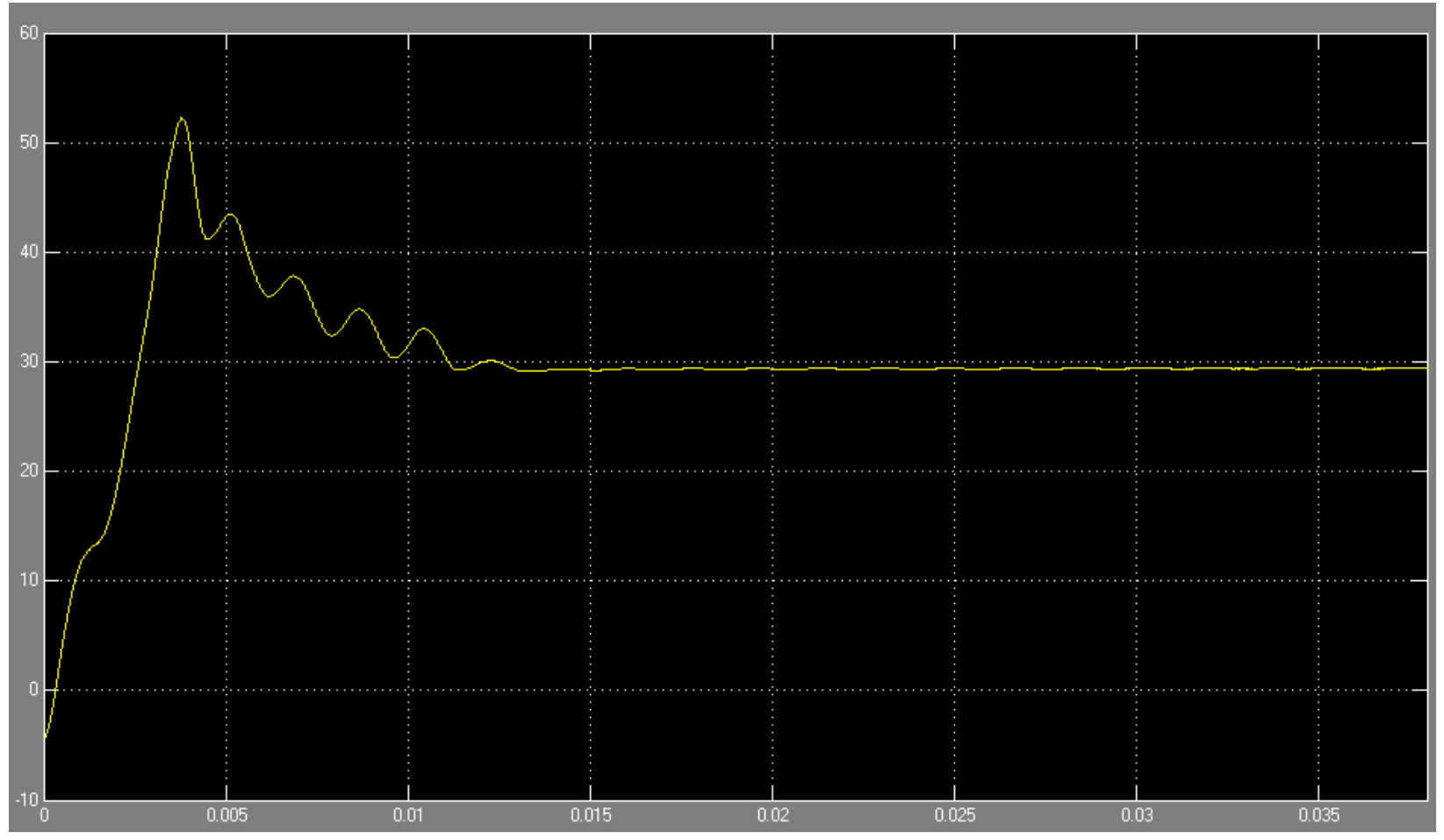

Figure 4-10: 30 Volt CUK Output Voltage as a function of time in seconds With a 12V Input Voltage at Full Load (1A) 
The 30 Volt CUK converter takes approximately 15 milliseconds to reach steady state output voltage. Enhancing and zooming in on the steady state voltage, it can be seen that the output voltage is approximately 29.4 Volts with less than a $0.1 \mathrm{~V}$ ripple As shown in Figure 4-11.

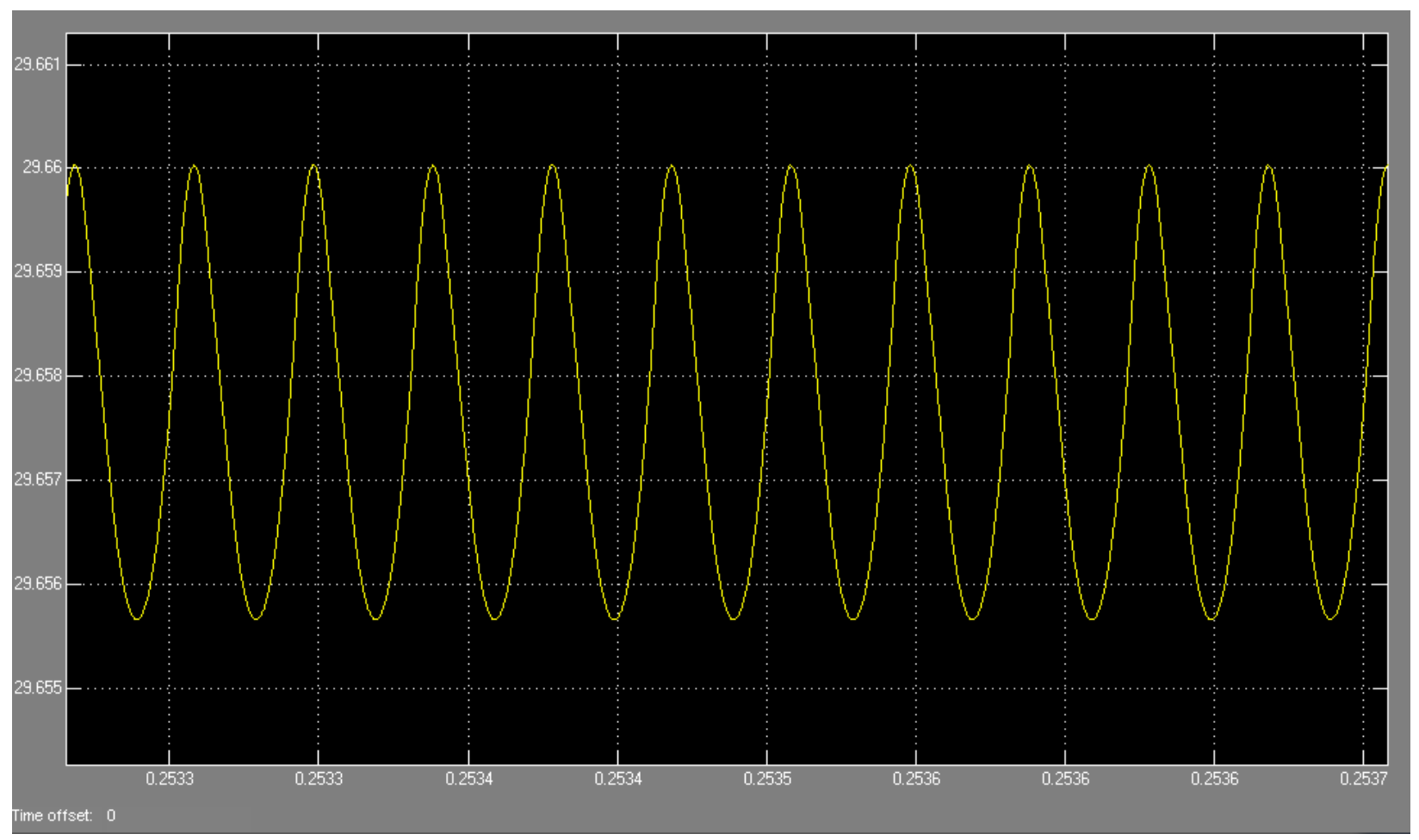

Figure 4-11: Zoomed in View of steady state output voltage for a setting of 30 Volts at full load

The circuit was re-simulated under many other conditions including: 48V input voltage, full load, and low-load. The process was then repeated for the $21 \mathrm{~V}$ output setting, as this is what will be used for the indoor luminaire. These results were tabulated in Table 42, and used to calculate load and line regulations of the device. Load regulation is a metric that indicates how much the output voltage changes for a given change in load size (also known as a change in output current at nominal input voltage). Ideally this number should be very small, so that we can count on the DC-DC converter to output a consistent voltage 
regardless of power output. The equation to calculate load regulation is shown by equation 4-3.

$$
\text { Load Regulation } \%=\left[\frac{\mathrm{V}_{\text {full load }}-\mathrm{V}_{\text {low load }}}{\mathrm{V}_{\text {full load }}}\right] \times 100 \%
$$

Line Regulation is a metric to determine how much a change in input voltage will affect the output voltage at full load. Again, this number should be small, so that a reliable DC-DC converter will output a consistent voltage regardless of input voltage. The equation for line regulation is shown by equation 4-4.

$$
\text { Line Regulation } \%=\left[\frac{\mathrm{V}_{\text {max input }}-\mathrm{V}_{\min \text { input }}}{\mathrm{V}_{\max \text { input }}}\right] \times 100 \%
$$

Finally, the response time is the time it takes for the DC-DC converter to reach steady state output voltage.

\begin{tabular}{|c|c|c|c|c|}
\hline \multicolumn{2}{|c|}{ 30V CUK Converter } & \multirow[b]{2}{*}{$\begin{array}{l}\text { Output Voltage } \\
\text { (Volts) }\end{array}$} & \multirow[b]{2}{*}{$\begin{array}{l}\text { Output Voltage Ripple } \\
\text { Peak to Peak (Volts) }\end{array}$} & \multirow[b]{2}{*}{$\begin{array}{c}\text { Response Time } \\
\text { (ms) }\end{array}$} \\
\hline Input Voltage & Load & & & \\
\hline 48 & Full & 30.75 & 0.06 & 20 \\
\hline 48 & Low & 30.67 & 0.15 & 30 \\
\hline 12 & Full & 29.37 & 0.005 & 15 \\
\hline \multirow[t]{3}{*}{12} & Low & 29.7 & 0.08 & 50 \\
\hline & & & Load Regulation: & $0.26 \%$ \\
\hline & & & Line Regulation: & $4.49 \%$ \\
\hline
\end{tabular}

Table 4-2: Characteristics of the 30V CUK converter in Simulink 
Table 4-3: Summary of Characteristics for the 21V Cuk Converter modeled in Simulink

\begin{tabular}{|c|c|c|c|c|}
\hline \multicolumn{2}{|c|}{$21 \mathrm{~V}$ CUK Converter } & \multirow[b]{2}{*}{$\begin{array}{c}\text { Output Voltage } \\
\text { (Volts) }\end{array}$} & \multirow[b]{2}{*}{$\begin{array}{l}\text { Output Voltage Ripple } \\
\text { Peak to Peak (Volts) }\end{array}$} & \multirow[b]{2}{*}{$\begin{array}{c}\text { Response Time } \\
\text { (ms) }\end{array}$} \\
\hline Input Voltage & Load & & & \\
\hline 48 & Full & 22.1 & 0.3 & 10 \\
\hline 48 & Low & 22.05 & 0.3 & 15 \\
\hline 12 & Full & 19.75 & 0.02 & 30 \\
\hline \multirow[t]{3}{*}{12} & Low & 20.7 & 0.02 & 15 \\
\hline & & & Load Regulation: & $0.23 \%$ \\
\hline & & & Line Regulation: & $6.12 \%$ \\
\hline
\end{tabular}

These results were spectacular, that is, they show the DC-DC converters are outputting the correct voltage levels, with minimal ripple, quick response times, and minimal load and line regulations.

In order to preserve the proper efficiency of the DC-DC converters, all switches, diodes, and inductors were assigned small resistive values consistent with real world components and the diodes were assigned appropriate forward voltage drops. This would ensure that any losses would be reflected in the efficiencies of the converters. These values were referenced using selected component datasheets [24][25][26][27].

\subsection{Laptop}

The typical laptop comes with an external power supply that converts 120VAC to approximately 19.5 VDC. Therefore, the model will need to incorporate the use of a DCDC converter that can provide a consistent 19.5 VDC output. Once this has been completed, the power consumption of a laptop must be explored so that it can be adequately replicated. A laptop will have several distinct modes of power consumption. They are: 
1. Laptop Battery has been depleted, and is plugged into the power supply.

2. Laptop Battery is fully charged and is plugged into power supply.

Therefore, in order to properly understand these conditions, a Dell laptop that used a TD230 power supply was chosen (out of convenience) and tested in lab under each condition and the power draw was measured. The results of this short experiment were summarized in the previous section. Additionally, a worst case scenario load of the rated 60 Watts was prepared for the third condition. In order to model these three different power consumption rates, a subsystem was created for the laptop. The subsystem was masked so that the user would be prompted to select which of the three load settings would be used. This subsystem consisted of switched resistive loads that could be dynamically controlled (based on user input/definition) to absorb power at the 3 different circumstances for power explored earlier. A screen capture of this subsystem and its corresponding input prompt can be found in Figures 4-12 and 4-13 respectively: 


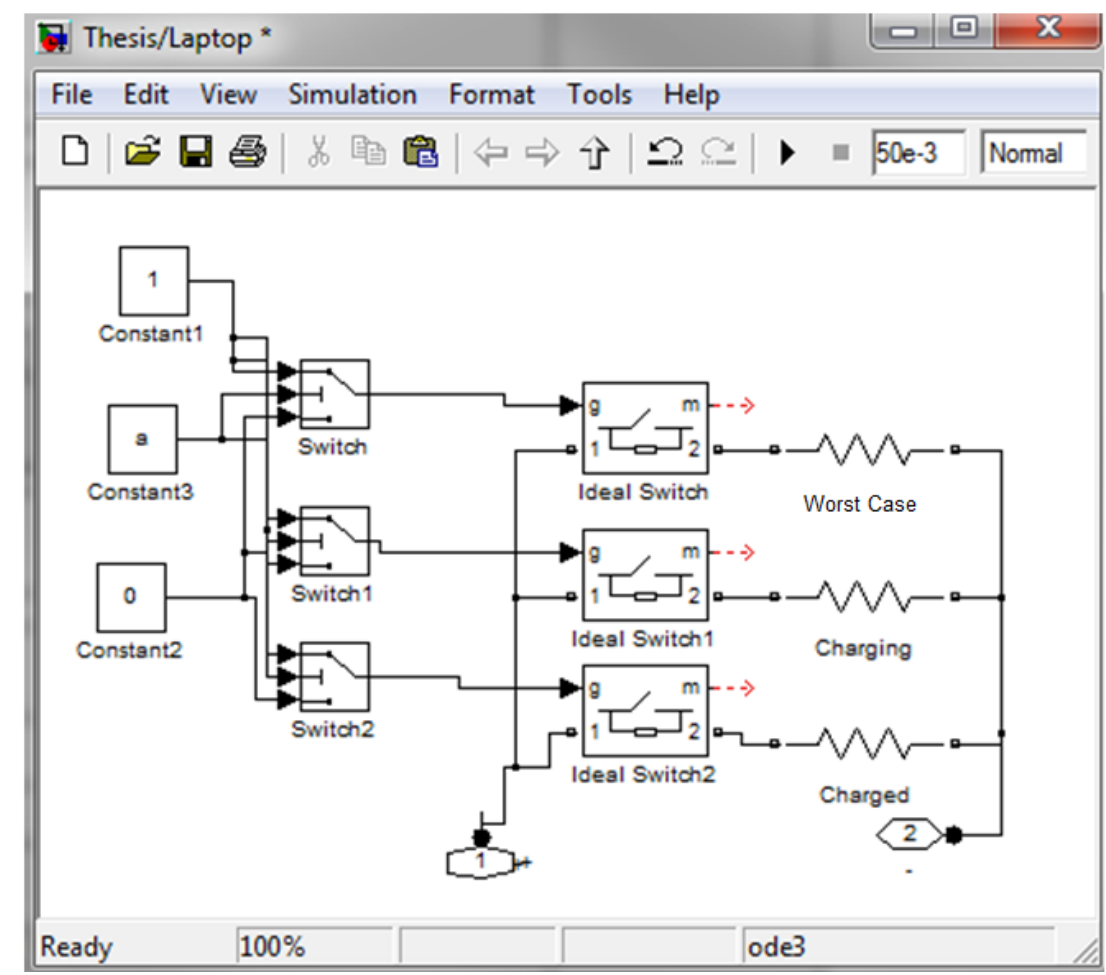

Figure 4-12: Subsystem to model the Power Consumption for the Laptop in Simulink

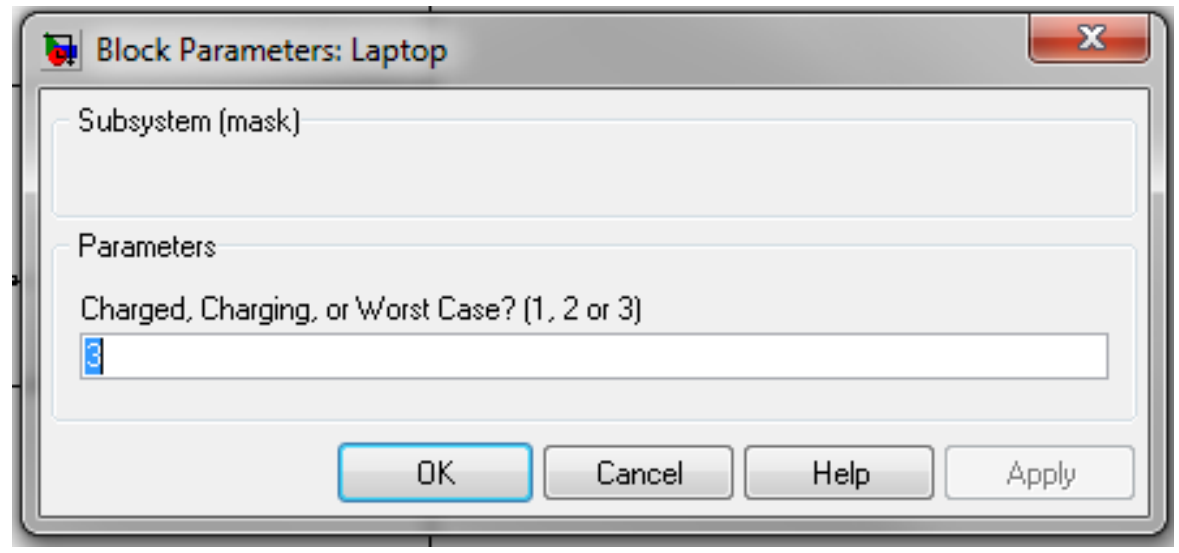

Figure 4-13: User Prompt for Determining the Steady State Power Usage of the Laptop

Now that the expected power consumption for the laptop has been determined, the DC-DC converter must be designed to fulfill the role of providing a reliable 19.5 Volts.

Luckily, the CUK converter design used for the LED luminaires is modifiable and could be easily tweaked to supply 19.5VDC. A slight change to the feedback circuit was all that was 
needed to make it a useful device for this application. The modified circuit is shown in Figure 4-14.

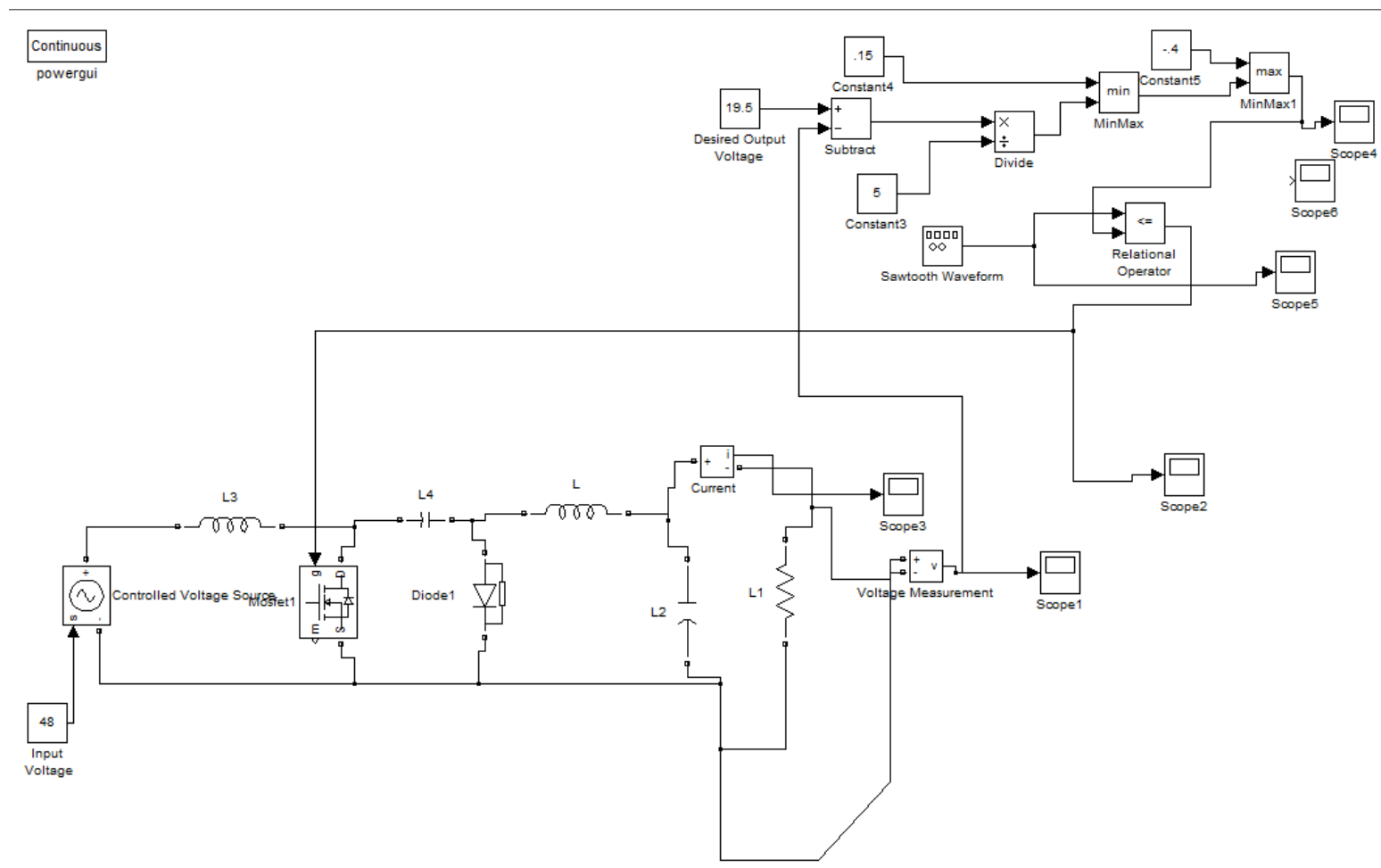

Figure 4-14: Simulink Schematic for modified 19.5V CUK Converter to be used for the Laptop The DC-DC converter functioned appropriately despite a large increase in load current. At worst, the converter would have to supply 60 Watts of power, or approximately 3Amps of current. The circuit was tested under this full load condition and the resulting output voltage response was captured in Figure 4-15. 


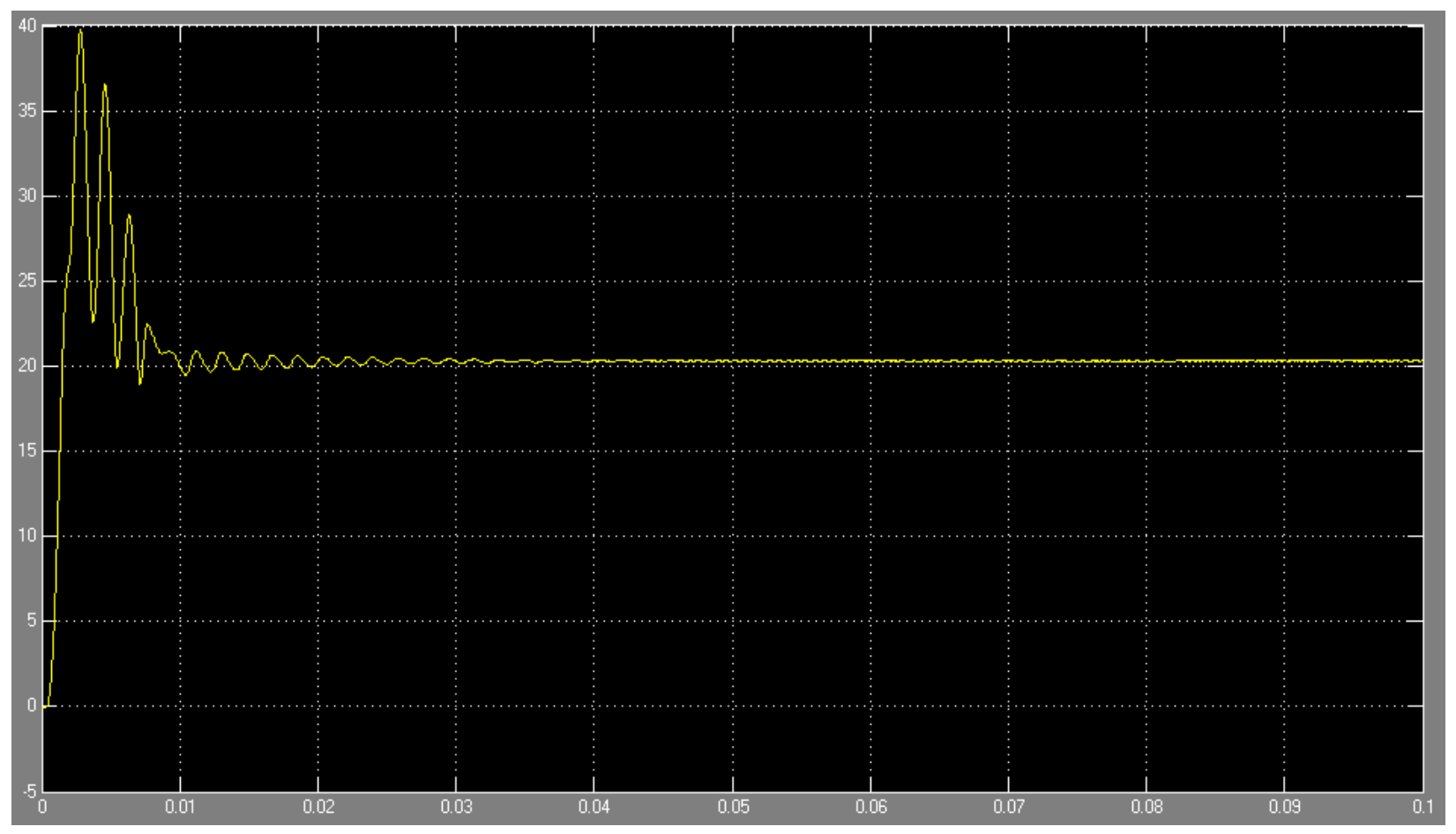

Figure 4-15: Screencapture of the output voltage of the 19.5V CUK converter at Full Load

The converters were also tested for their efficiency, so that an expectation for their efficiency at various input voltages could be assessed. This posed a significant problem in the simulation primarily because of the significant current ripple on both the input and output. Specifically, the input current had a rather large ripple, which is reflected in the input power waveform as shown for the 30V CUK converter at $12 \mathrm{~V}$ input in Figure 4-16. 


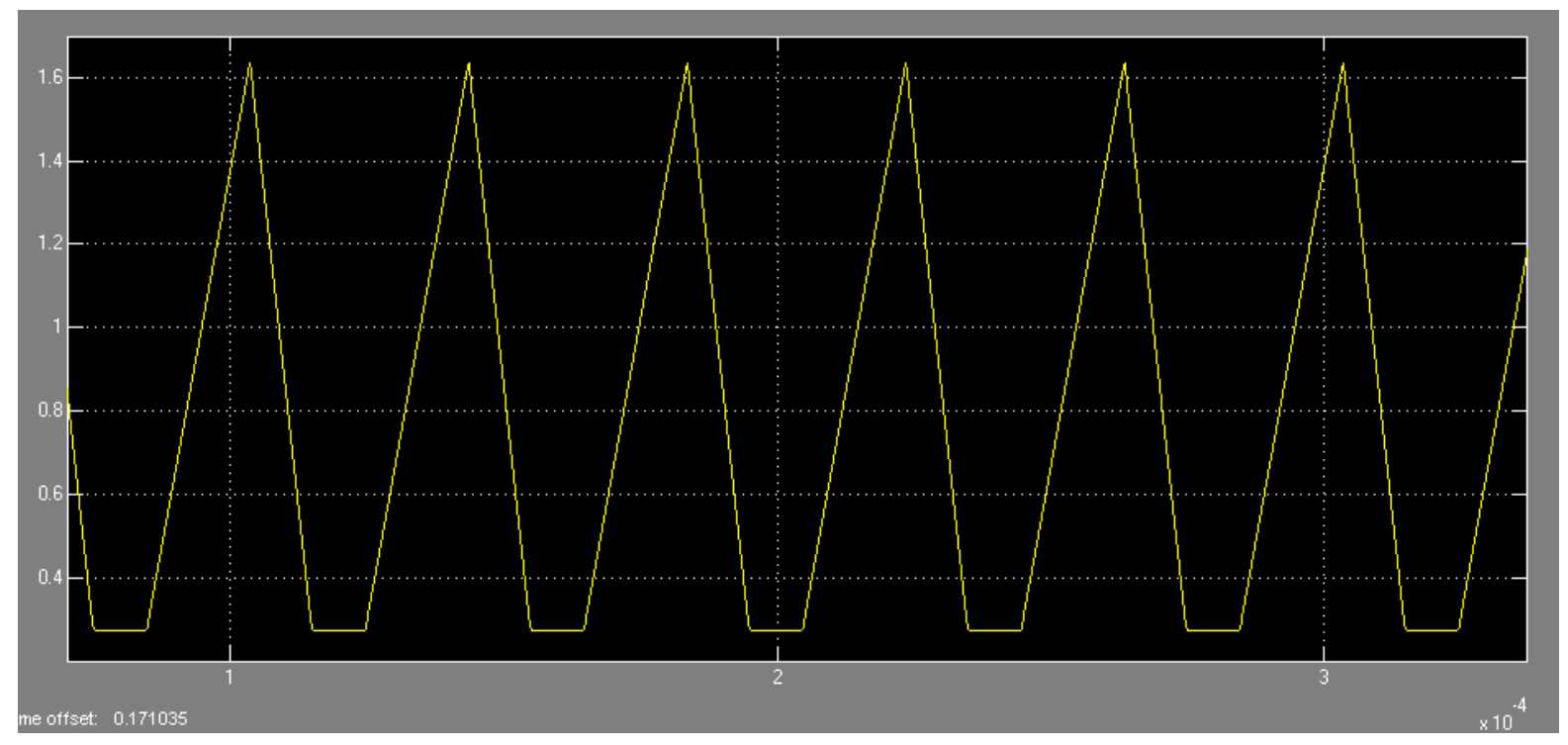

Figure 4-16: Intput Current(Amps) for the 30V CUK Converter with 12V input Voltage Without RMS Configuration

This makes determining the input power difficult, because any calculation in simulink for input power will fluctuate just like the waveform in figure 4-17. Therefore it was necessary to calculate the RMS value for this waveform (and any other voltage and current waveform with a ripple for that matter). This was achieved by using the weighted average component, the squared, and the square root components in simulink. They were combined to form the Root Mean Square of any waveform as shown in Figure 4-17:

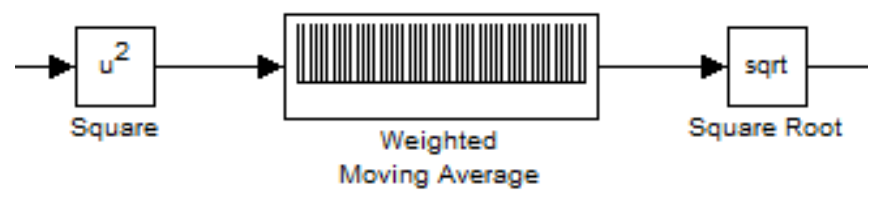

Figure 4-17: Square, Weighted moving average and square root Blocks in Simulink configured to calculated RMS Value

This block will sample the waveform every user defined period, and will make a moving weighted average. Therefore in order to get an accurate average, 80 samples will be taken at a sampling period that will fit 80 samples inside one period of the sampled 
waveform. Therefore for a switching frequency of $25 \mathrm{kHz}$, and 80 samples per period, the sampling time of the average calculator block was calculated as shown in equation 4-5.

$$
\mathrm{T}_{\text {sample }}=\frac{\mathrm{T}_{\text {signal }}}{\text { Number of Samples }}=\frac{4 \times 10^{-5}}{80}=5 \times 10^{-7} \text { seconds }
$$

Running the waveform in Figure 4-16 through this weighted moving average produced the following results:

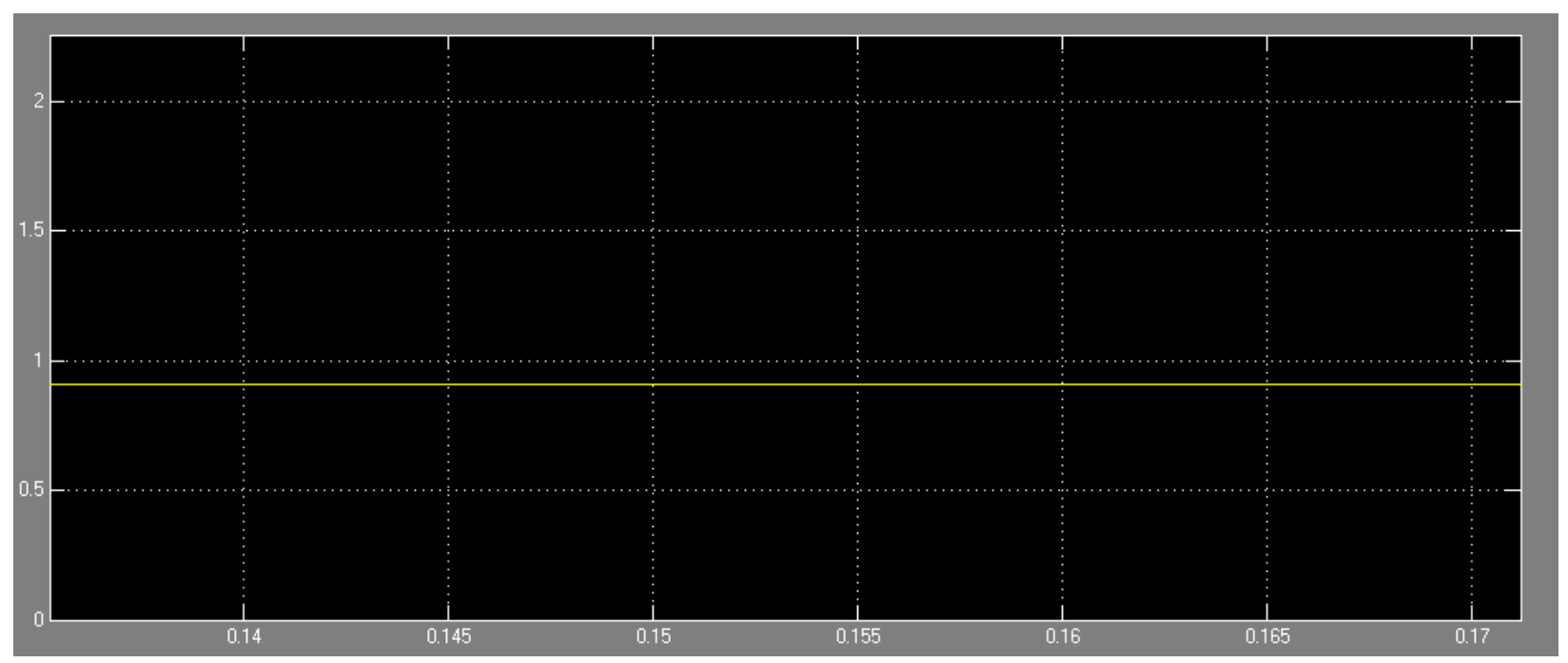

Figure 4-18: Input Current (Amps) For the 30V CUK Converter with $18 \mathrm{~V}$ Input voltage after being passed through The RMS Block

This was a huge improvement, as there was now a means to measure RMS Voltage and current to get a more accurate Average power value. The efficiency was calculated in simulink using some monitoring circuitry. This monitoring circuitry is shown below, and could be used for any DC-DC converter with the same switching frequency. 


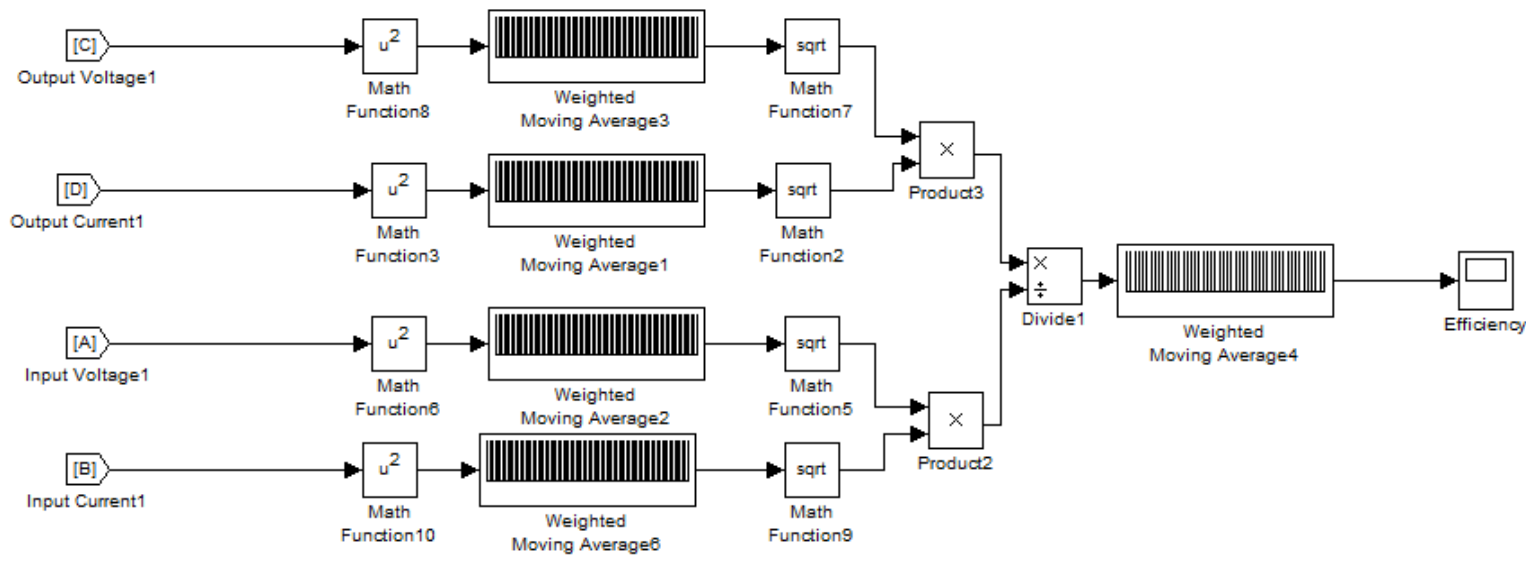

Figure 4-19: Circuitry to provide Efficiency Values for CUK Conveter in Simulink

The efficiencies of the $30 \mathrm{~V}$ and $21 \mathrm{~V}$ CUK converters were summarized in the Table 4-4.

Table 4--4: Summary Of DC-DC Converter Efficiencies

\begin{tabular}{|r|r|}
\hline \multicolumn{2}{|c|}{ 30V CUK Converter } \\
\hline Input \\
Voltage & Efficiency \\
\hline 48 & $97.2 \%$ \\
\hline 12 & $98.0 \%$ \\
\hline $21 V$ CUK Converter \\
\hline Input & \\
\hline Voltage & Efficiency \\
\hline 48 & $97.30 \%$ \\
\hline 12 & $98.30 \%$ \\
\hline
\end{tabular}


This entire system was consolidated into a subsystem block pair consisting of the DC-DC converter and the multi-level power consumption tool. It will be circuited together with the other loads based on various test conditions outlined in chapter 5 of this thesis.

\subsection{Floor Fan}

The floor fan is a simple permanent magnet DC motor. Its maximum power draw (as stated in previous sections) is approximately 45 Watts. In order to correctly model this device, some effort was required to create a simulink model that accurately represents the transient and steady state characteristics of a DC motor. The transient characteristics will be more difficult to model simply because the steady state operation does not need to account for transient and sub transient reactances in the motor windings.

Because the DC fan will not be ordered until later on in the course of the DC house project, a generalized model of the fan was modeled that was on the same order of magnitude in terms of power consumption as the one selected in the previous chapter. A model was constructed so that an acceptable fan speed of 1000 RPM was achieved. The Torque for the motor was calculated using the rated electrical power of the fan, and was using the following:

$$
\begin{gathered}
\mathrm{P}=\mathrm{T} \times \omega \\
\mathrm{T}=\frac{\mathrm{P}}{\omega}=\frac{35 \mathrm{~W}}{1000 * 2 \pi}=.0334[\mathrm{Nm}]
\end{gathered}
$$

This model was then used to drive a current source that would serve to emulate its operation in the complete model. The complete model is shown in Figure 4-20. 


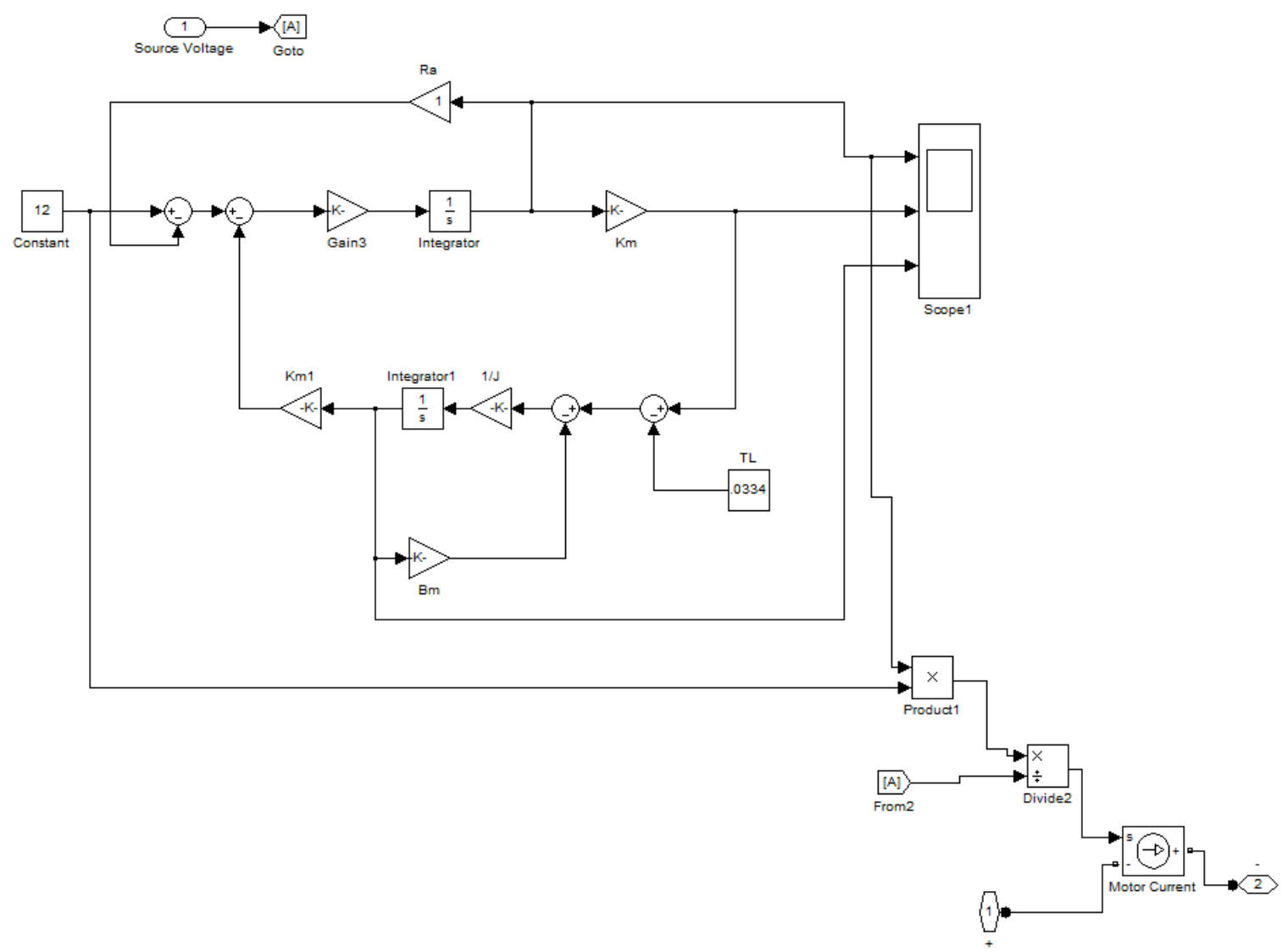

Figure 4-20: Simulink model of DC Motor:

This model was obtained from [23]. The load torque was set to the calculated value of $0.334 \mathrm{Nm}$. The input voltage set to $12 \mathrm{~V}$, and the armature resistor was set to $1 \mathrm{ohm}$.

This created the following armature current waveform as shown in Figure 4-21. 


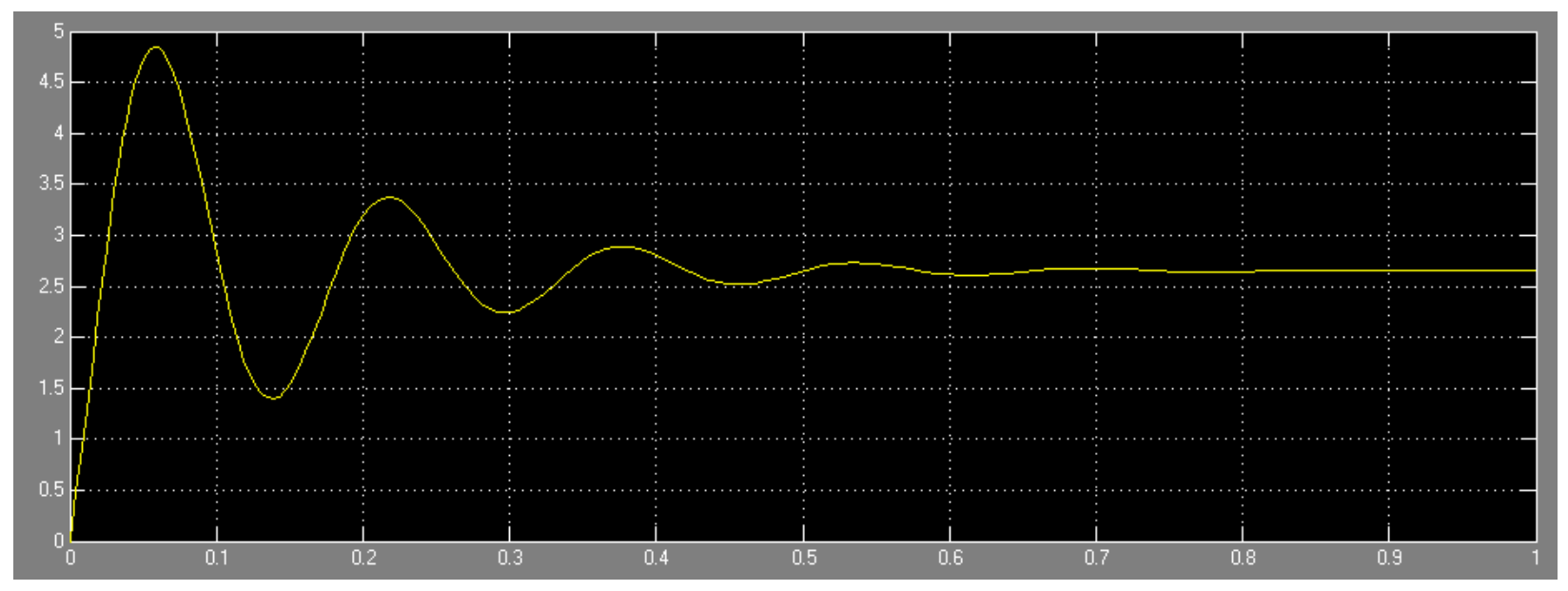

Figure 4-21: Permanent Magnet DC Motor Current in Amps at varying time in seconds operating at 12 Volts

The intention of this Permanent Magnet DC motor is to create an inrush current waveform that is scalable to any range of input voltages from 12 to 48 . The Motor Speed is proportional to input voltage, and therefore creates a problem when trying to model the device at higher voltages (at steady state). This is because the power consumption will not scale appropriately for the intended voltage sweep. This DC motor is not intended to be used at higher voltages, and therefore a static load trick will be used so that the current waveform will be scaled according to the input voltage so that power consumption remains constant.

\subsection{Refrigerator}

The Engel MRFD-015 Refrigerator/freezer was modeled primarily based on information obtained from the data sheet for the device [13]. The datasheet provided the rated maximum power consumption for the refrigerator. The datasheet also detailed the unique operation of the swing compressor which is the primary power consumption contributor in the device. Particularly, that the compressor slowly begins oscillating until maximum power draw is reached. This warmup period will be approximated to last for 1 second, based on the inverter frequency of approximately $60 \mathrm{~Hz}$. That is, 60 oscillations is 
enough for the swing compressor to attain maximum stroke length, and due to the proportionality of stroke length to current draw, will only take 1 second to reach maximum power consumption.

The power consumption for this period will be called the "cooling" cycle. It will begin with this transitory power ascension, then will level off at the rated power consumption rate ranging from 0.9 to 3.8 Amps [13]. Therefore the power consumption for the cooling cycle will be assumed as the maximum current of 3.8 amps, and the inactive mode was rated at the minimum rating of $0.9 \mathrm{~A}$.

This characterization was primarily for transient simulation capability. The steady state operation however is a slightly different story. Typical refrigerator controls function run a cooling cycle until a certain temperature level is reached. Once this level is reached, the cooling cycle is disabled and the refrigerator goes into an "inactive" mode in which no power is drawn. This state remains until the temperature rises to a certain threshold which triggers the cooling cycle. A quick block diagram state machine model of this control is shown in Figure 4-22. 


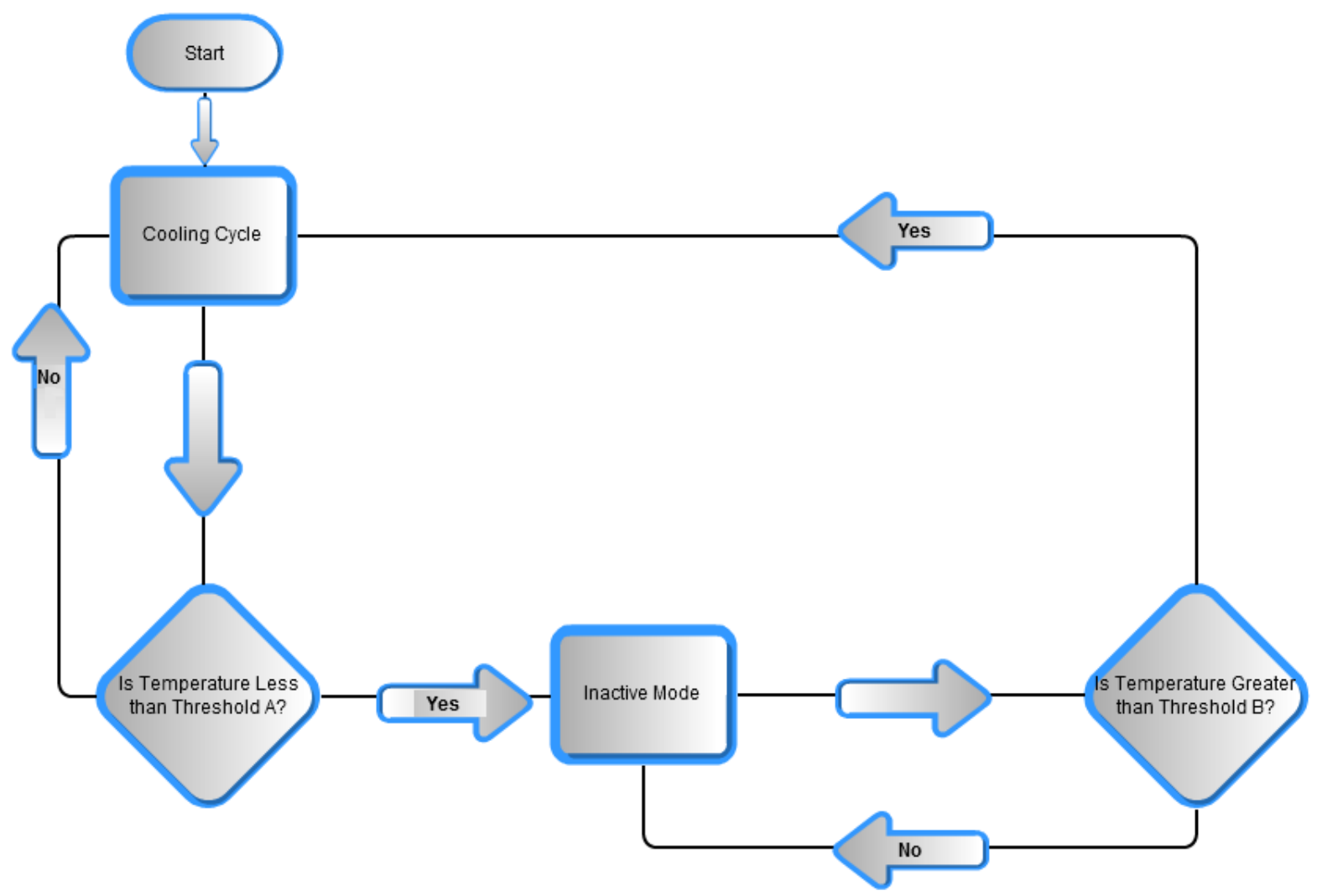

Figure 4-22: Flowchart for the Logic operation of the Refrigerator Unit

The refrigerator steady state power consumption will be modeled using the logic from this flowchart. The reason for using two different thresholds is so that there is no instance where the control system flutters back and forth between the two modes of operation extremely quickly. This occurs as the temperature approaches a single threshold, there is a risk of the temperature not crossing past the threshold decisively. Therefore threshold A will be a lower temperature than threshold B, this way there will be no risk of an event where the current temperature is right on the border of the two threshold values. This extra depth will provide some flexibility for future testing. For the purposes of steady state 
analysis, the important take away is that there are two modes of operation and therefore two modes of power consumption.

The most important steady state behavior for the device will be the cooling cycle stage. That is, we are most concerned with the power consumption of the DC house under typical load settings. Therefore the steady state operation will be modeled under maximum power draw of 3.8 Amps. The circuit subsystem appears in Figure 4-23:

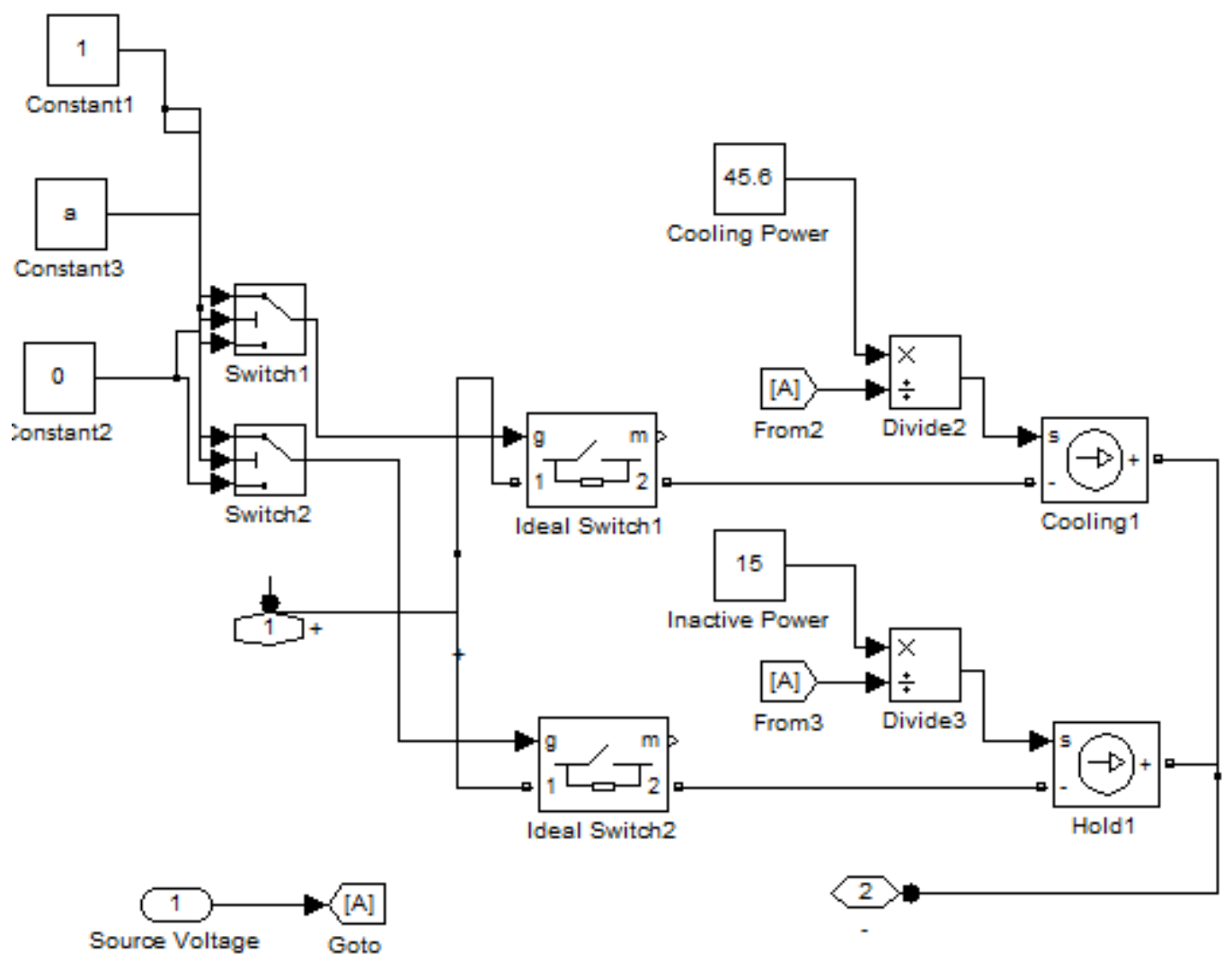

Figure 4-23: Simulink model of the Refrigerator Power Consumption, Subject to either cooling or inactive States

\subsection{LCD Television Screen}

The LCD Television screen requires yet another DC-DC converter for proper operation. The LCD TV has both an AC and DC power input. Since we will only be 
interested in providing DC power, a buck converter will be used to ensure $12 \mathrm{~V}$ is always provided. Therefore, a buck converter will be incorporated that steps the voltage down from the input variance of 12 to 48 VDC to $12 \mathrm{VDC}$ output. The Buck schematic is shown in Figure 4-24 as modeled in simulink.

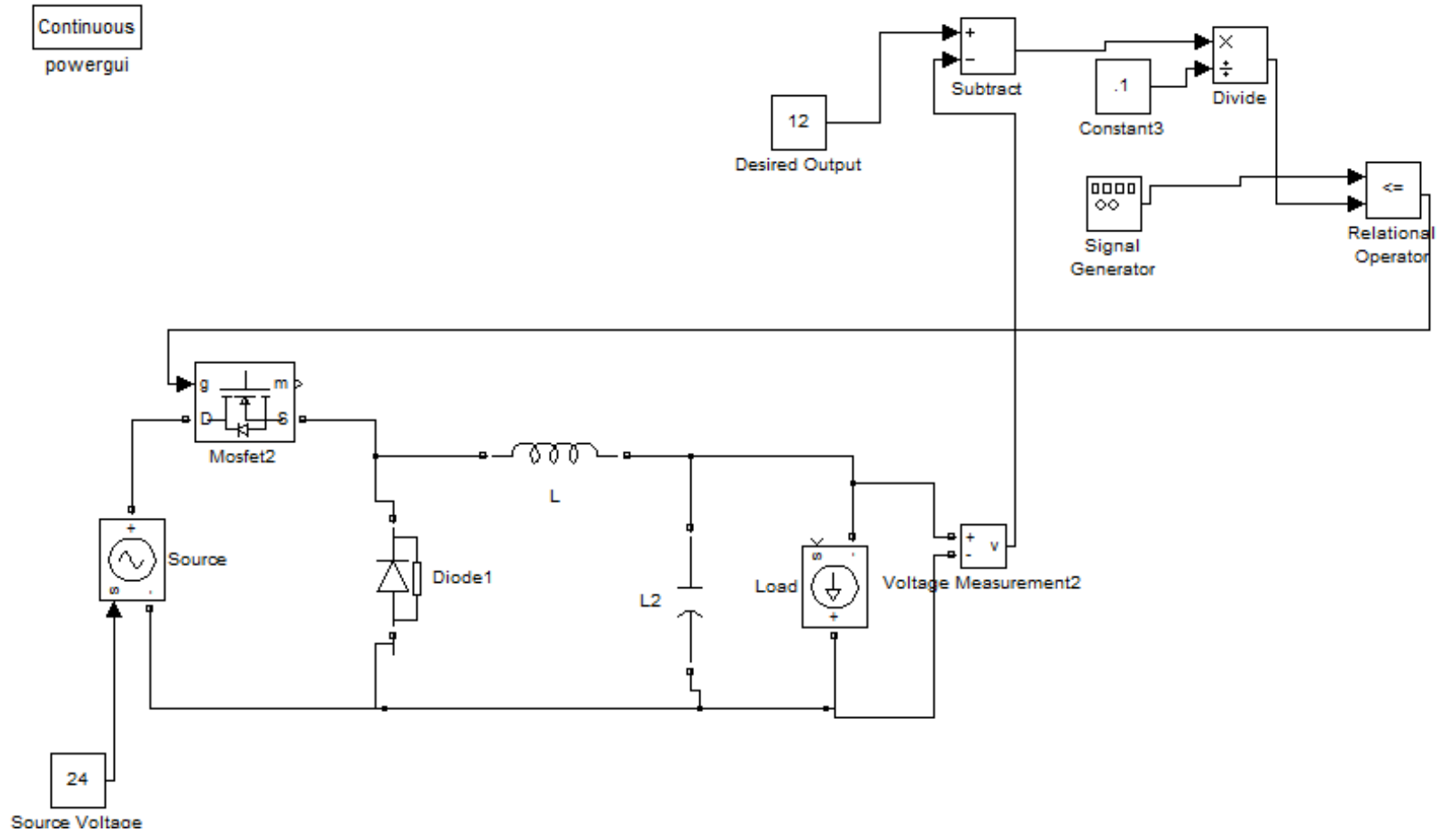

Figure 4-24: Simple Buck Converter Modeled in Simulink

Notice that a similar control circuitry has been implemented as the controls in the CUK converter. The output and desired value output are compared to create an error signal. This error signal is amplified, then compared with a sawtooth waveform that will generate an appropriate PWM square wave that will be used to control the gate. A resistor of size 4 Ohms is used to draw a power of 36Watts as specified in the ratings of the LCD display [22]. 
The resulting output response to 12 and 48 Volt inputs are shown in Figures 4-25 and 4-26 respectively.

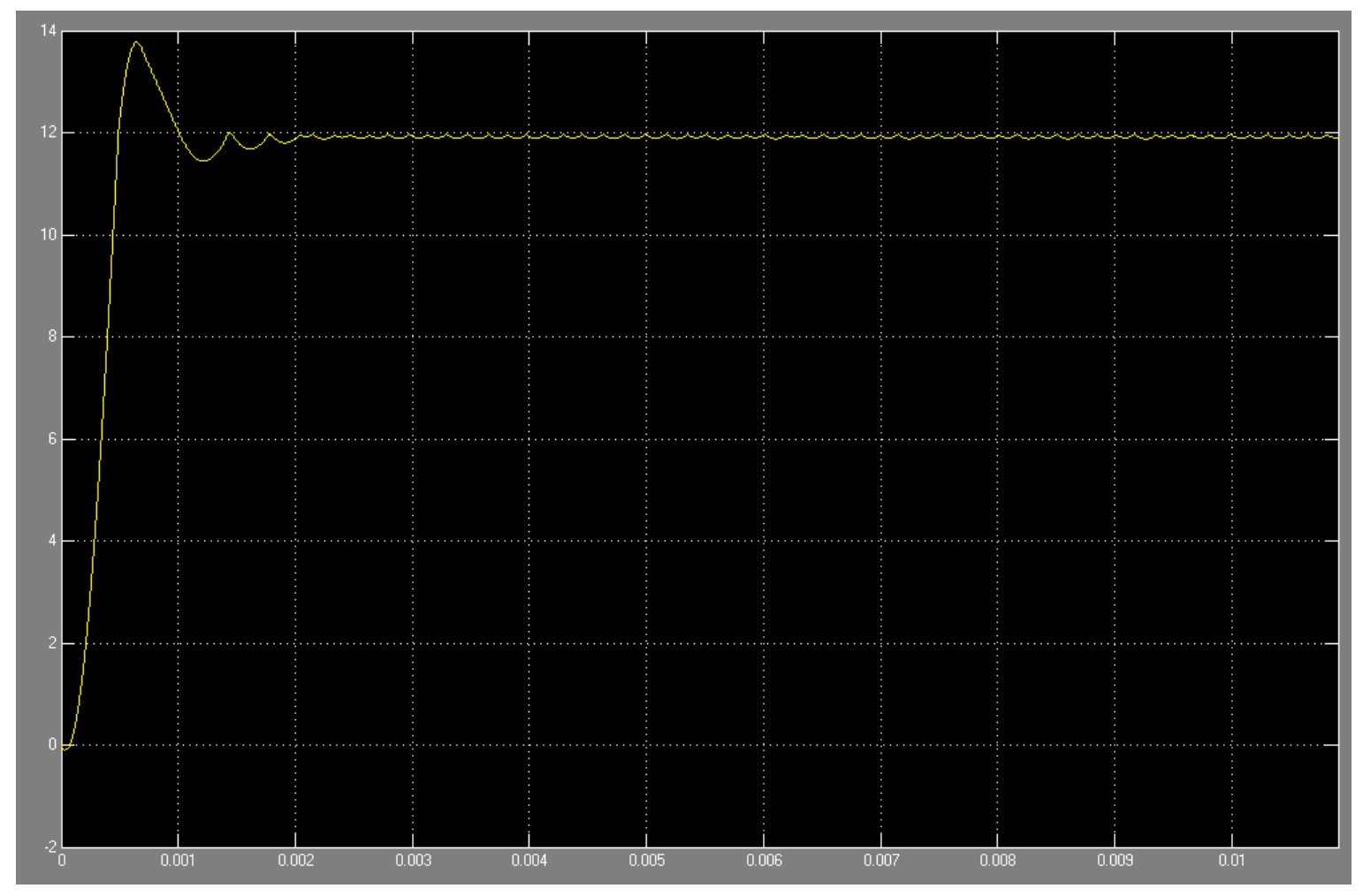

Figure 4-25: Output Voltage as a Function of time for the $12 \mathrm{~V}$ Buck Converter with $12 \mathrm{~V}$ input 


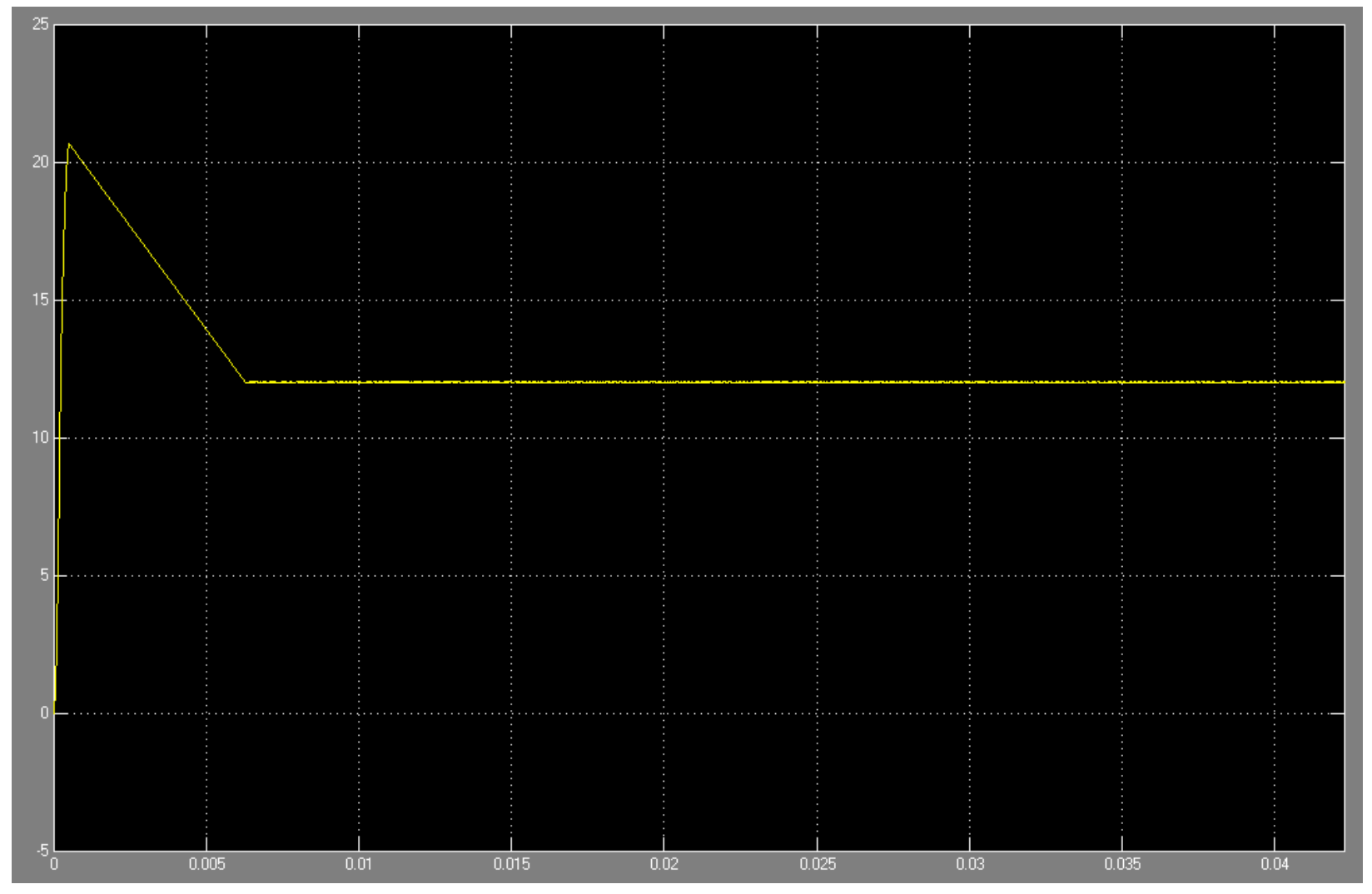

Figure 4-26: Output Voltage as a function of time for the 12V Buck converter with 48V input

Now that the DC-DC converter has been modeled, the power draw was modeled as a constant power load that will always draw 36 Watts as previously discussed. The constant load was created using the same trick as done previously with a variable current source. The complete block diagram form of the simulink implementation is shown in Figure 4-27.

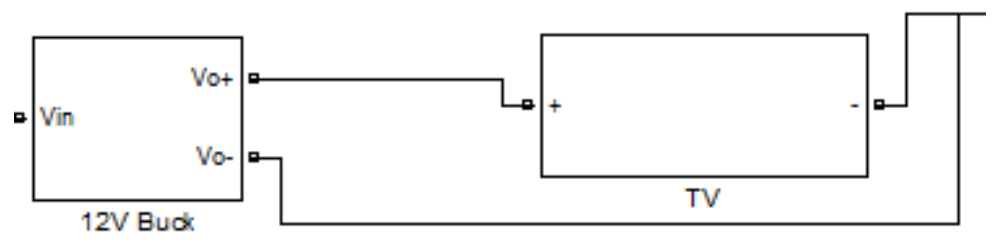

Figure 4-27: Block Diagram Level View of the 12v Buck Driving the TV Load 


\subsection{Crockpot}

The Crockpot does not feature any special power features or requirements, and was therefore a simple device to model. It was modeled as a simple static load using the same method as previous devices. A power setting was defined as the rated 78 Watts[20], then is used in conjunction with the source voltage to control a current source so that the power draw of the device is exactly the rated amount, regardless of the variable source voltage. The block diagram is shown in Figure 4-28.

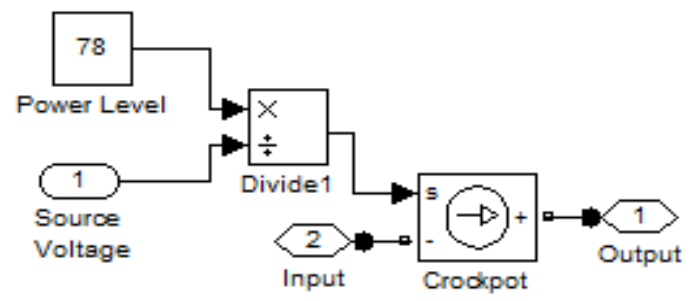

Figure 4-28: Simulink Model for the Crockpot

\subsection{The Complete System and Efficiency Monitoring Rig}

Now that the details of each subsystem have been modeled in detail - they had to be integrated into a single hierarchical file. All of the previously discussed subsystems were integrated into a single Simulink file. This file would have to be rigged and organized so that the principle variables that were to be tested can be simulated and changed easily. Therefore, steps had to be taken so that the system could be easily modified in the context of the desired test variables, and quickly calculate and display the efficiency of the system for each simulation.

In order to calculate the efficiency of the system, the power consumption of the loads and the power provided by the source had to be measured. To measure the output 
power, each load's power consumption would have to be measured and then summed up to a single value. The input power would have to be measured by simply monitoring the power output of the source. To perform these measurements, virtual watt-meters were constructed so that they could be attached to each load. The virtual wattmeter subsystem block is shown in Figure 4-29.

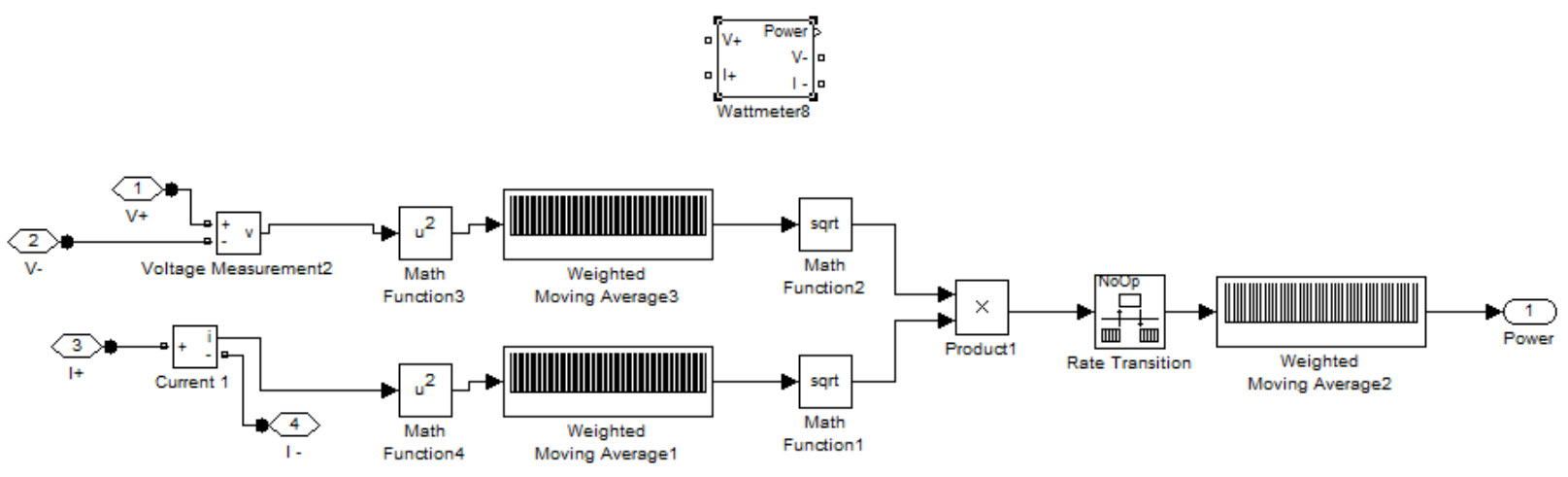

Figure 4-29: Virtual Wattmeter Subsystem View (Top), and Detailed View (Bottom)

As can be seen, the watt-meter block functions just as a real watt-meter does, the current leads must be placed in series to measure the current, and the voltage leads connect across the load. Notice that the wattmeter takes a weighted moving average of the power waveform. This is done because the device is measuring power in the time domain. This way, any current and/or voltage ripples will be essentially filtered out and an average power value is measured. The wattmeter block calculates the average power, then outputs the signal to be transmitted to an aggregator. This aggregator will sum all of the power consumed by each load, then divide that summed "output power" by the measured input power. This product will yield efficiency, and the efficiency value will only be valid once the system has reached steady state, approximately 150 ms. The aggregator block is shown in Figure 4-30. 


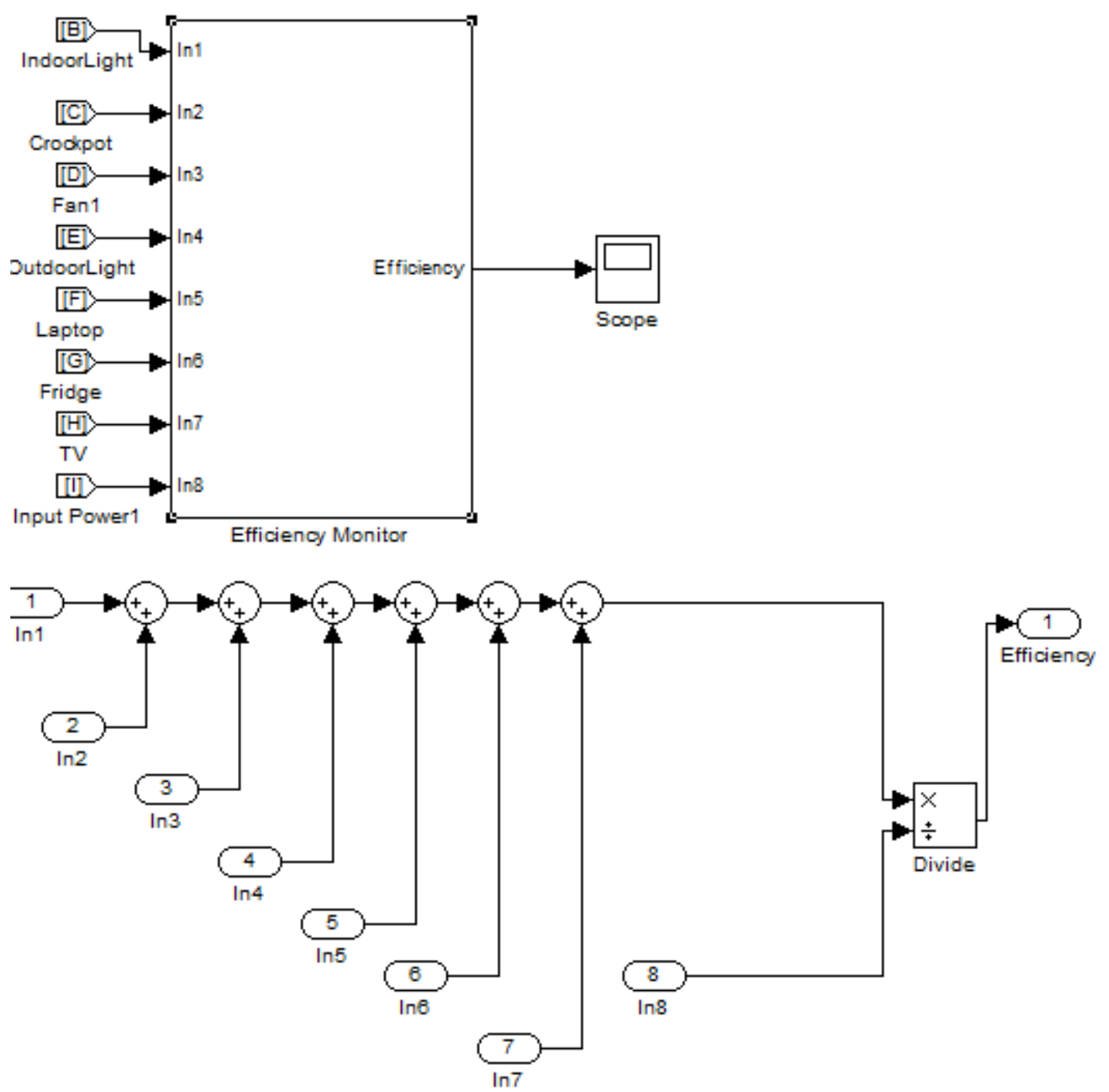

Figure 4-30: Block Diagram View of the Efficiency Monitor Block (top), Detailed View of Efficiency Monitor Block (bottom)

The wattmeters were all connected to their respective loads and routing tags were applied to each so that the diagram would not be cluttered. The final modification made to the complete system would be a current monitoring system that would indicate if any of the circuits was drawing more than the NEC mandated maximum of 15 Amps. This was done by forwarding the current measurements made by the wattmeters to another aggregator that would display a signal if the current was too high. The resulting complete system diagram was screen captured in Figure 4-31. 

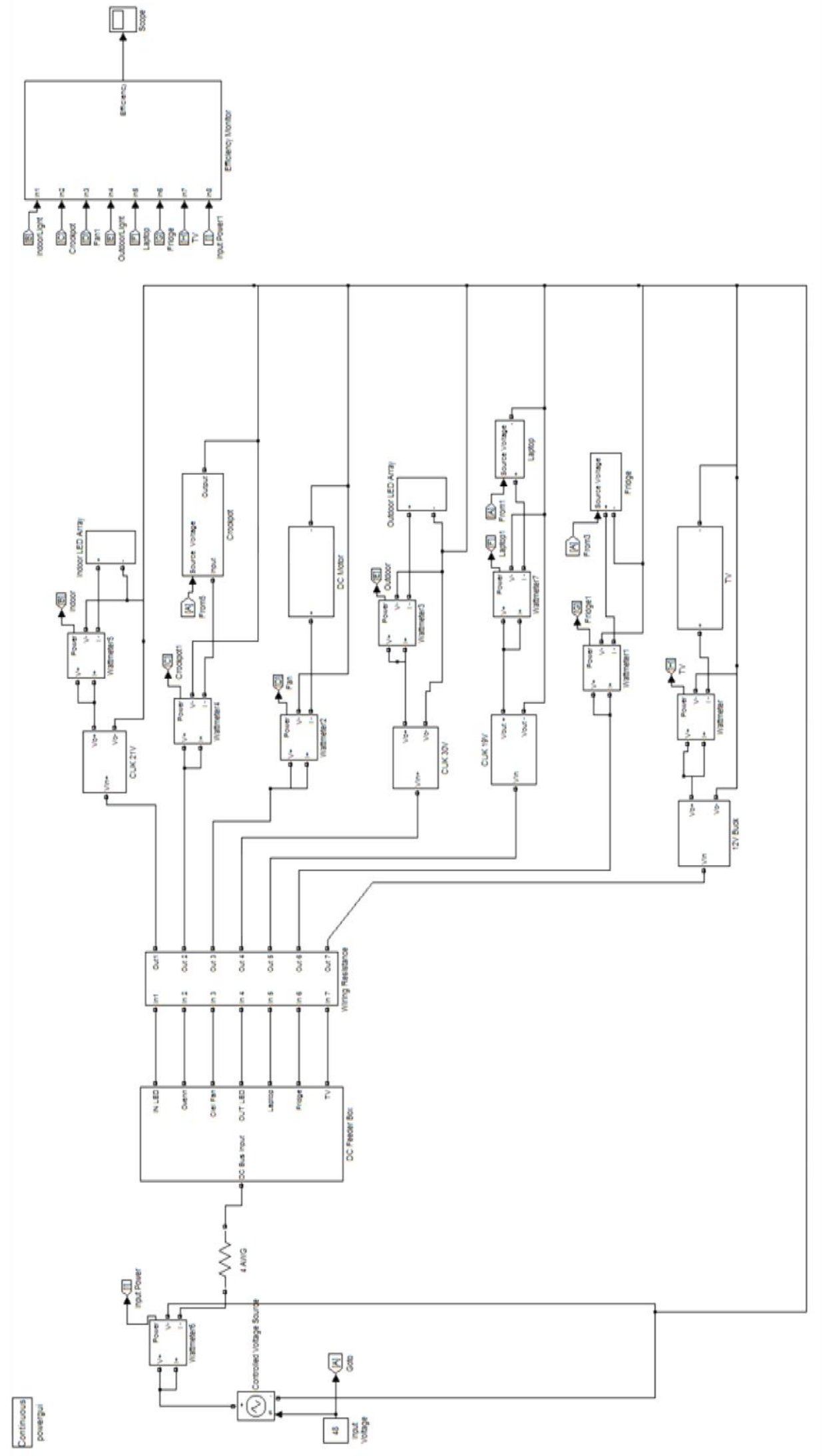

Figure 4-31: Screen capture of the Complete Simulink Model of the DC House 


\section{Chapter 5: Efficiency Characterization and Testing}

Now that a complete and functioning model of the DC House loads has been constructed, it is time to determine the most efficient setup for the complete load side of the DC house. The simulink model will serve as the means for future testing on transients, but will be used in this thesis to determine a power profile of the house. The variables that will be tested are source voltage, total number of circuits, wire gauge/size, and load size. This chapter will discuss the motivation for testing these variables, some expectations and predictions for the results, then a collection of the actual simulation results.

\subsection{Voltage Variation}

\subsubsection{Predictions and Expectations}

The Multi-Input DC-DC converter that takes in the power generation sources, and outputs a single voltage can be represented as a simple model. This output voltage level is the principle driving force that delivers power to the house, and will have the greatest effect on the efficiency of the distribution system.

The voltage bus level will affect the efficiency in several ways. A low voltage bus for the same power levels will mean high currents. High currents will create large power losses in the resistive wiring from the bus to the loads. These high currents will also create significant voltage drops from the sending end of the bus toe the receiving end of the bus where loads will be attached. This will negatively affect the performance of some of the devices such as the buck converter which will not be able to supply 12 Volts on its output if it's input voltage is less than 12 volts due to voltage drops across wire leads. Additionally, as 
shown in the characterization of the DC-DC CUK converters, the efficiency of each device decreased slightly as the input voltage increased. Therefore despite reduced line current there could be some tension at high voltage levels that may pull the overall efficiency down.

\subsubsection{Simulation Results}

The simulink model had already been prepped for an efficiency profile acquisition in the previous section. That is, the source voltage was left to be variable, and the circuit was rigged with virtual wattmeters to determine the power being delivered to the loads and the power delievered from the source. These all feed into a subsystem that will calculate the efficiency of the distribution system. All wire sizes were set to the minimum requirements for NEC compliance and each load was set to its own circuit. This setting was labeled the Standard model - changes in the wire size and number of circuits was tested in the next sections. The source voltage was changed initially set to 12 volts and was swept via 1 volt increments up to 48 volts. The system was permitted to reach steady state before the efficiency value was recorded for each setting. A plot of the efficiency at varying voltage was constructed using these data and was captured in Figure 5-1. 


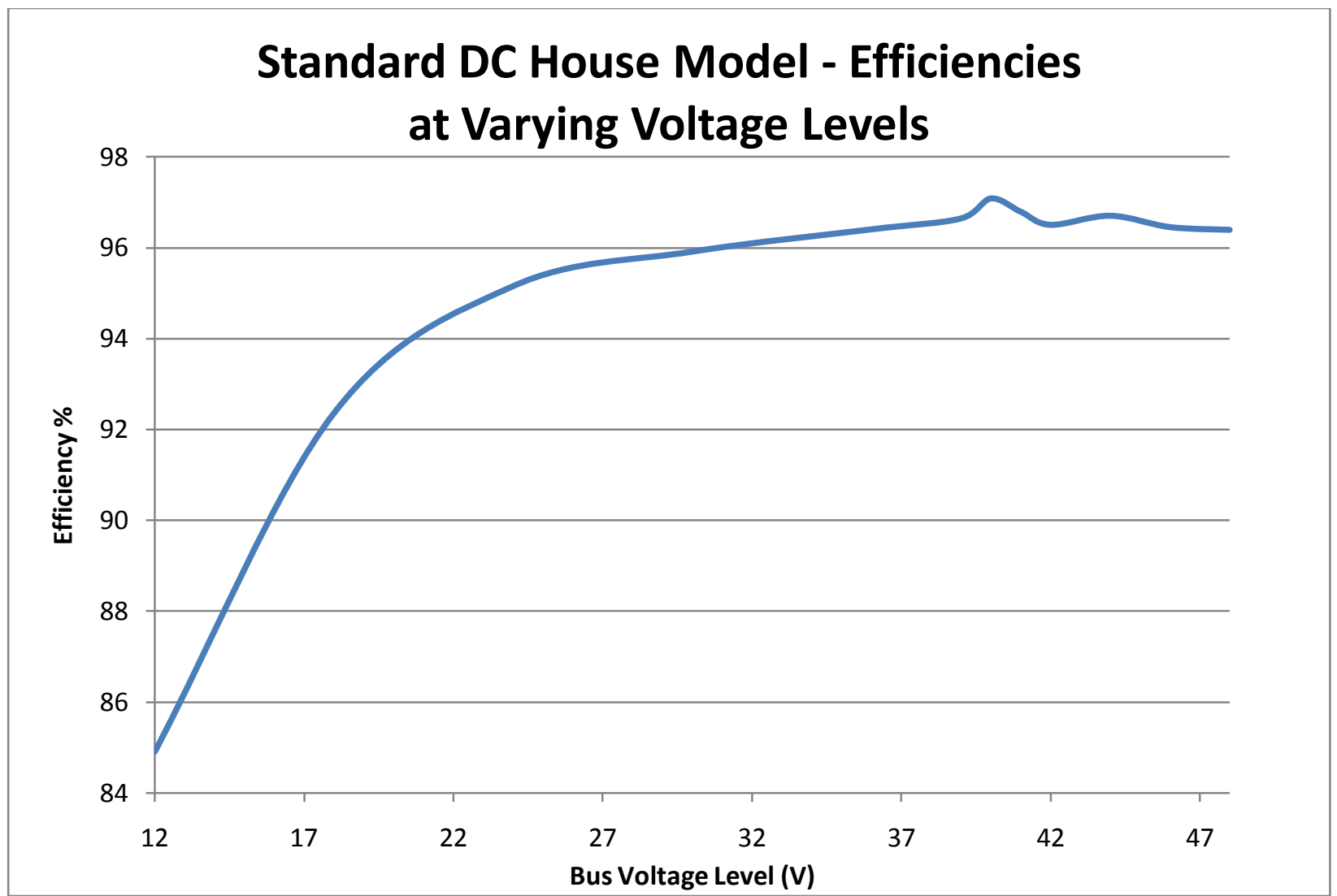

Figure 5-1: Efficiency Plot for Standard Model of DC house at Varying Voltage Levels

As can be seen, the peak efficiency under the standard settings is approximately at 40

Volts. The reason that the efficiency initially increases drastically, is because increased voltage will result in drastically less currents, and therefore less power loss in the lines. The Efficiency gains are minimized at higher voltages, because the resistive losses due to current are the result of an exponential function:

$$
\mathrm{P}_{\text {Resistor }}=I^{2} \times \mathrm{R}
$$

Therefore, as the current decreases, the power approaches zero exponentially, with drastic changes at the beginning, and more subtle changes at very small currents. The relative loss in the wiring becomes less and less significant. This is also partly the reason why the efficiency begins to decrease once again after the $40 \mathrm{~V}$ mark. The other factor affecting 
the efficiency of the system is the efficiency of the DC-DC converters. As previously detailed, the efficiency of the DC-DC converters slightly decreases at higher input voltages. Therefore there are essentially two forces pulling efficiency - the wiring losses which decrease as voltage increases, and the DC-DC converters which increase as voltage increases. This simulation showed that under the standard settings, point at which the incremental decrease in efficiency from the DC-DC converters outweighs the incremental efficiency increase from wiring losses is approximately at the $40 \mathrm{~V}$ marker.

The second variable tested was individual circuit current. That is, if the current in any circuit branch exceeded 15 Amps, an alarm was recorded. It is important to know if an individual circuit exceeds this rating because according to the NEC it is not allowed [6]]. The real risk for this alarm to be triggered occurs when the voltage is low, this is because the static loads will draw more current to maintain the same power, and DC-DC converters will use more current to step up the voltage. Because each load has its own circuit, it is unlikely that there will be an instance where the current exceeds $15 \mathrm{~A}$.

This results showed that because each load was on its own circuit, there was no risk of exceeding the $15 \mathrm{amp}$ limit dictated by the NEC. These results will be tested more thoroughly again later in section 5.3 when the number of circuits will be decreased.

Now that a power profile has been established for the standard conditions, It was necessary to continue the testing by changing the other two variables - number of circuits, and wire size independently. 


\subsection{Wire Size}

The standard wire size for the wiring used in the DC house was defined already using the National Electric Code. That is 10 AWG for individual circuits and 4 AWG for the Bus to feeder box connection. Initially it may seem pointless to test for the efficiency of the system with different wire sizes. This is because as wire size increases, the DC resistance will decrease, and therefore the efficiency of the system will obviously increase and vice versa for smaller wires. This is true however, as the wire size increases, the cost of that wire also increases. Because this DC house will eventually be constructed, it is worth exploring the increased efficiency performance for the given increase in price for each larger wire size. It will also be possible to go the other direction and test for the incremental loss in efficiency for a given savings in cost.

The corresponding costs for the wire types were calculated using prices from the same vendor for consistency [28]. The prices for all wire sizes were summarized in the Table $5-1$.

Table 5-1: Summary of Wire cost per foot and Ampacity rating for all wire sizes tested. [25]

\begin{tabular}{c|c|c|}
$\begin{array}{c}\text { Wire Size } \\
\text { (AWG) }\end{array}$ & $\begin{array}{c}\text { Cost per Foot } \\
\text { (\$/foot) }\end{array}$ & $\begin{array}{c}\text { Ampacity Rating } \\
\text { (Amps) At } \mathbf{6 5} \mathbf{5}^{\circ} \mathbf{C}\end{array}$ \\
\hline 2 & 1.624 & 115 \\
\hline 3 & 1.292 & 100 \\
\hline 4 & 1.024 & 85 \\
\hline 6 & 0.6459 & 65 \\
\hline 8 & 0.4159 & 50 \\
\hline 10 & 0.2639 & 35 \\
\hline 12 & 0.1619 & 25 \\
\hline 14 & 0.1119 & 20 \\
\hline
\end{tabular}




\subsubsection{Bus to Feeder Box Wire Size}

The wire size testing will be split into two main sections: The first test increased the Wire size from the bus to the feeder box starting at 4 AWG, and was continued for 8 AWG, 6 AWG, 3 AWG, and 2 AWG. The length of the wire was kept constant, the number of circuits was kept at the standard setup. The voltage was swept from 12 to 48 for each setup and the resulting efficiencies were plotted in Figure 5-2.

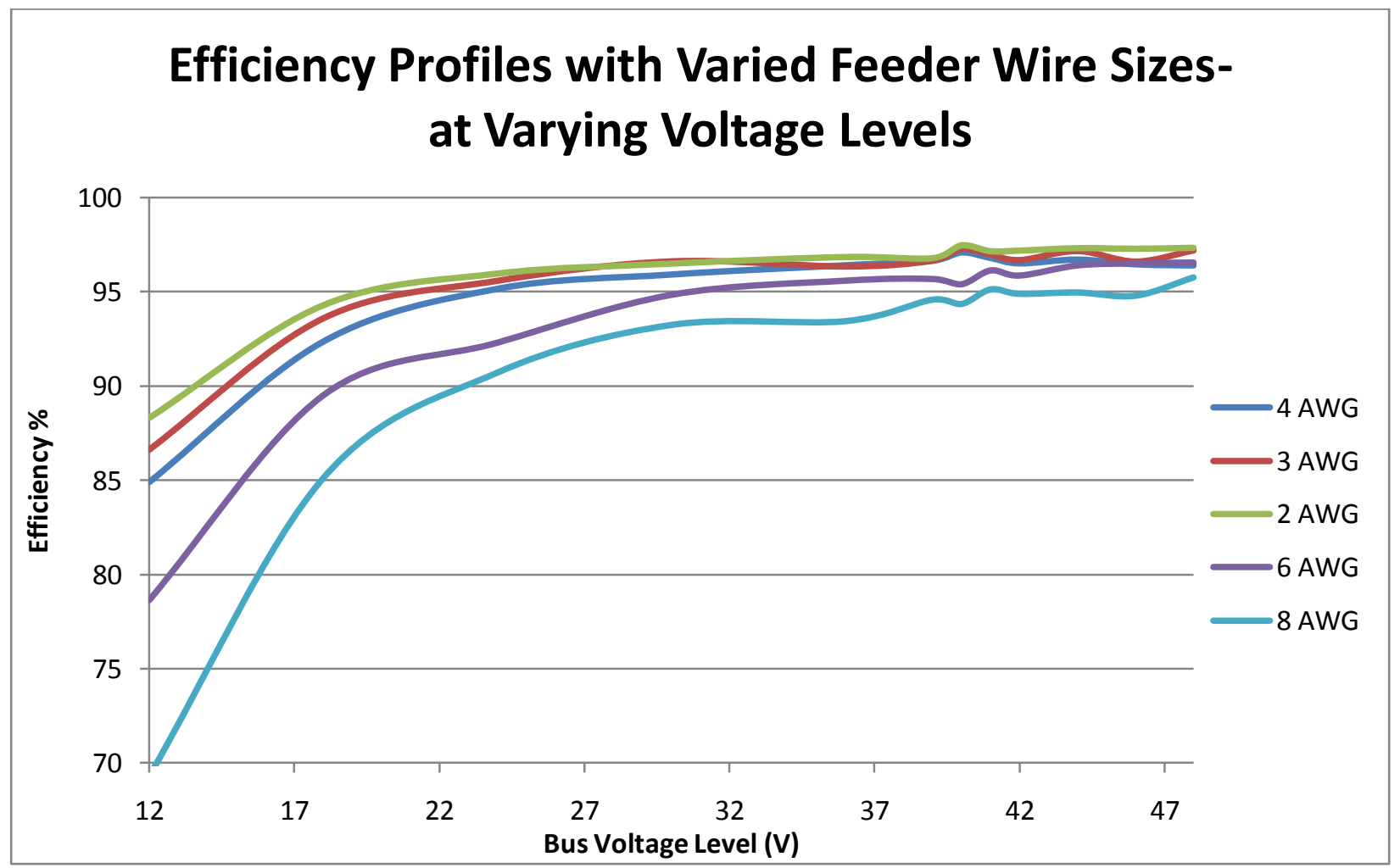

Figure 5-2: Efficiency Profiles For Varied Bus to Feeder Box Wire Size

As can be seen in the graph, using a larger wire does increase efficiency, especially at lower voltage levels. However, at higher voltage levels, there is simply such a small change in efficiency with larger wire sizes. The incremental increase in efficiency per cost in dollars 
from one wire gauge to another was calculated and plotted in Figure 5-3. This was done by taking the difference in efficiency for a given voltage setting between two incremental wire sizes, and dividing by the incremental cost from one wire to the other shown by equation 5-

2. The results were plotted in Figure 5-3.

$$
\text { Incremental Efficiency Gain per Dollar Spent }=\frac{(\eta 1-\eta 2)}{\Delta \text { Price }}=\left[\frac{\%}{\$}\right]
$$

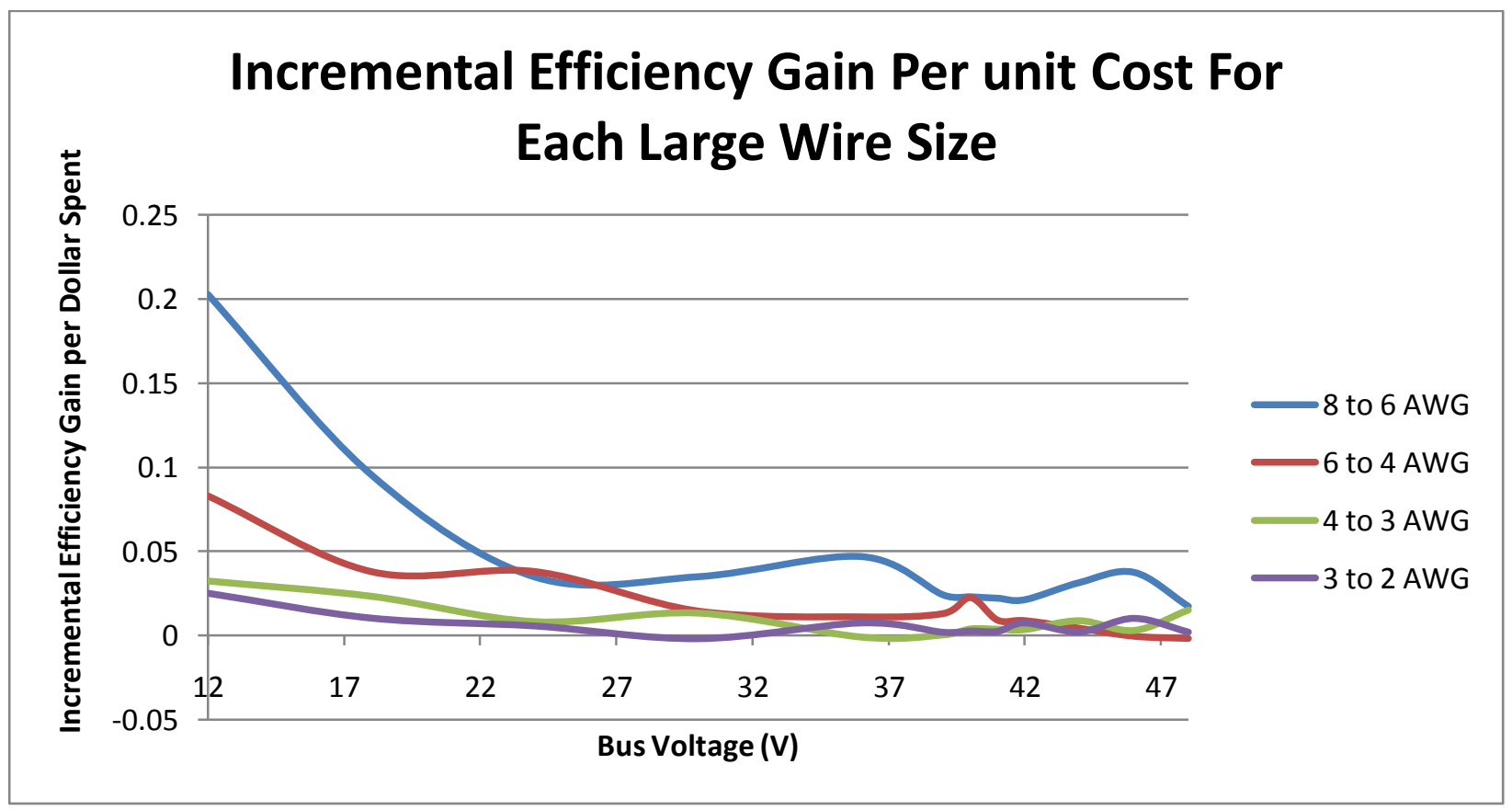

Figure 5-3: Incremental Efficiency Gain Per unit Cost for Going with larger Wire Sizes

As expected, the larger wire size will increase the efficiency, but Figure 5-3 demonstrates how the increased efficiency is not significant at higher voltage levels. The upgrade from 8 to 6 AWG shows as an exception because it consistently has a gain of about $0.05 \%$ per dollar spent even at higher voltages. If anything this plot makes the case that upgrading from 8 to $6 \mathrm{AWG}$ is the only worthwhile upgrade. Additionally, the $6 \mathrm{AWG}$ wire has an ampacity rating of 65 amps, which is well above the expected load current, even at lower bus voltage settings. Therefore the optimum Bus to Feeder Wire size is 6 AWG. 


\subsubsection{Individual Circuit Wire Size}

Now that we have some more detailed information on the effects of changing the wire size of the bus to feeder box wiring - it is time to carry on and explore the impacts of using different sized individual circuit wires. The approach for simulation was the same as the previous section - wire sizes both bigger and smaller than the standard "10 AWG" were tested and efficiencies recorded. The results were plotted for each AWG setting in Figure 5-

4.

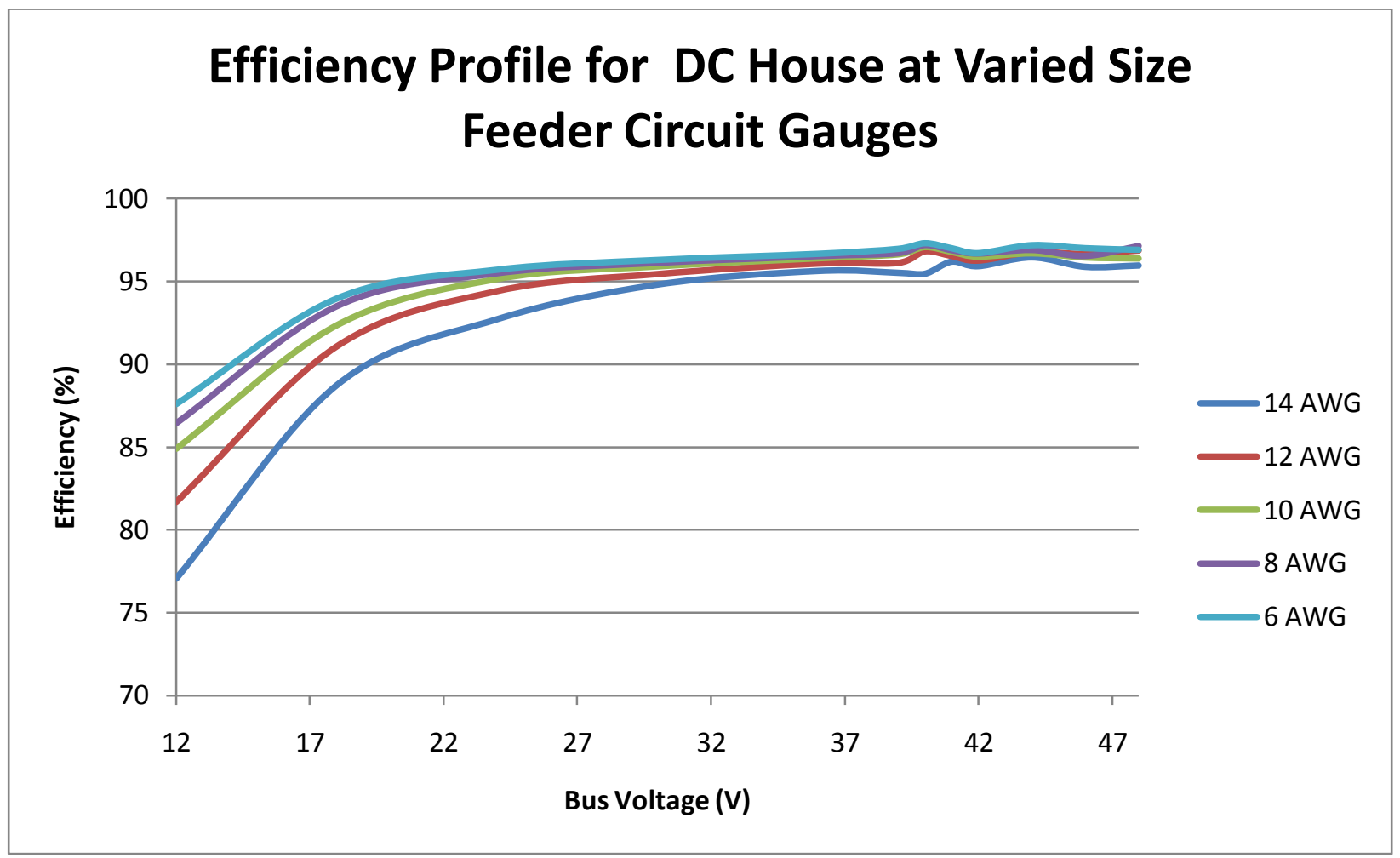

Figure 5-4: Plot Of Efficiency Profiles of the DC House at Varied Individual Circuit Sizes

As can be seen, the efficiency increases most drastically at lower bus voltage levels.

This is similar to the previous test and occurs because the wiring losses are largest at low voltage levels. To demonstrate the trade-off of using larger or smaller wire sizes, the 
incremental efficiency gain for a given change in price was calculated using the obtained data and defined wire size costs and lengths. These results were calculated in excel and plotted in Figure 5-5.

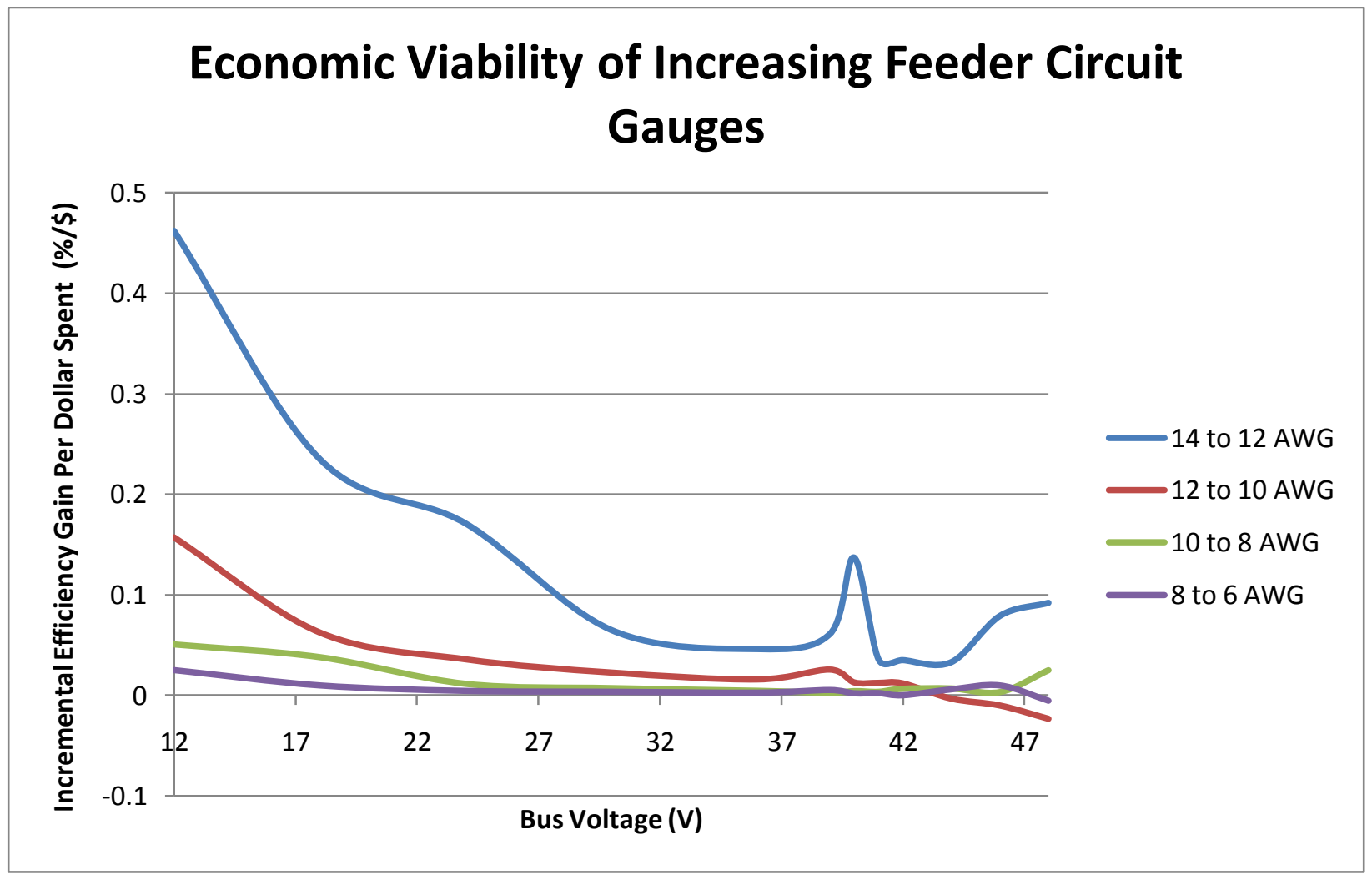

Figure 5-5 Incremental Increase in Efficiency Per Unit Cost for Upgrading from Each wire Size

Once again, there is significant efficiency gain at the lower voltage levels for the price. The plot demonstrates that there is still a significant efficiency gain when going from 14 to 12 AWG and 12 to 10 AWG. However, the increased cost of upgrading beyond 10 AWG is rather insignificant. 10 AWG wire has an ampacity rating of 35 Amps, which is well above the maximum circuit current rating of 15Amps - therefore the best circuit wire size is 10 AWG.

\subsection{Number of Circuits}


The DC loads connected to the DC house in the standard model are each connected in their own circuit. That is, there is a separate run of wiring from the feederbox to each load, 7 total. It would be interesting to test the effects on efficiency and cost if some loads were put on the same circuit. Using fewer circuits will save money by using less material. However, the efficiency of the system will suffer because the circuit currents will be higher. Additionally, the safety of the system must be ensured by not having a single circuit with more than $15 \mathrm{~A}$ of current flowing through it.

The system was reconfigured so that initially only one circuit was used to connect all of the DC loads at full load. An efficiency profile was simulated and tabulated in excel. Time was also taken to ensure that if the current ever exceeded $15 \mathrm{~A}$ in a single circuit that it would be noted. This process was repeated with 2, 3, 4, and 7 circuits and care was taken so that the load distribution was as even as possible. The resulting data were plotted in Figure 5-6 and 5-7. 


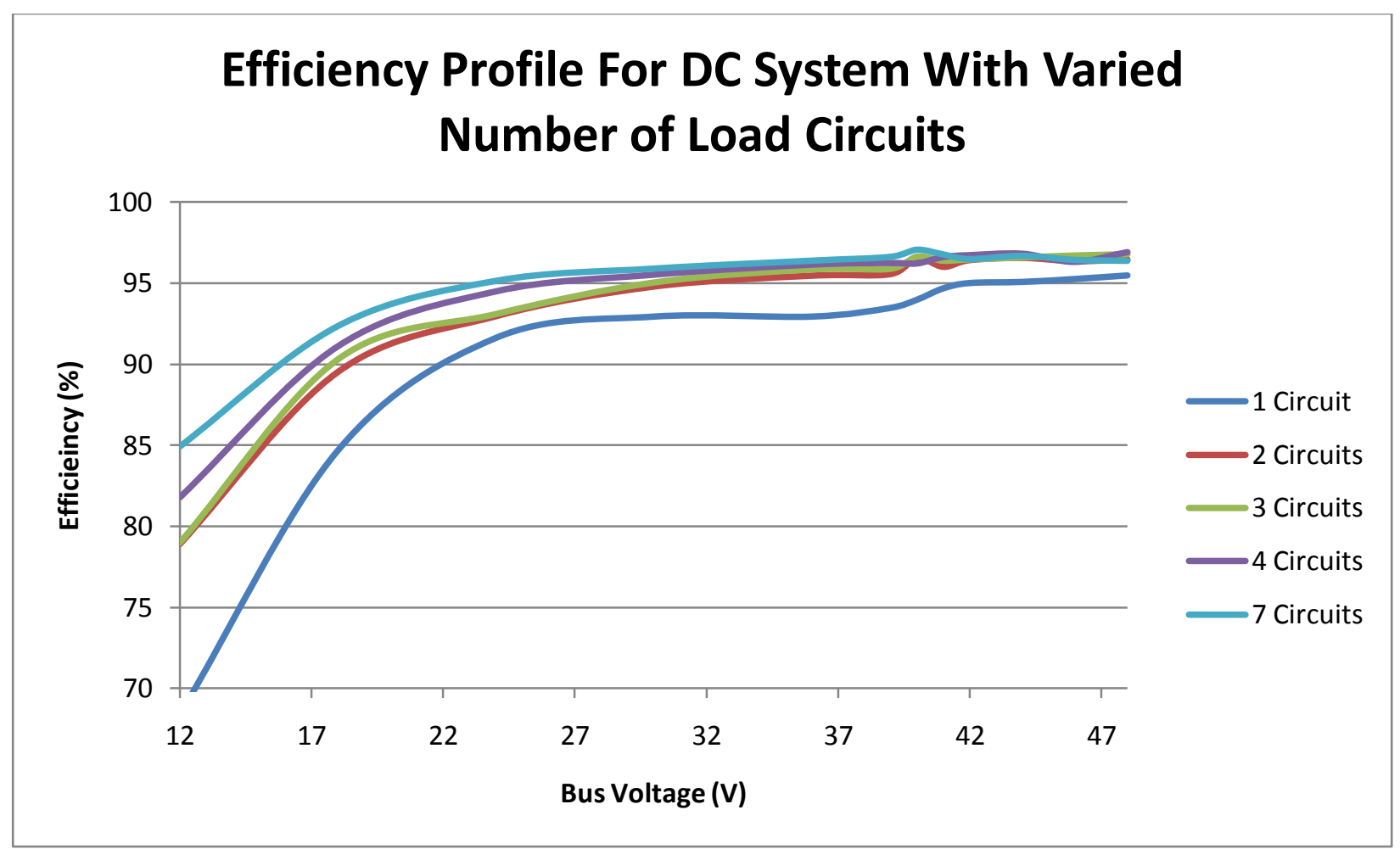

Figure 5-6 Efficiency Profile for DC System With Varied Number of Load Circuits 


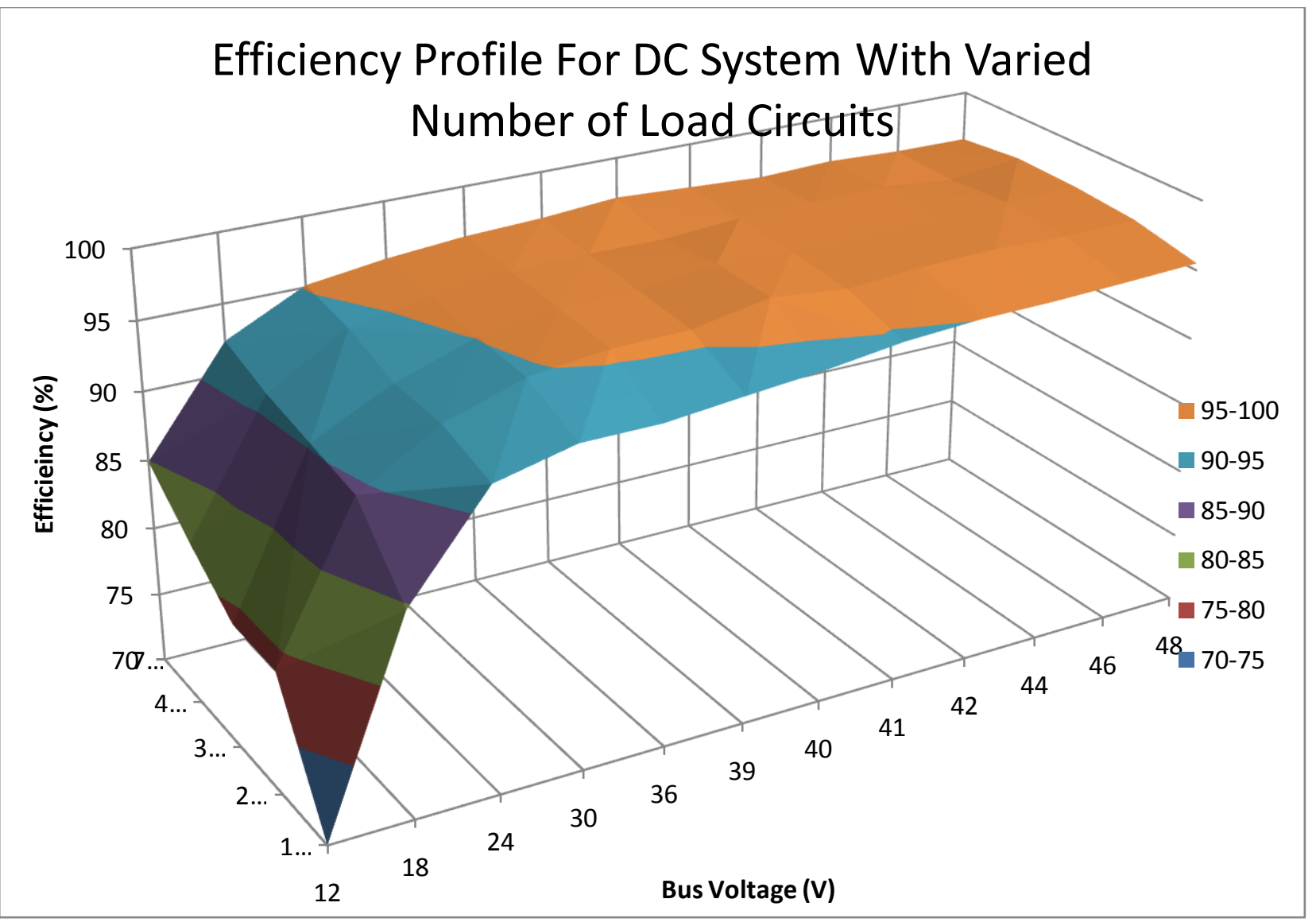

Figure 5-7: 3D Depiction of Figure 5-6, Efficiency Profile For Varied Number of Circuits and Bus Voltage

The plot indicates that as the number of circuits increases, the efficiency also increases. This coincides with expectations, as adding more circuits distributes the current through more pathways, and reduces the resistive losses. It is also important to notice that at higher voltages the efficiency increase for each increase in

In order to put into perspective the cost of adding another circuit, and the resulting tradeoff with efficiency, each change in efficiency for a given change in the price of increasing the amount of wire necessary for an additional circuit was calculated. This was done according to the same method listed in the previous two sections. The results were tabulated and plotted in Figure 5-8. 


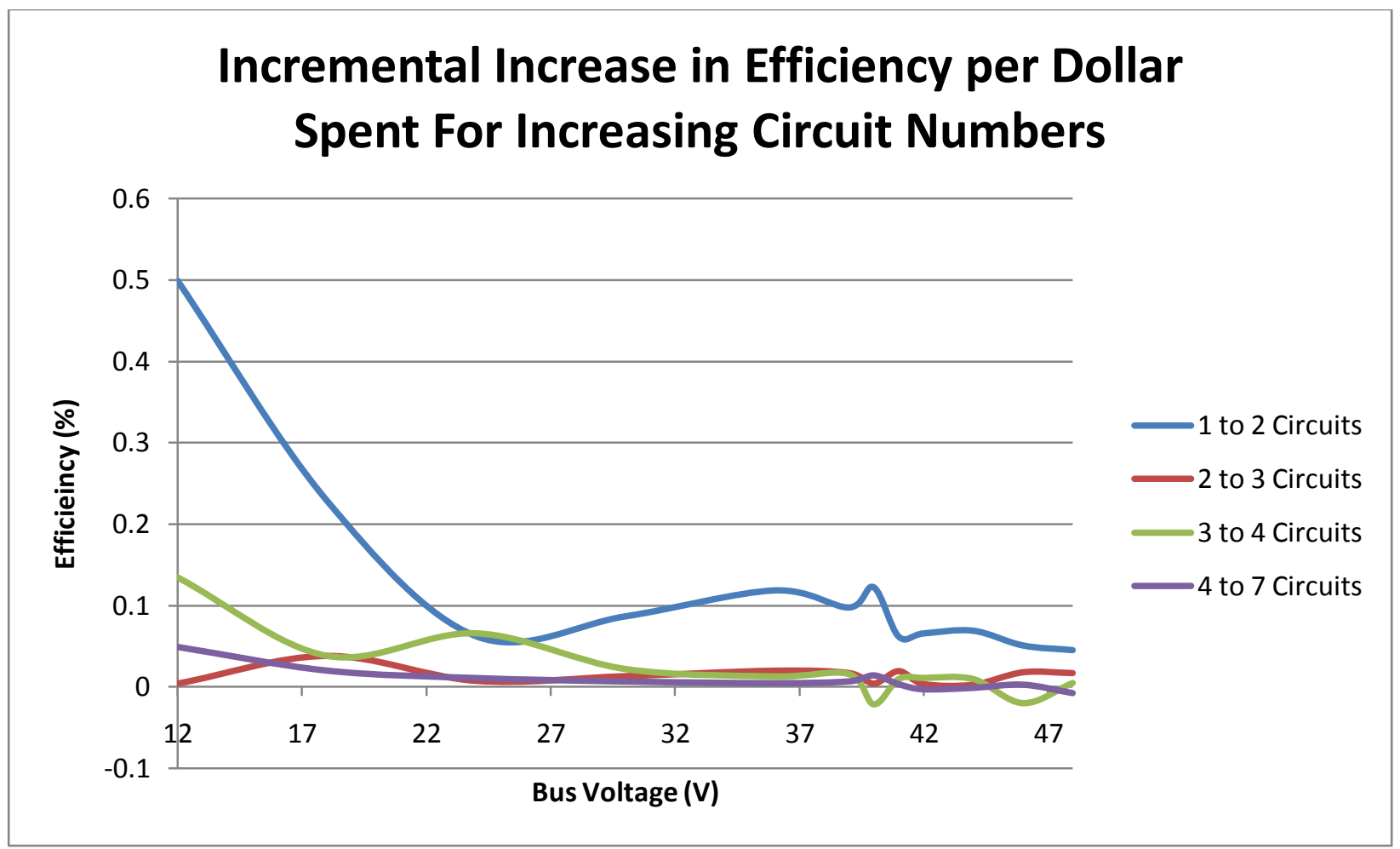

Figure 5-8 Incremental Increase in Efficiency Per Dollar Spent for Increasing Circuit Numbers:

This plot clearly shows the benefit of using more than one circuit for load

distribution. It also demonstrates that a system with more than two circuits does not yield a significant increase in efficiency for the cost. Therefore the optimal number of circuits for the cost is two.

One final piece of information to note was that the only setting that triggered the alarm for a maximum current over 15 Amps was for the single circuit setting. The alarm was triggered for all voltages less than $25 \mathrm{~V}$. This makes the Single circuit configuration very non-desirable, as it presents a safety issue at low voltages, as well as it is much less efficient. 


\subsection{Special Load Case Studies}

All previous tests have assumed a "full-load" condition, that is all loads are turned on and are drawing maximum power. It is difficult to perform a straight linear scale of load usage, because each of the 7 loads draw different amounts of power. Instead, several special cases of load usage were defined and tested. The first two cases were a Day and Night cycle. These two states were chosen because they were realistic models of how the loads in the DC house would be used. A "Day" and a "Night" cycle were defined by the typical load usage during the day and typical load usage during the night. Additionally, some rural homes may only need electricity for lighting purposes, so a set of lighting loads only was constructed and tested. Additionally, a medical station would only require lighting and a refrigerator for storage of medical supplies. This special case was also explored. The exact operation of each of these cases is defined in the following sections.

\subsubsection{Day and Night Cycles}

The Day cycle will disable loads that will not typically be used in the daytime. Lighting loads will not be necessary in the daytime and were disabled. The TV and laptop are generally used after people are done with work, school and other activities, therefore it was disabled. The crockpot was left enabled because it typically will be left on all day to cook a dinner meal. The refrigerator and fan were also left enabled as the refrigerator is always running, and the fan will be used during hotter periods such as the mid-day. The night cycle was reversed except for the refrigerator, which will always be running. The breakdown of each load cycle is summarized in Table 5-2. The efficiency profile for each setting was simulated and the results were plotted in the Figure 5-9. 
Table 5-2: Summary of the Day and Night Load Cycles

\begin{tabular}{c|c|c|} 
Load & Day & Night \\
\hline Lighting & No & Yes \\
\hline Crockpot & Yes & No \\
\hline Fan & Yes & No \\
\hline Laptop & No & Yes \\
\hline Refrigerator & Yes & Yes \\
\hline TV & No & Yes \\
\hline
\end{tabular}

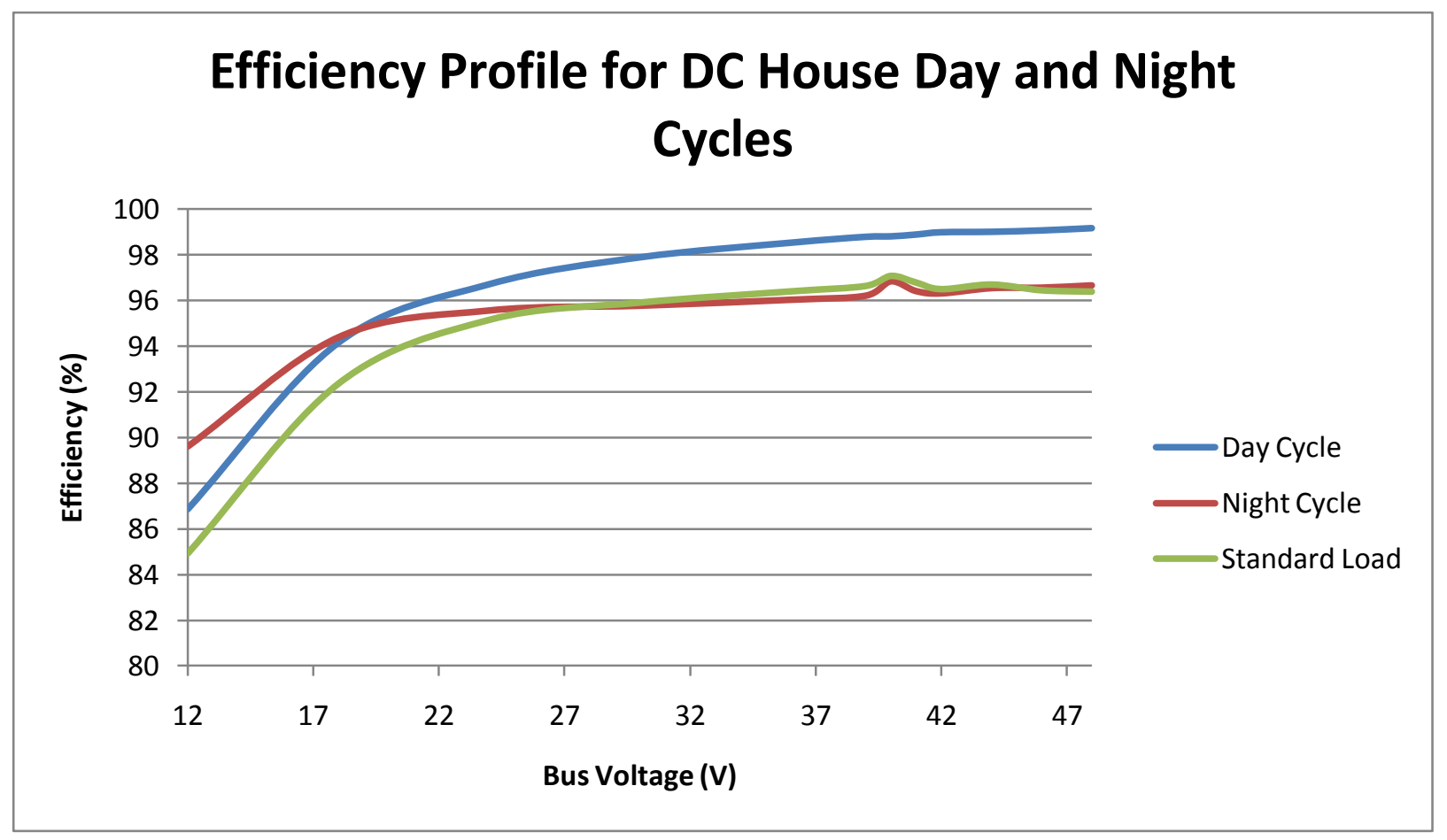

Figure 5-9: Efficiency Profile for DC House Day and Night Cycles

These results are interesting for several reasons. The first is that the Day cycle doesn't have the same peak of efficiency at around 40 volts as all the other power profiles have had. This is probably because the loads which use DC-DC converters are all disabled for the Day Cycle. Recall that the DC-DC converters become slightly less efficient at higher voltages. This would be consistent with the Night Cycle's Power profile curve that shows 
the distinct notch in the graph at around $40 \mathrm{~V}$. Additionally, it is worth noting the Day and Night Cycles are more efficient than the Standard load. This is because the system is operating at a reduced power, and the relative impact of current losses is reduced. Therefore the system operates more efficiently at lower loads.

\subsubsection{Lighting only Load}

As described earlier, some homes will require the use of electricity for lighting purposes only. This is very typical for people living in remote areas or secluded islands or jungles. Therefore, to test the effects of the DC system under lighting loads only, the simulink model was modified to remove all loads except lighting. The number of luminaires was also doubled, so that the resulting power usage would be approximately 100 Watts. The new luminaires were added in parallel to the existing luminaires, and tied in after their respective DC-DC converters. This would eliminate unnecessary additional DC-DC converters, and provide a means for the proper driving circuitry for the light. The modified simulink model was captured in Figure 5-10.

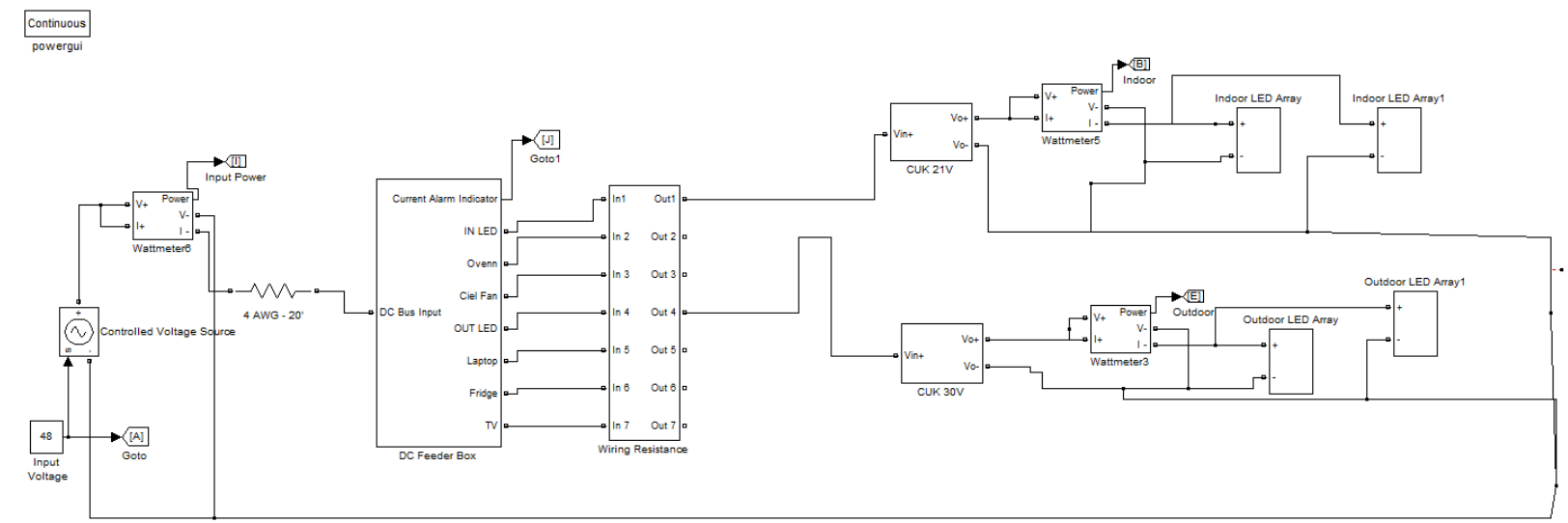

Figure 5-10: Modified Simulink Model for the Special Case of Lighting Only Load 
The simulation was performed just as the previous data collection processes were performed. The bus voltage was increased, and the efficiency was recorded. The results were plotted in Figure 5-10.

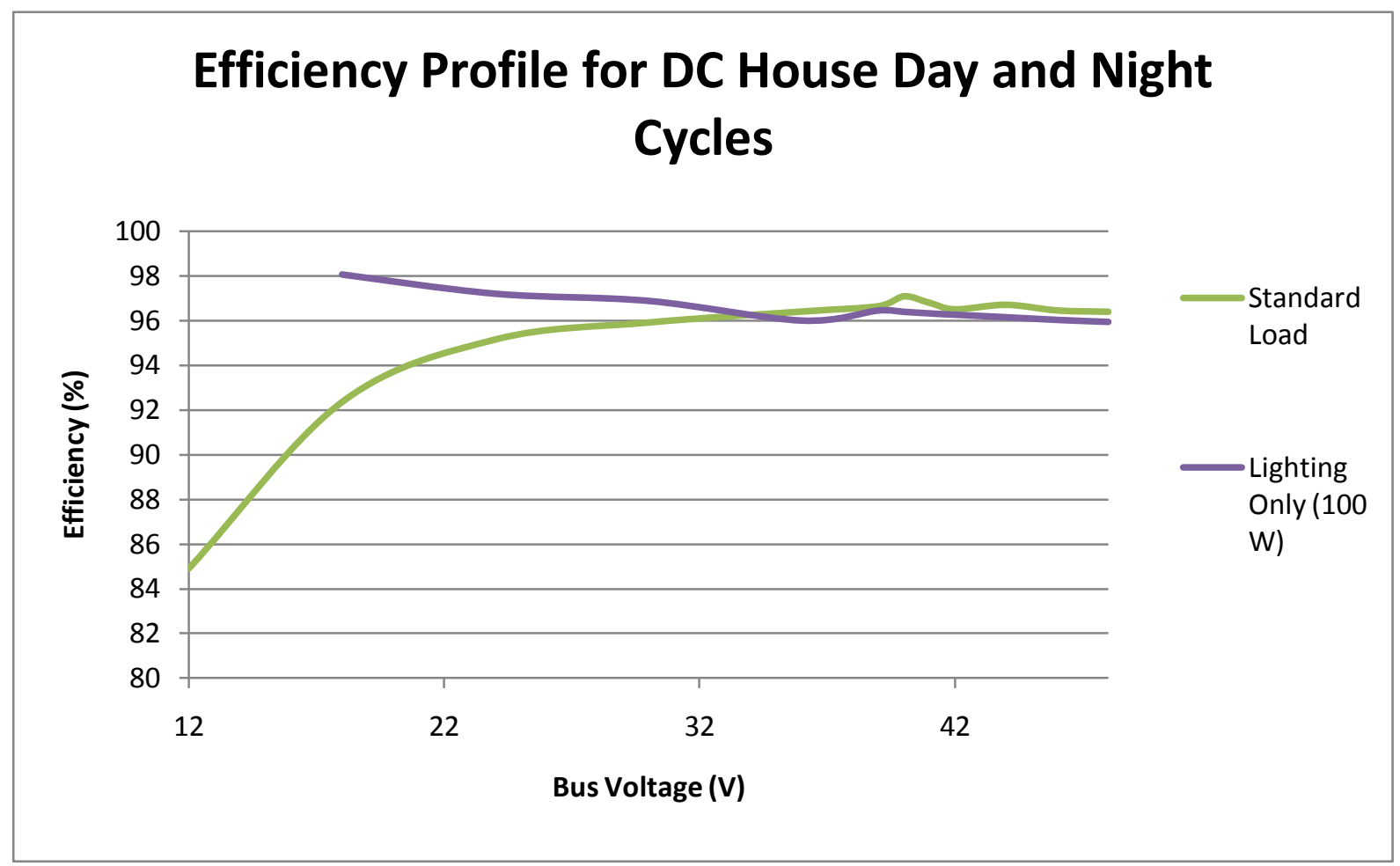

Figure 5-11: Plot of Efficiency for the Lighting only Load at Varying Voltages

These results were interesting because they show that the efficiency decreases as the voltage bus increases. This is likely because of two factors. The first is that the DC-Dc converter is slightly less efficient at higher Voltage ratings. The second reason is that at higher input voltages, the CUK Converters that drive the luminaires will output slightly higher voltage levels due to the line regulation effect. This increased output voltage will create an increased current in the output, and therefore will create more losses. 
Another important note would be that if a home only needed LED lighting, there would be no need for multiple DC-DC converters, as all the luminaires could be designed for the same voltage level, thus further reduce the cost and reliability issues that DC-DC converters create. This could also increase the efficiency of the system by eliminating the efficiency drop from the converters, the approximate efficiency increase would depend on the efficiency associated with the previous DC-DC converter. For a converter that was 98\% efficient, there would be a $2 \%$ increase in efficiency. However one potential risk with this solution would be ensuring that each luminaire would be driven at the same voltage and therefore the same current. Any fluctuations in the voltage directly at the luminaire terminals could produce inconsistent currents, and therefore inconsistent light radiance.

\subsubsection{Lighting and Refrigerator Load (Medical Station)}

Medical stations require the use of cooling systems so that temperature sensitive medical supplies can be stored at the proper temperature. For this section, the load was modified to also include a larger refrigerator. The larger refrigerator actually doesn't draw more power than the smaller unit, rather it simply takes longer to cool the contents. The Simulink model was simulated the same as the previous section. The results were tabulated and plotted in Figure 5-12: 


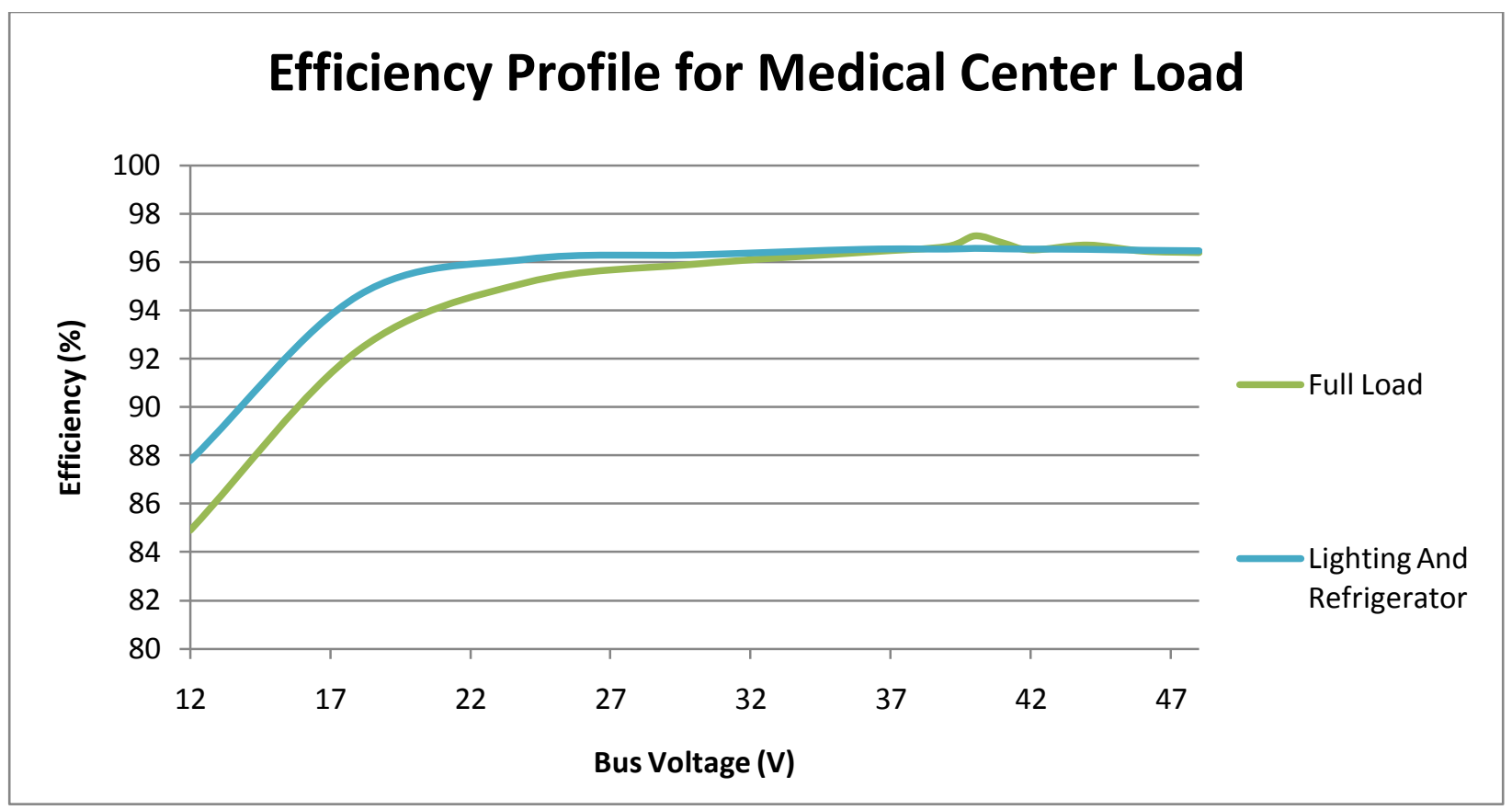

Figure 5-12: Efficiency Profile for the Medical Center Load Case Study

This plot indicates that the efficiency is higher for lower voltage levels up to approximately 32 Volts. This is likely because of the higher proportion of the efficiency coming from the lighting load which pulls the overall efficiency up at lower voltage levels. However when this plot is compared to the lighting only load, it demonstrates how much the refrigerators current draw pulls down the efficiency drastically at low voltages due to the high current. Finally, It continues the trend of lower loads operate at higher efficiency. 


\section{Chapter 6: Conclusion and Future Work}

This thesis demonstrated how a DC system was designed, modeled, and characterized steady state using the simulink toolbox in MATLAB. This characterization provides a strong basis for future design decisions when the DC House is eventually constructed. This includes: the ideal wire sizing, the circuit configuration, and the bus voltage level that produces the best efficiency for the best price. The model also accurately modeled the transient behaviors of DC-DC converters and their controls. The simulink model requires a relatively large initial investment in time to properly model all devices, however once complete can be easily tweaked to test for additional transient or steady state characterizations.

Chapter 3 outlined and justified the load selection for the DC house. This was done via thorough research of typical home loads and requirements such as lighting, cooking, and entertainment. These devices had to be fully justified for their inclusion in the DC house, so that a realistic load selection could be achieved. Additionally, developing a strong understanding of how each device operates was necessary to create an accurate model of their performance in the Simulink model.

Chapter 4 detailed the exact process of building a DC system in Simulink. It began with the simple approach to the overall distribution, and how the devices would be connected. Then each load was broken down and modeled specifically and as closely to its real world counterpart as possible. The LED Lighting, the DC motor, the DC-DC converters, and the static loads were all characterized in detail. All of the loads were broken down into subsystems, and the resulting overall simulation model was constructed. It was 
then rigged so that the efficiency of the system could be easily captured, and the intended independent variables could be easily changed for testing.

Then Chapter 5 documented the simulation results by explaining what was tested, the expected results, and a short discussion of the actual results. The variables tested were the circuit configuration, the size of the wire used, and the bus voltage. The complete recommendation is summarized as follows:

- Bus Voltage set to 40 Volts

- Bus to feeder wire size of $\mathbf{6}$ AWG

- Individual circuit wire size of $\mathbf{1 0}$ AWG

- Configure loads evenly into two distributed circuits.

This section also explored the special cases of lighting only loads and lighting only plus refrigerator loads. The lighting only load was highly efficient at all bus voltage settings, because of its relatively low current draw. The results also showed how the system in the standard model operates more efficiently at low loads, because of the reduced relative impact of current losses.

Simulink provides a different set of advantages for simulating small-scale DC systems. It can model both transient and steady state operations accurately, but requires extra effort to build the initial model. It also provides the ability to create models for devices that don't exist in the preset libraries of other simulation software, or provide more detailed behaviors for those generic devices that already exist. The trade-off is that it does not have very many devices already modeled in its library set for power systems. Instead it provides many basic components that can be configured into more complex models. The 
resulting simulink model for this thesis is very powerful because it provides extra details on how each component in the system should behave. This model was used for mostly steady state analysis such as power efficiency, however, it is capable of providing transient responses as was shown with the DC-DC converters and DC Motor. It also provides a means for controlibility - that is logic functions can be easily created and interfaced with the electrical componenets. For example, the controls for a DC-DC converter are much easier to implement in the logic library of simulink than it is to implement them in electrical circuitry. Another potential drawback is the simulation time for the system to reach steady state is quite long, taking at least several minutes when the entire system was simultaneously simulated.

Future work for DC House simulations could include many specific topics. The first of which is a more in depth use of the transient response ability of this simulation model. For example, studying the effects of how simulink can model faults. Additionally, the use of any protective equipment such as fuses and breakers could be modeled and their transient response times and coordination could be tested in the simulink environment. Another application for using simulink would be the ability to model the larger scale distribution system that is planned in future DC house works. This thesis could be used as a template to recreate a simplified power grid between several DC houses. Another idea would be to explore the modeling of the generation side of this DC house project including the various renewable power sources, battery, and multi-input DC-DC converter being design by the other DC House projects.

One final topic of interest to explore further would be to use the results of this thesis to define the conditions for an all-lighting based load. Many rural homes only need 
electricity for lighting purposes. LED luminaires could be custom designed to operate at the optimal voltage rating of approximately 40 volts, and be implemented on the same circuit without the need for DC-DC converters. This concept could possibly be applied to modern home design, with the possibility of DC circuits being integrated into the home for lighting purposes only. Both options remove the need of individual DC-DC converters to drive LED luminaires, and provide an efficient and long lasting alternative for home lighting. 


\section{Bibliography}

[1] James M. Rubenstein, An Introduction to Human Geography, Pearson Prentice Hall, New Jersey, 2008.

[2] S.E. Shaheen, D.S. Ginley, and G.E. Jabbour, "Organic-Based Photovoltaics: Toward Low-Cost Power Generation”, MRS Bulletin, January 2005.

[3] "International Energy Statistics - Electricity." US Energy Information Administration. Web. 2011. $<$ www.eia.doe.gov/>.

[4] Enphase Energy, “Enphase MicroInverter”, 230 Watt, D380 MicroInverter Datasheet, 2009.

[5] Eaton Corporation, "S-Max Series 250 kW Grid-Tied Solar Inverter", TD04010001E Technical Datasheet, 2010.

[6] National Electric Code 2005 Edition. Quincy, MA: NFPA, 2005. Print.

[7] Michael Davidson. "Tungsten Halogen Incandescent Lamps." Carl Zeiss MicroImaging Online Campus | Education in Microscopy and Digital Imaging. N.p., n.d. Web. 10 May 2011. < http://zeisscampus.magnet.fsu.edu/>.

[8] Phillips, "Generic Standard Incandescent, Shaped frost Light Bulbs", 75W Incandescent Datasheet, 2011

[9] Joseph Kao. "Caged Molecules: Principles and Practical Considerations." current protocols (2006): n. pag. http:// wnw.currentprotocols.com/protocol/ns0620. Web. 10 Apr. 2011.

[10] Phillips, "A compact lamp with enhanced performance", PL-C 4-Pin Compact Fluroescent Lamp Datasheet, 2010.

[11] Phillips Lumileds, “Luxe on Rebel ES”, DS61 Technical datasheet, 2010

[12] Phillips, “100 Watt Mini White SON T-6 High Pressure Sodium Lamp”, Technical Datasheet, 2010

[13] Engel, “AC/DC 12 Volt Portable Fridge-Freezers”, MRFD-015/MHFD-015 Datasheet, 2007

[14] General Electric, “GE Spacemaker”, JVM1665SN Information Manual, 2011.

[15] General Electric, “GE Profile 2.0 Cu. Ft. Countertop Microwave Oven”, PEB2060DM Information Manual, 2011.

[16] General Electric, “GE 1.1 Cu. Ft. Countertop Microwave Oven”, JES1142S Information Manual, 2011.

[17] General Electric, JKP70SP Information Manual, 2011. 
[18] General Electric, PP972SMSS Information Manual, 2011.

[19] General Electric PHP960SMSS Information Manual, 2011.

[20] RoadPro. 12 Volt 3.5 Quart Slow Cooker. RoadPro, 2011. www.roadtrucker.com. Web.

[21] "DC Ceiling \& Floor Fans 12 volt, 24 volt and 48 volt." Soldon Sun. Web. 11 May 2011.

$<$ http://www.soldonsun.com/Pr/App/DC-FreedomFan.html>.

[22] RoadPro. 13.3” NAXA AC/DC Digital Flat Screen Television. RoadPro, 2011. www.roadtrucker.com. Web.

[23] "Permanent Magnet DC Machine Simulation in MATLAB Simulink." Missouri University of Science and Technology. Web. 2011. <http://ece.mst.edu/>.

[24] Toshiba, "Switching Mode Power Supply, applications (low voltage)", CLS03 Schottky Barrier Diode Datasheet, November, 2006.

[25] Epcos, “Aluminum Electrolytic Capacitors”, B41695 Capacitor Datasheet, November 2008.

[26] Cooper Electronic Technologies, "Inductor, Boost PFC, Toroid, 200uH @2.0A”, CTX1617309 Datasheet, 2009.

[27] Vishay, “N-Channel Mosfet”, SiR494DP FET Datasheet, May 2009.

[28] "Wire \& Cable | Wire | THHN Building Wire - Multi-Purpose, Heat Resistant GlobalIndustrial.com." GlobalIndustrial.com - Material Handling

Equipment $\mid$ Workbenches $\mid$ Furniture $\mid$ Tools $\mid$ Motors $\mid H V A C$. Web. 11 May 2011.

$<$ http://www.globalindustrial.com $>$. 